Florida International University FIU Digital Commons

FIU Electronic Theses and Dissertations

University Graduate School

$10-12-2011$

\title{
Analysis of Housing Partnerships Using the Balanced Scorecard Framework
}

Zhayda L. Garzon

Florida International University, zgarz001@fiu.edu

DOI: $10.25148 /$ etd.FI11120205

Follow this and additional works at: https://digitalcommons.fiu.edu/etd

\section{Recommended Citation}

Garzon, Zhayda L., "Analysis of Housing Partnerships Using the Balanced Scorecard Framework" (2011). FIU Electronic Theses and Dissertations. 476.

https://digitalcommons.fiu.edu/etd/476

This work is brought to you for free and open access by the University Graduate School at FIU Digital Commons. It has been accepted for inclusion in FIU Electronic Theses and Dissertations by an authorized administrator of FIU Digital Commons. For more information, please contact dcc@fiu.edu. 


\title{
FLORIDA INTERNATIONAL UNIVERSITY \\ Miami, Florida
}

\section{ANALYSIS OF HOUSING PARTNERSHIPS USING THE BALANCED SCORECARD FRAMEWORK}

\author{
A dissertation submitted in partial fulfillment of the \\ requirement for the degree of \\ DOCTOR OF PHILOSOPHY \\ in \\ PUBLIC AFFAIRS \\ by \\ Zhayda Garzon
}

2011 
To: Dean Kenneth Furton

College of Arts and Sciences

This dissertation, written by Zhayda Garzon, and entitled Analysis of Housing Partnerships using the Balanced Scorecard Framework, having been approved in respect to style and intellectual content, is referred to you for judgment.

We have read this dissertation and recommend that it be approved.

$\begin{array}{r}\hline \text { Meredith A. Newman } \\ \hline \text { Marilys R. Nepomechie } \\ \hline \text { Sukumar Ganapati, Major Professor }\end{array}$

Date of Defense: October 12, 2011

The dissertation of Zhayda Garzon is approved.

Dean Kenneth Furton College of Arts and Sciences

Dean Lakshmi N. Reddi

University Graduate School

Florida International University, 2011 
(C) Copyright 2011 by Zhayda Garzon

All rights reserved 


\section{DEDICATION}

This dissertation is dedicated to my mother Amanda, who always believed in all my

pursuits and goals by providing encouraging words and support daily. Even throughout difficult times she has been there for me sharing her patience and kindness. 


\section{ACKNOWLEDGMENTS}

I would like to thank the members of my dissertation committee for their support, guidance and assistance in completing this very special and meaningful milestone. Their suggestions, patience and kind words of encouragement allowed me to find purpose, meaning, and joy to happily complete this dissertation.

I would like to especially thank my major professor, Dr. Sukumar Ganapati, who always displayed confidence in my abilities by supporting my ideas and going an extra step in providing any assistance to improve my skills as a researcher and writer. Thank you for always listening and providing your support and knowledge in all aspects of my development as a scholar and as a person. The growth and maturity gained will help me in future endeavors. I would also like to thank Dr. Howard Frank for his continuous feedback and assistance to improve the dissertation. Throughout my experience as a doctoral student he has followed and encouraged me to continue my studies. He is always willing to help and through his enthusiasm and knowledge, he makes learning a very joyful experience. I owe a great deal of gratitude to Dr. Meredith Newman for her support in all aspects of my doctoral education. Her kind spirit, support, and empowering words allowed me to have courage and determination when facing challenges both academic and personal. Although very busy, Dr. Newman's door is always open for anyone seeking assistance. I would like to thank Marilys R. Nepomechie for her support throughout this endeavor. She always brings a smile and warmth that makes anyone around her feel at ease.

I would also like to thank the housing partnerships that took part in my study. Particular appreciation goes to the Executive Directors who took time from their busy 
schedules to help me understand the complexities of community development and affordable housing delivery.

I am truly indebted to the University Graduate School and the Public Administration department at Florida International University for providing financial support allowing me to complete the study and write the dissertation in a timely manner.

Special thanks also go to my fellow peers in the program and the writing center at FIU who helped me in many ways throughout this challenging journey.

Finally, I would like to thank Michael. Although several challenges occurred between us throughout my years as a doctoral student, all of this would have not been possible if you were not there seven years ago. I will always be thankful to you for any of my future accomplishments knowing that although they are results of my work and dedication, your decisions gave me a second chance at life. 


\title{
ABSTRACT OF THE DISSERTATION \\ ANALYSIS OF HOUSING PARTNERSHIPS USING THE BALANCED SCORECARD FRAMEWORK
}

\author{
by \\ Zhayda Garzon \\ Florida International University, 2011 \\ Miami, Florida

\section{Professor Sukumar Ganapati, Major Professor}

Housing Partnerships (HPs) are collaborative arrangements that assist communities in the delivery of affordable housing by combining the strengths of the public and private sectors. They emerged in several states, counties, and cities in the eighties as innovative solutions to the challenges in affordable housing resulting from changing dynamics of delivery and production.

My study examines HPs with particular emphasis upon the identification of those factors associated with the successful performance of their mission of affordable housing. I will use the Balanced Scorecard (BSC) framework in this study. The identification of performance factors facilitates a better understanding of how HPs can be successful in achieving their mission. The identification of performance factors is significant in the context of the current economic environment because HPs can be viewed as innovative institutional mechanisms in the provision of affordable housing.

The present study uses a mixed methods research approach, drawing on data from the IRS Form 990 tax returns, a survey of the chief executives of HPs, and other secondary sources. The data analysis is framed according to the four perspectives of 
BSC: the financial, customer, internal business, and learning and growth. Financially, revenue diversification affects the financial health of HPs and overall performance. Although HPs depend on private and government funding, they also depend on service fees to carry out their mission. From a customer perspective, the HPs mainly serve low and moderate income households, although some serve specific groups such as seniors, homeless, veterans, and victims of domestic violence. From an internal business perspective, HPs' programs are oriented toward affordable housing needs, undertaking not only traditional activities such as construction, loan provision, etc., but also advocacy and educational programs. From an employee and learning growth perspective, the HPs are small in staff size, but undertake a range of activities with the help of volunteers. Every part of the HP is developed to maximize resources, knowledge, and skills in order to assist communities in the delivery of affordable housing and related needs. Overall, housing partnerships have played a key role in affordable housing despite the housing market downturn since 2006. Their expenses on affordable housing activities increased despite the decrease in their revenues. 


\section{TABLE OF CONTENTS}

CHAPTER

PAGE

1. PERFORMANCE EVALUATION OF HOUSING PARTNERSHIPS.................. 1

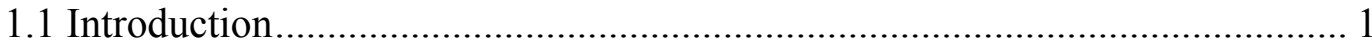

1.2 Background: Evolution of Affordable Housing in the U.S........................... 3

1.3 Purpose and Significance of the Dissertation .................................................. 8

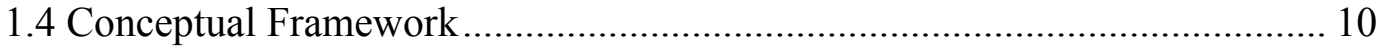

1.5 Research Questions.................................................................................. 12

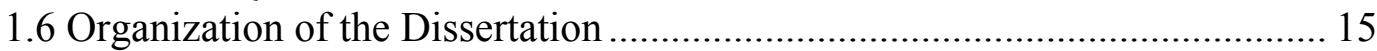

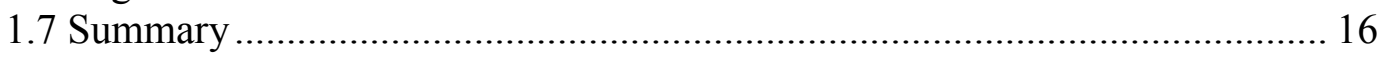

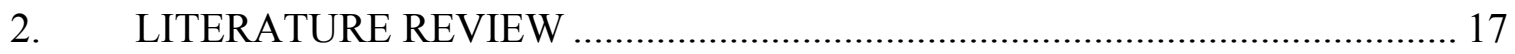

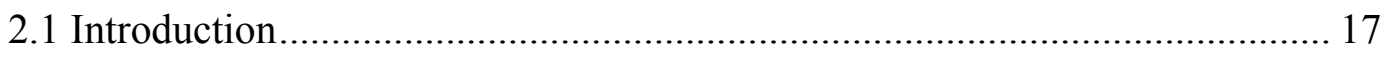

2.2 Housing Partnerships ............................................................................ 18

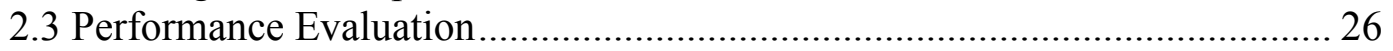

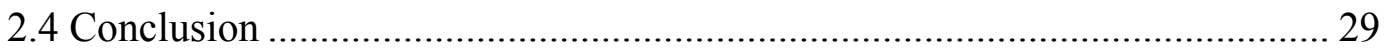

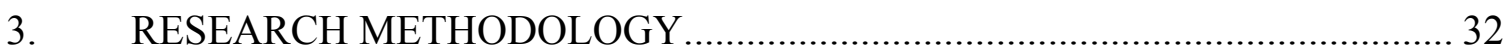

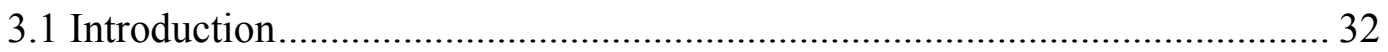

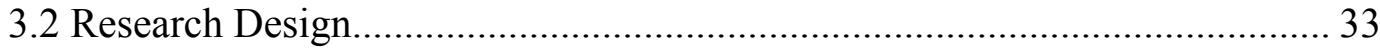

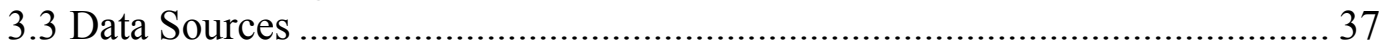

3.4 Limitations and Conclusion ........................................................................ 44

4. HOUSING PARTNERSHIPS: A NATIONAL OVERVIEW ............................ 45

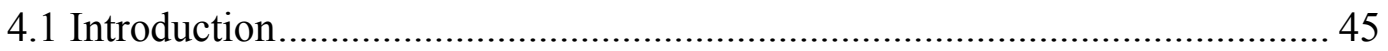

4.2 Growth of Housing Partnerships ................................................................. 45

4.3 Mission of Housing Partnerships .................................................................. 51

4.4 Housing Partnerships' Characteristics ....................................................... 56

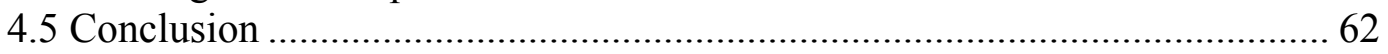

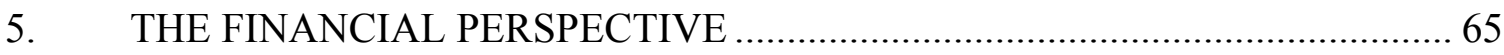

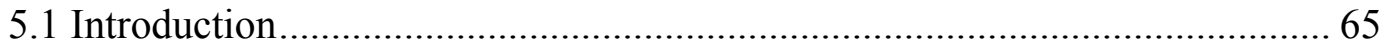

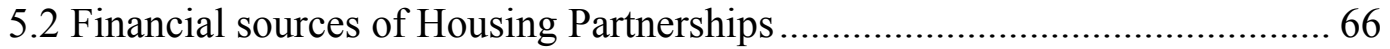

5.3 Financial activities of Housing Partnerships …………............................... 72

5.4 Cross-Tabulation Analysis......................................................................... 78

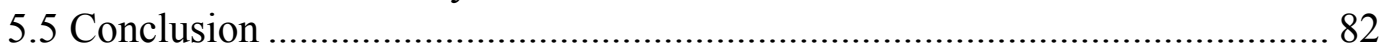

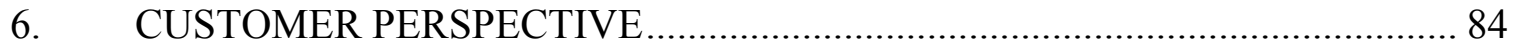

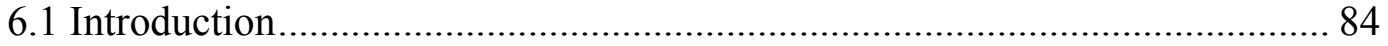

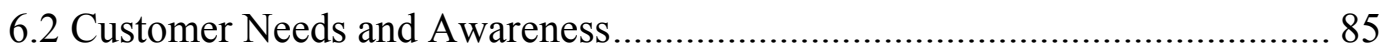

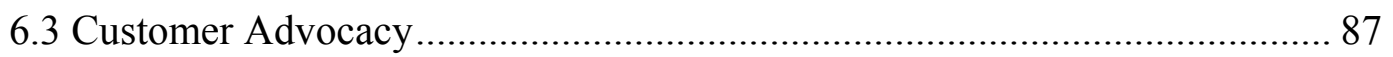

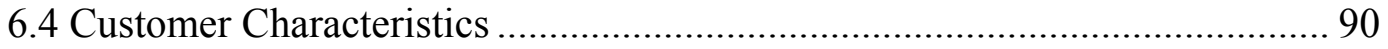

6.5 Customer Feedback................................................................................... 93 


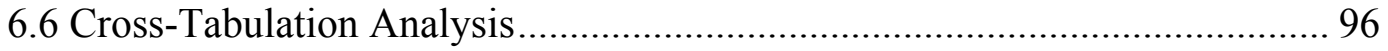

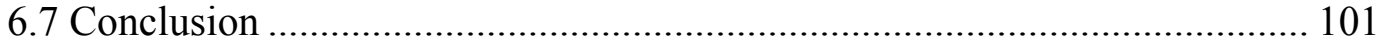

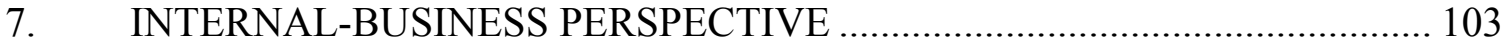

7.1 Introduction....................................................................................... 103

7.2 Housing Partnership Programs: Overall Success Factors............................. 104

7.3 Housing Partnerships' Internal Process and Program Characteristics.......... 106

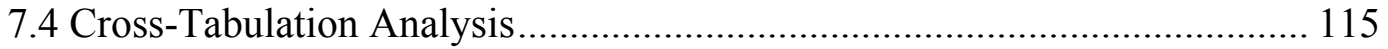

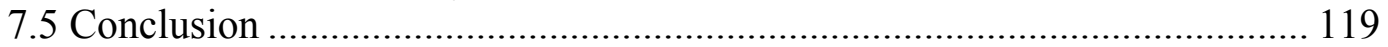

8. LEARNING AND GROWTH PERSPECTIVE ............................................ 121

8.1 Introduction........................................................................................ 121

8.2 Housing Partnerships’ Employee Capacity Needs .................................... 122

8.2 Housing Partnerships' Employee Characteristics...................................... 128

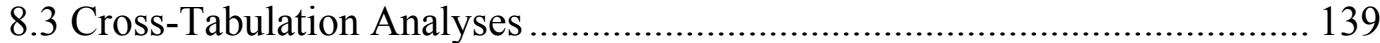

8.4 Conclusion .................................................................................... 142

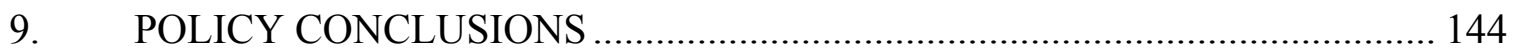

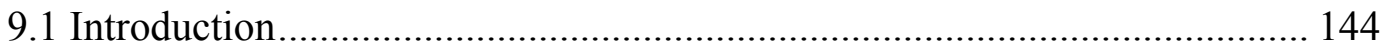

9.2 Findings from each BSC Perspective ..................................................... 144

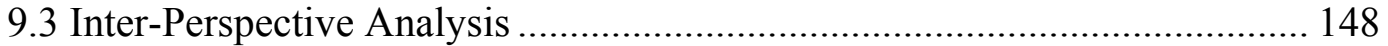

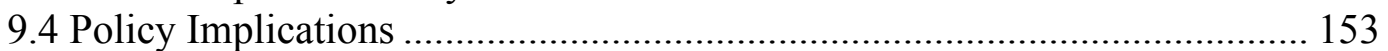

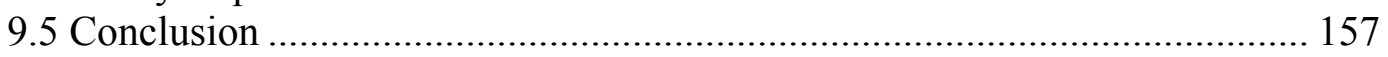

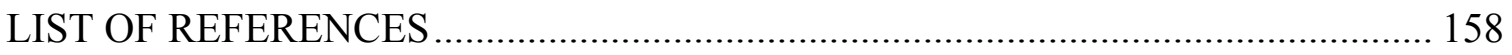

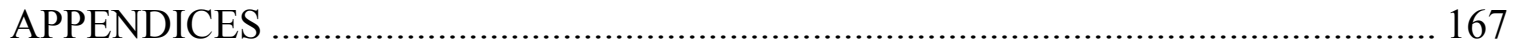




\section{LIST OF TABLES}

TABLE

PAGE

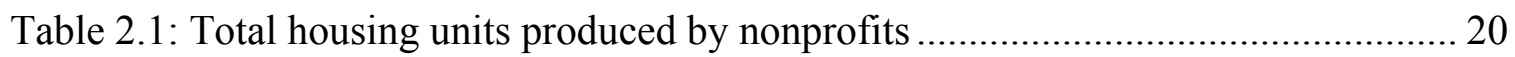

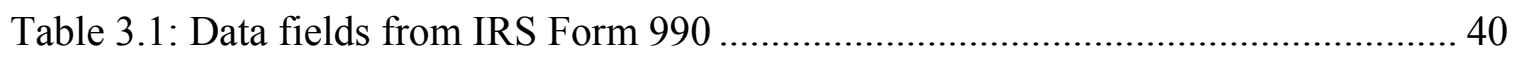

Table 3.2: BSC Variables based on Survey Questionnaire........................................... 42

Table 4.1: Housing Partnership Formed by Decade ................................................. 46

Table 4.2: Cross-tabulation of Emergence Year with Annual Revenues (2005 to 2008). 49

Table 4.3: Distribution of Housing Partnerships by Census Bureau Regions ................. 50

Table 4.4: Range of Activities Performed by Housing Partnerships .............................. 52

Table 4.5: Housing Partnerships' Activities Based on Mission Statements .................... 52

Table 4.6: Relationship Between Mission and Revenues: ANOVA Results.................... 55

Table 4.7: Relationship Between Mission and Census Regions.................................. 56

Table 5.1: Funding Streams Cross-Tabulations ........................................................... 79

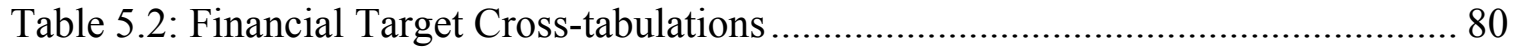

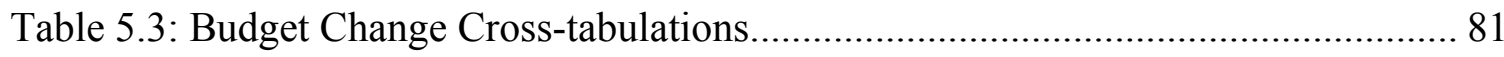

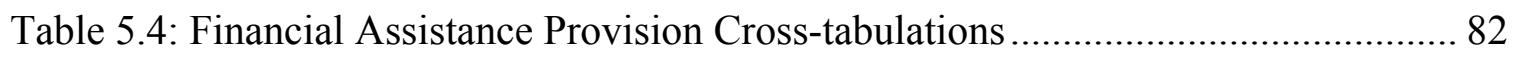

Table 6.1: Top Three Customer Feedback Comments ............................................... 96

Table 6.2: Cross-tabulations of Change in the Number of Households .......................... 98

Table 7.1: Programs Implemented and their Achievement in 2009 ............................ 109

Table 7.2: Change in Program Size, 2007 to 2009 .................................................... 112

Table 7.3: Program Target Achievement Cross-tabulations....................................... 116

Table 7.4: Mission and the Percentage of Program Target Achievement ..................... 117

Table 7.5: Cross-tabulations of Change in Size of Programs ...................................... 117

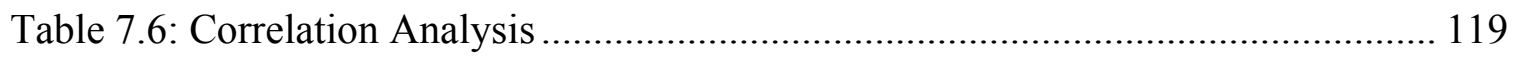

Table 8.1: Cross-tabulations of the Board of Directors' Representatives ..................... 140

Table 8.2: Cross-tabulation of Number of Board Meetings ....................................... 140 
Table 8.3: Cross-tabulations of Number of Employees .............................................. 141

Table 8.4: Cross-tabulations of Chief Executive Officer's Characteristics ................... 142

Table 9.1: Association between Funding Sources and Income Groups served .............. 149

Table 9.2: Association between Budget Changes from 2007 to 2009 and Programs..... 150

Table 9.3: Association between Income Groups Served and Programs ........................ 151

Table 9.4: CEOs' Role in Program Size Changes from 2007 to 2009 ......................... 152

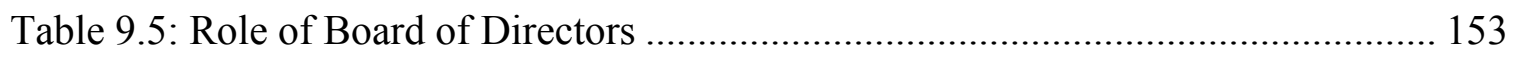




\section{LIST OF FIGURES}

FIGURE

PAGE

Figure 1.1: Balanced Scorecard Framework for Nonprofit Housing Partnerships ........... 12

Figure 4.1: Five-year Interval Growth in Number of Housing Partnerships, 1980-2009. 47

Figure 4.2: Housing Partnerships' Total Revenues and Expenditures, 2005 to 2008 ...... 48

Figure 4.3: Housing Partnerships' Average Revenues and Expenses, 2005 to 2008 ....... 49

Figure 4.4: Distribution of Housing Partnerships by State ........................................ 50

Figure 4.5: Overview of Housing Partnerships' Functions/Programs ............................ 57

Figure 4.6: Housing Partnerships’ Missions (Based on Survey) .................................... 58

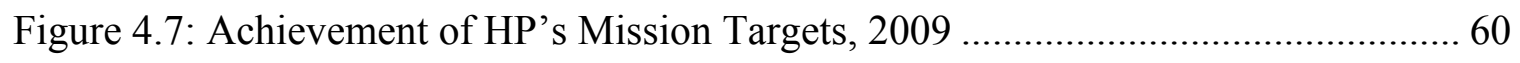

Figure 4.8: Principal Jurisdiction Served by Housing Partnerships .............................. 61

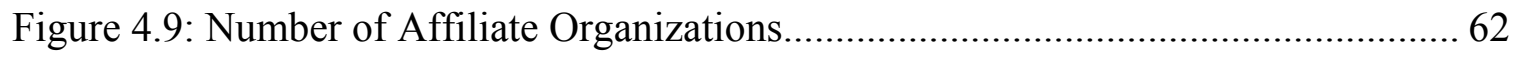

Figure 5.1: Housing Partnerships' Funding Sources ................................................. 70

Figure 5.2: Percentage of Funds Spent in Various Activities by HPs in 2009 ................. 73

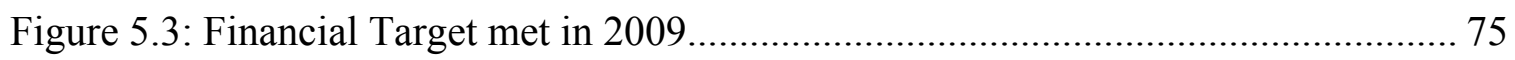

Figure 5.4: Housing Partnership Budgetary Changes from 2007 to 2009 ...................... 76

Figure 5.5: Percentage of Customers Receiving Financial Assistance .......................... 77

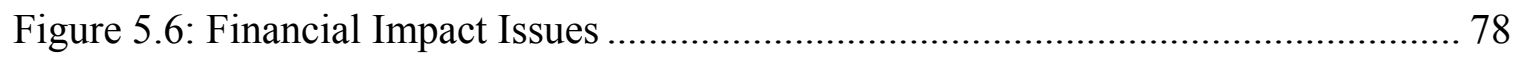

Figure 6.1: Change in Number of Households Assisted Between 2007 and 2009 .......... 90

Figure 6.2: Percentage of Households Assisted......................................................... 92

Figure 6.3: Services Provided to Specific Groups ...................................................... 93

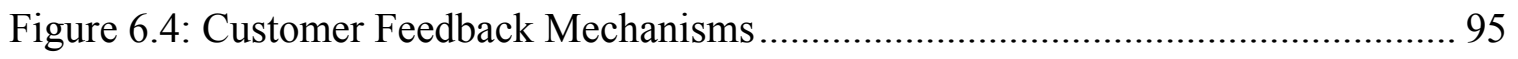

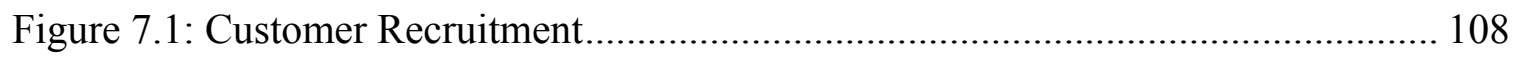

Figure 7.2: Types of Internal Management Systems ................................................ 113

Figure 8.1: Housing Partnership Board Composition .............................................. 130

Figure 8.2: Frequency distribution of Board Meetings........................................... 131 


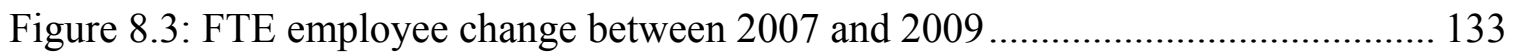

Figure 8.4: Employee Turnover Ratio .................................................................... 134

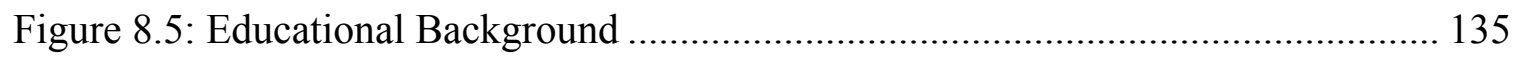

Figure 8.6: Learning and Growth Programs Offered by Housing Partnerships ............. 136

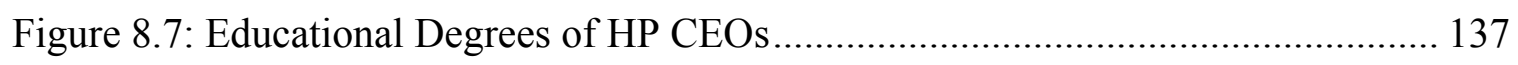

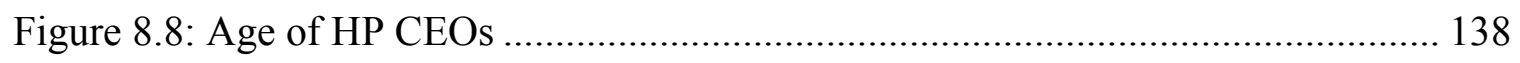




\section{LIST OF ABBREVIATIONS AND ACRONYMS}

ANOVA

AMI

BSC

CDBG

CDCs

CEO

CRA

ERP

ESG

Fannie Mae or FNMA

FHA

Ginnie Mae

HP

HPN

HPRP

HUD

INHP

IRS

JCPS

LAHP

MHC
Analysis of Variance

Average Median Income

Balanced scorecard

Community Development Block Grant

Community Development Corporations

Chief Executive Officer

Community Reinvestment Act

Enterprise Resource Planning

Emergency Shelter Grant

Federal National Mortgage Association

Federal Housing Administration

Government National Mortgage Association

Housing Partnership

Housing Partnership Network

Homeless Prevention and Rapid Re-Housing

Program

Department of Housing and Urban Development

Indianapolis Neighborhood Housing Partnership

Internal Revenue Service

Jefferson County Public Schools

Los Angeles Housing Partnership

Metropolitan Housing Coalition 
MHP

NSP

PEA

SJHP

VCHHC
Massachusetts Housing Partnership

Neighborhood Stabilization Program

Procurement Executives' Association

St. Johns Housing Partnership

Ventura County Homeless and Housing Coalition 


\section{PERFORMANCE EVALUATION OF HOUSING PARTNERSHIPS}

\subsection{Introduction}

Public-private Housing Partnerships (HPs) are defined as collaborations among public, private, and nonprofit organizations to deliver affordable housing by providing housing services and addressing community housing needs. They are typically nonprofit organizations (i.e., tax-exempt under section 501 (c) (3) of the U.S. Internal Revenue Code) and are structured formally as partnerships, alliances, networks, and coalitions. The Housing Partnerships serve as intermediary entities providing the balance between public and private requirements by working within the parameters of both sectors to meet communities' affordable housing needs (Wylde, 1986). According to the 2009 Internal Revenue Service (IRS) Publication 78, there were over 375 such organizations distributed around the country. The Housing Partnerships emerged in several states, counties, and cities in the eighties in response to changing dynamics of delivery and production of affordable housing (Stegman, 1999; Suchman, et al., 1990). Affordable housing is below market rate housing, usually constructed for the benefit of low and moderate-income households. The generally accepted definition of affordability is for a household to pay no more than 30 percent of its annual income on housing. Households that spend more than 30 percent of the income on housing are considered cost burdened and could have difficulty in affording other necessities (e.g., food, clothing, transportation and medical care).

Housing Partnerships deliver affordable housing and address community housing needs through the provision of direct services such as housing construction, 
rehabilitation, credit counseling, and down-payment assistance and indirect efforts such as advocacy, research, and policy analysis. Housing Partnerships combine public and private sector strengths in their funding, skills, and knowledge. Financially, HPs diversify their funding streams through public and private funding, donation, and service fees. Governmental entities assist HPs by means of local, state and federal funding, such as housing trust funds, tax credits, and community development programs. Private entities assist HPs with funding of loans and investments. Besides funding, each sector contributes unique skills and knowledge to collaborative agreements. In terms of skills and knowledge, private sector agencies can share their innovative business operations and practices. Governmental agencies can share their knowledge of housing policies. Nonprofit and grass roots agencies can provide their skills and knowledge in social services and advocacy. In addition, all sectors can provide technical assistance to the Housing Partnerships.

My dissertation deals with the growth of HPs and their performance in the delivery of affordable housing. Despite their growth since the eighties, the scholarly literature examining the performance of HPs is limited. Housing Partnerships are less well known than Community Development Corporations, which are also community based nonprofit agencies for the delivery of affordable housing. My dissertation contributes by narrowing the research gap on Housing Partnerships. The Balanced Scorecard (BSC), which is a well-known framework for evaluating organizational performance, is used for the evaluation of Housing Partnerships.

The rest of this introductory chapter is organized as follows. The following section gives the background context in which HPs emerged across the United States. 
Next, the purpose and significance of the dissertation study is outlined. Then, the conceptual framework of BSC applied in the study is described. This section is followed by the principal research questions that form the core of the dissertation study. After this, the chapter gives a summary outline of the dissertation's organization. The final section concludes with a summary of the principal aspects of this chapter.

\subsection{Background: Evolution of Affordable Housing in the U.S.}

Housing production was limited principally to the private sector before the Great Depression in nineteen twenty-nine. The federal government's involvement in housing increased with the New Deal programs instituted since then. The Federal Housing Administration (FHA) was established in 1934 to regulate the housing mortgage industry. The Federal Housing Administration insurance program paved the path for low downpayments and long-term mortgages. The landmark Housing Act of 1937 (also called the Wagner-Steagall Act) addressed the issue of low-income housing for the first time at the national level. The United States Congress chartered the Federal National Mortgage Association (FNMA) in 1938 (later called Fannie Mae) to ensure liquidity, stability and affordability in the housing and mortgage markets by creating a secondary mortgage market. In essence, the agency bought pools of primary mortgages, which freed up the cash reserves of the primary lenders to provide further mortgage loans. In the late forties, as troops returned home, the federal role was to meet postwar housing needs. The Federal Housing Administration programs helped finance military housing and homes for returning veterans and their families (HUD, 2010). 
In the fifties, the federal government began urban renewal programs after the passage of the Omnibus Housing Act of 1949, authorizing federal assistance to help local communities to rehabilitate deteriorating areas. By clearing and redeveloping deteriorating neighborhoods, communities limited the growth of slum areas and the spread of urban blight. National policies targeting housing affordability and housing discrimination emerged in the sixties as a result of social changes and civil rights movements. Indeed, housing was recognized as an activity of national significance, with the enactment of the U.S. Department of Housing and Urban Development Act in 1965, which established the Department of Housing and Urban Development (HUD) as a cabinet-level agency. The HUD's primary mission currently is to "create strong, sustainable, inclusive communities and quality affordable homes for all.” The U.S. Department of Housing and Urban Development consolidated several other housing programs and federal entities, including the Federal Housing Administration. The Fair Housing Act of 1968 gave HUD enforcement responsibility for the prevention of housing discrimination. In 1968, the Government National Mortgage Association (Ginnie Mae) was separated from Fannie Mae and established as a wholly owned government corporation under the U.S. Department of Housing and Urban Development. The Ginnie Mae mainly provides guarantees to mortgage based-securities for those loans insured by FHA, Veterans Administration, US Department of Agriculture's Rural Development program, and Public and Indian Housing (PIH) loan program.

In the seventies, federal policies sought to strengthen and improve affordable and low-income housing delivery. The Section 8 program (Tenant Based Assistance: Housing Choice Voucher Program) enacted in 1975 began to provide housing subsidies 
(principally rental) to low-income households so that they could afford housing in the private market. Policies such as the Community Development Block Grant of 1974 and the Community Reinvestment Act of 1977 began to include community development endeavors, rather than focusing solely on individual households (Suchman, et al., 1990). The Community Development Block Grant (CDBG) program provides local governments with resources to address community development needs, and provides annual grants on a formula basis. The Community Reinvestment Act (CRA) holds banks and savings institutions accountable for meeting the credit needs of all communities they are chartered to serve, including low and moderate-income communities.

Federal funding for low-income and affordable housing programs began to decline in the eighties (Brassil, 2010). Public programs during the eighties and nineties sought to leverage public funding with private and other funding sources. Public housing funded by federal, state, and local agencies was reduced drastically with the vilification of such projects. In 1992, HUD changed its public housing approach with the HOPE VI program. Instead of targeting low-income households only, the HOPE VI program is aimed toward mixed income housing to rejuvenate distressed public housing. Although the HOPE VI projects involve partnerships with private entities, the private investment has been principally limited to the extension of loans and the purchase of low-income housing tax credits (Schill and Wachter, 2001).

In order to deal with the federal funding cuts since the eighties, local governments and states began developing their own programs for low-income and affordable housing. A range of local and regional nonprofit organizations also arose to fill in the affordable housing gap. The nonprofits gained further significance during the nineties in the face of 
the decline of public housing on one hand, and the increasing failure of the private sector to provide affordable housing on the other hand.

It is in the above context that organizations such as Community Development Corporations (CDCs) and Housing Partnerships (HPs) gained ground as innovative solutions to improve both the financing and delivery of affordable housing programs and services (Stegman, 1999; Suchman, 1990). Community Development Corporations (CDCs) have become well known as important vehicles of affordable housing. Community Development Corporations (CDCs) are community-based nonprofits with strong neighborhood representation on the corporation's board of directors. There is broad literature on the role of CDCs in terms of their organization, financing, and construction of affordable housing (Melendez and Servon 2007; Nye and Glickman, 2000; Robinson, 1996; Rohe and Bratt, 2003).

Similar to CDCs, HPs also focus on affordable and workforce housing. Housing Partnerships are broad coalitions of businesses, nonprofits, and public agencies. There are over 375 such organizations distributed through the country. Despite their long history and growth, HPs have received little attention in the housing literature as compared to Community Development Corporations. There are only four publications directly related to Housing Partnerships (Mayer and Temkin, 2007; Suchman et al., 1990; Wylde, 1986; 1997). Wylde (1986) documented the rise of the New York City Housing Partnership in response to the then on-going affordable housing crisis in the city. Wylde (1997) documented the significance of the public-private partnerships in alleviating the affordable housing problem in New York. Suchman et. al. (1990) conducted comparative 
case studies of five Housing Partnerships across the country to identify the factors affecting the performance of Housing Partnerships.

Mayer and Temkin (2007) examined the performance of the 87 organizations within the Housing Partnership Network, which is a national peer network of Housing Partnerships to manage and finance affordable homes that revitalize communities. Their study revealed that the partnerships are mainly involved in housing development, lending, education, and community support services. The study also highlighted the significant nationwide impact on affordable housing delivery: they served over 80,000 people, and financed over \$1.1 billion for over 240,000 affordable housing units (p. 3). The partnerships leverage funding from HUD, state, and other local government agencies with private funds to conduct these activities.

The role of the nonprofit organizations like Housing Partnerships remains significant in the new millennium. In the first decade, the housing market has shown considerable volatility, with rapid rise in housing prices across the country in the first half and the housing market crash in the second half of the decade (Wall Street Journal, 2009). The current economic downturn first emerged in the housing market because of subprime mortgage lending. It then spread across the entire economy causing several issues, such as high levels of foreclosures and unemployment (NeighborWorks America, 2009). These factors affected the health of entire communities, and the ability of individuals to purchase homes. Communities implemented various approaches to lessen the extent of negative impacts of the housing downturn and economic changes. In this light, The Neighborhood Stabilization Program (NSP) program implemented in 2008 assisted state and local governments with targeted emergency assistance to acquire and 
redevelop foreclosed properties. A few communities created housing partnerships for the development of programs and services to assist affected households. With the changing environment, Housing Partnerships had to adjust their strategies to deal with new needs at local levels. Some Housing Partnerships received the NSP funds to develop or expand programs and services. While a few Housing Partnerships expanded on existing foreclosure and homeownership programs, others developed services or programs to target specific needs.

\subsection{Purpose and Significance of the Dissertation}

As outlined in the previous section, the literature on Housing Partnerships is thin, despite their growth since the nineteen-eighties. Housing Partnerships have played a significant role in the housing market across urban America. The purpose of my dissertation is to examine the role of Housing Partnerships, particularly with respect to affordable housing. The main objective of the study is to identify the principal factors that contribute to the successful performance of Housing Partnerships in achieving their affordable housing mission. Successful performance is conceptualized as the degree to which the Housing Partnerships have delivered affordable housing (financing, construction, and other related services). Therefore, success results from the ability of a Housing Partnership to provide for the affordable housing needs of a community. Housing Partnerships provide for these needs by developing strategies that create, preserve, and encourage the improvement of the supply, quality, and affordability of housing in a community (Sengupta and Tipple, 2007). Though Successful performance, Housing Partnerships provide long-term solutions that assist the communities served 
(Katkov, 2009). The analysis is performed using the Balanced Scorecard framework, which is well recognized in the literature of organizational performance (Bryson, 2004; Kaplan and Norton, 1996; Niven, 2003).

My study is significant from both a scholarly perspective and a pragmatic policy perspective. From a scholarly perspective, my dissertation builds on literature on HPs in particular and public-private partnerships in general to explore the factors that lead to successful performance. Although Housing Partnerships fill a crucial need for affordable housing, literature on evaluating HPs has yet to emerge. My dissertation bridges this important gap in the literature by systematically documenting the nationwide growth and role of HPs, and by building on earlier studies to identify the factors that lead to successful performance. Second, the study has a national scope with an emphasis on performance. As such, the recommendations can be generalized for informing national, state, and local level policies. Public administrators will be able to use my examination to gain policy directions regarding strengthening the role of HPs in the delivery of affordable housing. Third, the dissertation uses the Balanced Scorecard (BSC) as a framework for examining the factors that lead to success of Housing Partnerships. The BSC framework is well recognized within the organizational performance literature in the private, public, and nonprofit sectors (Bryson, 2004; Kaplan and Norton, 1996; Niven, 2003).

From a pragmatic policy perspective, the study will be a useful reference for policy directions to public administrators and practitioners, as its main objective is to identify the factors that affect the performance of Housing Partnerships. The Department of Housing and Urban Development described Housing Partnerships as local solutions 
that work positively in assisting deteriorated neighborhoods; yet very little is known about the "the right mix" of factors that allow for HPs to perform positively (HUD, 2007). In addition, the BSC framework allows managers and practitioners from all sectors to incorporate the results of this study into practice. Lastly, this examination is significant in the context of the current economic and affordable housing challenges. Housing Partnerships could be a part of the innovative set of solutions during these challenging times for the provision of affordable housing.

\subsection{Conceptual Framework}

There are two major approaches to performance and improvement across the public, private, and nonprofit sectors: single-dimension approach and systems approach. The single-dimension approach focuses on one major organizational factor (e.g., leadership) at a time. The systems approach views organizations as complex open systems, in which "all the parts, or subsystems, work together to achieve the purpose of the whole organization" (Swanson, 1994). My study utilizes a systems approach of analyzing organizational performance of Housing Partnerships. The Balanced Scorecard (BSC) framework employed in this study takes as a given that every part of the organization plays a critical role in its performance.

Robert Kaplan and David Norton (1996) developed the Balanced Scorecard framework, and Paul Niven (2003) later adapted it for nonprofit organizations. The identification and evaluation of performance measures using the Balanced Scorecard framework allows agencies to improve their processes (Chan and DeGroote, 2004). Figure 1.1 illustrates how the Balanced Scorecard framework is applied to Housing 
Partnerships in this study. The organizational vision and mission are at the center of the Balanced Scorecard framework; the framework is thus centrally oriented towards the achievement of the mission. The framework consists of four component perspectives: financial, customer, internal business process, and learning and growth. In order for agencies to improve using the Balanced Scorecard framework, they must align the component perspectives with the mission of the agency. Each perspective represents an aspect of the organization. In the context of Housing Partnerships, the financial perspective is to ensure revenue sufficiency from different sources. The customer perspective focuses on the type of consumers served and their satisfaction levels. The learning and growth perspective focuses on the staff capabilities. The internal process perspective addresses the Housing Partnership programs and services.

The Balanced Scorecard is used as the structure for this study because it has been widely recognized as a performance evaluation framework in the private, public, and nonprofit sectors. It is often used as a framework for performance evaluation in both the practitioner and academic fields. As a result, the results of this study can be useful to scholars and practitioners interested in enhancing the mission and goals of Housing Partnerships. 


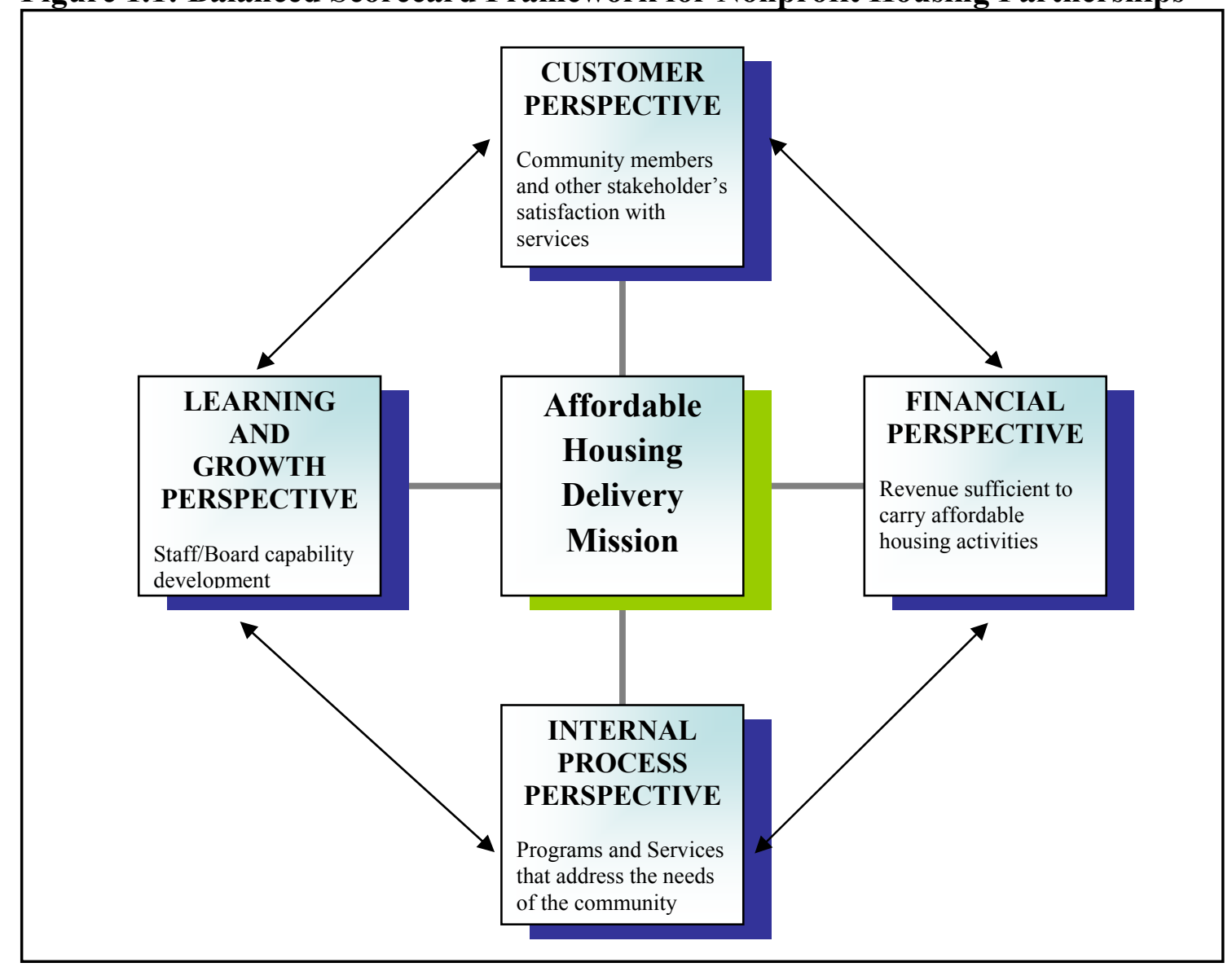

Source: Adapted from Niven (2003)

\subsection{Research Questions}

\section{a. Primary Research Question}

The main objective of this study is to identify the principal factors that contribute to the successful performance of Housing Partnerships in achieving their affordable housing mission. Hence, the primary research question of the study is: What are the factors affecting the successful performance of Housing Partnerships? The emphasis is on identifying the factors that lead to success of Housing Partnerships with respect to their mission of delivering affordable housing. In alignment with the Balanced Scorecard 
framework, the primary research question is examined from four perspectives: financial, customer, internal business process, and learning and growth. In keeping with the systems approach, the argument is that the four perspectives put together would provide insights into the factors along each dimension for the successful performance of Housing Partnerships. The sub-questions along the four perspectives are outlined below.

\section{b. Financial Perspective}

The Financial Perspective emphasizes financial performance for cost effective and efficient delivery of services to the customers (Niven, 2003). The Financial Perspective will assist with the identification of financial-related Housing Partnership performance factors, such as the funding sources and areas of expenditure. The research question from this perspective is: What are the financial activities of successful Housing Partnerships? I hypothesize that Housing Partnerships are mainly oriented toward funding affordable housing related activities. Such activities could include providing funds for housing construction, loans, credit counseling, and other such programs (Suchman, et. al., 1990). The diversity of sources of Housing Partnerships' revenues is also important for the nature of their financial activities.

\section{c. Customer Perspective}

The Customer Perspective deals with the customers emphasized by the organization's mission (Niven, 2003). The Customer Perspective will assist with the identification of customer related factors that affect Housing Partnership performance, such as the type of customers served by the HP and their satisfaction with the services provided by the Housing Partnership. The research question from this perspective is: 
Who are the main clientele of Housing Partnerships? I hypothesize that Housing Partnerships cater mainly to low and moderate-income households. If Housing Partnerships are oriented toward affordable housing development, they should be considered successful if low- and moderate-income households form a majority of their customers.

\section{d. Internal Perspective}

The Internal Business Process Perspective deals with issues relating to functions, activities, work process, and programs that organizations pursue to achieve their mission (Niven, 2003). The Internal Perspective will assist with the identification of internal process related factors that affect Housing Partnership performance, such as type of programs and services. The research question from this perspective is: What are the programmatic activities of Housing Partnerships? I hypothesize that Housing Partnerships undertake programmatic activities that contribute toward increasing affordable housing options. These activities include: affordable housing construction, affordable rental housing, loans, and credit counseling.

\section{e. Employee Learning and Growth Perspective}

The Employee Learning and Growth perspective deals with the skills and the capacity of the staff to achieve the organization's mission (Niven, 2003). The Employee Learning and Growth perspective will assist with the identification of learning and growth related performance factors such as the necessary level of staff expertise of Housing Partnerships. The research question from this perspective is: What are the organizational capacities of Housing Partnerships? I hypothesize that successful 
partnerships have a committed leader, high degree of involvement of a board of directors, and the requisite staff trained in affordable housing issues. As established in the performance literature, lack of organizational capacity is often a limitation for nonprofits to deliver their services (Fredericksen and London, 2000).

\subsection{Organization of the Dissertation}

The dissertation includes nine chapters to give a holistic analysis of the factors contributing to the successful performance of Housing Partnerships in achieving their affordable housing mission. The introductory chapter gives the background of the research, along with its significance and the research questions. Chapter two provides a detailed literature survey of the Housing Partnerships. Chapter three outlines the research methodology in detail. Chapter four gives a summary analysis of Housing Partnership's growth and role in the housing market in the United States. Chapters five through nine provide an analysis of HPs' performance with respect to each of the four BSC perspectives. Chapter five of the dissertation deals with the performance of HPs with respect to their financial perspective. Chapter six of the dissertation examines the performance of HPs in respect to their customer perspective. Chapter seven examines the performance of HPs in respect to their internal business process perspectives. Chapter eight of the dissertation provides an analysis of HPs in respect to their learning and growth perspective. Chapter nine concludes with a summary analysis of the HPs from all four perspectives and outlines the major policy and administrative lessons of the study. 


\subsection{Summary}

Housing Partnerships are local intermediary nonprofits that seek to deliver affordable housing by encouraging and supporting collaboration and combining the resources, knowledge, and expertise from the public and private sectors (Stegman, 1999). They emerged in the eighties across major cities in the United States in the face of decline of public funding for housing at the federal, state, and local levels. Housing Partnerships were adopted by local areas as innovative solutions to address the affordable housing needs of communities. The Housing Partnerships have contributed significantly to the affordable housing market over the last three decades. They continue to be significant in the current economic downturn, serving as innovative local approaches to affordable housing delivery. Yet, there is a wide gap in the scholarly literature on the role and performance of Housing Partnerships. My dissertation seeks to fill this literature gap by examining Housing Partnerships with an emphasis on the identification of factors that lead to the successful performance of their mission. The Balanced Scorecard framework is used as the conceptual framework to identify the factors. 


\section{LITERATURE REVIEW}

\subsection{Introduction}

The scholarly literature examining Housing Partnerships (HPs) is thin. As a result, despite two decades of their history, growth, and significance in local housing revitalization, HPs are less well known than other organizations associated with the development of affordable housing such as Community Development Corporations (CDCs). Community Development Corporations (CDCs) are community centered nonprofits with strong neighborhood representation on the corporation's board of directors. They usually serve a specific geographic location such as a neighborhood or a town. They often focus on constructing affordable housing for lower-income residents and can also be involved in economic development, education, and real estate development. Similar to CDCs, HPs assist communities with affordable housing. The main difference between the two is that CDCs are narrower in geographical and functional coverage than Housing Partnerships. Unlike CDCs, the partnerships are broad coalitions of businesses, nonprofits, and public agencies. Although there are fewer Housing Partnerships nationally than Community Development Corporations, HPs have developed more affordable housing units than CDCs annually (Mayer and Temkin, 2007). The impact of HPs on the development of affordable housing has not been well documented. Hence, my study is significant for narrowing the gap in the literature by examining HPs nationally, focusing on their performance.

The literature review includes four sections. The first section provides an overview of the literature on Housing Partnerships. The second section examines the 
development and growth of Housing Partnerships, identifying the factors that affect HP performance. The literature survey informs the research questions included in my study. The third section reviews the literature on performance evaluation as it relates to Housing Partnerships. It highlights how the Balanced Scorecard framework is useful to examine HP performance. The fourth section of summarizes the review.

\subsection{Housing Partnerships}

\section{a. HPs as Public-Private Partnerships}

Housing Partnerships began as collaborations between the public and private sectors in order to arrive at solutions to housing issues such as housing affordability and homelessness. In public-private partnerships such as HPs, private organizations participate in the decision-making and production of a public good or service that has traditionally been provided by the public sector and in which the private sector shares the risk of that production (Forrer, et. al., 2010). Public-private partnerships in general offer several benefits in addressing complex public policy problems by combining public and private sector expertise, funding, and innovation (Frederickson and Ghere, 2005; Wettenhall, 2001). Kamensky and Burlin (2004), Marwell and Husain (2005), and Douglas (2009), argue that shared vision and goals to address a need underlies the motivation to form a collaborative agreement or partnership. Trust, respect, and communication between partners are essential to keep them committed to the partnership and assist in achieving its mission. Cooper (2003) and Donahue (1989) indicate that the public and private sectors may enter into a partnership in the spirit of collaboration and mutual trust in order to assist in meeting a need that requires combined efforts and 
expertise; at the same time, differing interests can lead to tensions and disputes that could dissolve the partnership. Kettl (2009) indicates that as partnerships have grown and become more common, "programs are more complex and harder to manage and control. More players with weaker links to policymakers combined to create a twin dilemma: big performance problems along with weakened accountability."

Housing Partnerships emerged in the eighties as local public-private cooperative solutions to the delivery of affordable housing through innovative ways to fund affordable housing construction and community development. Highlighting the benefits of the partnership model, Wylde (1986, p. 121) argues, "Through the process of building a cooperative effort, all parties transcend traditional roles and demonstrate how existing resources can be applied in new ways to achieve greater objectives." By mixing public and private funds, HPs were successful in maximizing their financial resources. Wylde (1986) and Lederman (1983) argue that the collaborative work of the private sector (such as banks and realtors), the public sector (such as housing and government officials), and nonprofit entities, allows for the maximization of resources in which knowledge and funds are used to meet a collective housing goal. Andrisani, Hakim and Leeds (2002) illustrate how the collaboration of the public, private, and nonprofit sectors work in the case of the Housing Partnership, Inc. of Louisville, Kentucky, a public-private partnership and a nonprofit 501 (c) (3) corporation created in 1989 with the mission of creating affordable housing. The Housing Partnership, Inc. pursues its mission by combining resources and efforts such as leveraging federal funds with private equity. The partnership also gets support from the local government and nonprofit groups. 
The main purpose of HPs is to deliver affordable housing and related support services. They achieve this purpose by carrying out various affordable housing activities such as, unit development and construction, providing loans, property management, education, and community support services. Financing and construction of affordable housing are the principal activities of Housing Partnerships. Mayer and Temkin (2007) examined the performance of 87 organizations within the Housing Partnership Network, which is a national peer network of HPs to manage and finance affordable homes. The study highlighted the significant nationwide impact on affordable housing delivery. Housing Partnerships served in excess of 80,000 people, and financed more than $\$ 1.1$ billion for over 240,000 affordable housing units (Mayer and Temkin, 2007, p. 3). The affordable housing stock produced by different nonprofits is summarized in Table 2.1. As the table indicates, the Housing Partnership Network has surpassed other major financial intermediaries such as Local Initiatives Support Corporation, Enterprise Foundation, and CDCs in terms of the average affiliate's total production.

Table 2.1: Total housing units produced by nonprofits

\begin{tabular}{|l|c|c|c|}
\hline \multicolumn{1}{|c|}{ Organization } & $\begin{array}{c}\text { Number of } \\
\text { Affiliate } \\
\text { Organizations }\end{array}$ & $\begin{array}{c}\text { Average Affiliate's Total } \\
\text { Unit Production Since } \\
\text { Founding }\end{array}$ & $\begin{array}{c}\text { Total Units } \\
\text { Produced }\end{array}$ \\
\hline $\begin{array}{l}\text { Housing Partnership } \\
\text { Network }\end{array}$ & 63 & 2,654 & 167,187 \\
\hline $\begin{array}{l}\text { Local Initiatives } \\
\text { Support Corporation }\end{array}$ & 2,800 & 70 & 196,000 \\
\hline $\begin{array}{l}\text { Enterprise } \\
\text { Foundation }\end{array}$ & 2,400 & 79 & 190,000 \\
\hline $\begin{array}{l}\text { Habitat for } \\
\text { Humanity US }\end{array}$ & 1,651 & 27 & 44,617 \\
\hline CDCs & 4,600 & 271 & $1,252,000$ \\
\hline
\end{tabular}

Source: Mayer and Temkin (2007, p. 14) 
Although affordable housing development through construction and funding remains a major function of HPs, they have broadened their purpose since the eighties. They have adopted comprehensive/holistic approaches by developing programs and services addressing the various affordable housing needs of a community as needs change. For example, HPs later realized that funding affordable housing or providing financial assistance alone was not sufficient for homeowners to maintain their homes, and for long-term community development. Other factors such as education and employment affect the ability of households to maintain and keep their properties and for communities to develop and grow. Consequently, several HPs adopted comprehensive approaches to affordable housing and community development that included ancillary support activities such as community rehabilitation, education, and counseling to achieve their mission.

A few HPs have added the roles of policy and advocacy to their approaches. For example, the Minnesota Housing Partnership developed a "lobbying arm and advocacy network" and the Massachusetts Housing Partnership views its advocacy role as a "voice regarding housing policy." Housing Partnerships' involvement in policy and advocacy is to promote and support affordable housing development in their jurisdiction. They do so by raising public awareness and encouraging civic and political participation to encourage policies that assist affordable housing.

b. HPs as a bridge between Public and Private Sectors

Wylde (1986) argues that in order for the public and private sectors to arrive at a successful collaborative arrangement, an intermediary agent is needed. The nonprofit entity serves as the institutional intermediary. The majority of HPs are also intermediary nonprofits, registered as 501(c) (3) organizations with the IRS. According to Suchman et 
al. (1990) and Lederman (1993) the organizational structure of the nonprofit supports their function as intermediary agents. As part of their structure, they serve as a central point for the public and private sectors to reach common plans and goals (Stegman, 1999). In addition, nonprofits facilitate expertise and information networks (Lederman, 1993). As expertise networks, nonprofit HPs have long-term involvement in the provision of affordable housing and related support services (Lederman, 1993). Stegman (1999) and Mayer and Temkin (2007) agree that as information networks, HPs are knowledgeable advocates for reforms and policies that promote affordable housing. Expertise allows HPs to establish credibility, funding, and linkage to potential partners.

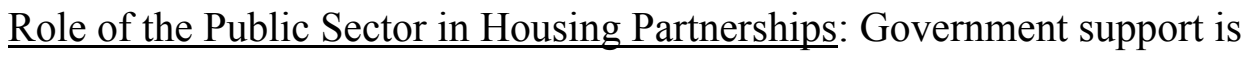
important to the efforts of Housing Partnerships. Government can sponsor community initiatives advocated by the HP (Kamensky and Burlin, 2004). Wylde (1986) and Stegman (1999) indicate that the public sector provides direct financing, technical assistance, and mediation assistance to Housing Partnerships. All levels of government can play a role in the efforts of Housing Partnerships. Wylde (1986) argues that federal government participation in the HP demonstrates to private partners the possibility of securing the long-term public commitments required to sustain development activities. Suchman et al. (1990) and Lederman (1993) indicate that local government participation assists the HP to receive local political support, municipal financial resources, and expertise in financing and the production of low-income housing. Furthermore, local governments can assist HPs by securing housing development sites and by securing project approvals. 
Role of the Private Sector in Housing Partnerships: According to Suchman et al. (1990), the private sector brings diversified funding, organizational experience, and financial expertise to Housing Partnerships. Lederman (1993) argues that private sector financing can assist with removing some of the market barriers to affordable housing. Additionally, Mayer and Temkin (2007) and Wylde (1986) indicate that the private sector assists HPs with loan origination. Overall, the main role of the private sector is in the financing and lending of funds that the HP requires to achieve its goals.

\section{c. Factors Affecting Successful Performance of Housing Partnerships}

Extant research on performance of Housing Partnerships is derived from case studies. Although case studies represent selected sites and findings may not be applicable to the general population of HPs, the research insights of these studies provide the basis for the hypotheses for my dissertation. Mayer and Temkin (2007) concluded that in order for a HP to perform successfully, they should be mission driven, as well as be sound businesses built on good leadership, staff, operational systems, and financial performance. They argued that successful HPs utilize the collaboration's strengths to improve current practices and pursue new opportunities (Mayer and Temkin, 2007). Since the study was limited to HPN members, its implications regarding the functions, outcomes, and performance of HPs are limited to this group. However, the findings of this study are broadly similar to other studies on performance factors affecting Housing Partnerships.

In 1986, Rockefeller and Wylde conducted separate studies documenting the rise of the New York City Housing Partnership. Both studies examined the development of the HP as a response to the then on-going affordable housing crisis in the city and 
identified factors affecting its performance. Wylde (1986) identified three factors in the organization's successful performance: strong leadership, an organizational structure for policy making and administration, and a clear delineation of decision-making between the partnerships' members. Rockefeller (1986) identified four factors in the organization's successful performance: a strong and comprehensive private-sector organization, the personal participation of the chief executives, a clear mission, and a receptive and supportive public sector. Subsequently, Wylde (1997) argued that publicprivate HPs are significant in alleviating affordable housing issues.

Suchman, Middleton and Guiles (1990) conducted comparative case studies of five HPs: Boston Housing Partnership, Inc., Chicago Housing Partnership, Cleveland Housing Network, Inc., Wisconsin Partnership for Housing Development, Inc., and BRIDGE Housing Corporation. They found that changing economic, regulatory, and incentive environments, difficult local political settings, multiple actors, needs, and goals, complicated financing, and limitations on capacity are all factors that negatively affect the performance of Housing Partnerships. In order for HPs to overcome these limitations and to perform successfully, Suchman et al. (1990) propose the following ten aspects affecting performance:

1. Identifiable need: the capacity of the HP to address specific community needs.

2. Responsiveness to local context: the ability of HPs to deal with the opportunities and limitations of their local environment.

3. Leadership: the leader of the HP is to attract support to the HP's efforts. 
4. Strong board of directors: the composition of the board of directors should be diverse and its members must bring knowledge and experience so that they can assist the HP to make decisions.

5. Trust relationships: partnership relations require trust, so that collaboration takes place between partners.

6. Access to public and private sources: the sources of funding must be diverse in order to have sufficient funds that support housing production.

7. Expertise: the staff and board of directors of the HP need the skills and knowledge in development and financing in order to deal with the challenges and issues of the housing projects supported by Housing Partnerships.

8. Strong, skilled staff: because staffs of HPs have several different responsibilities, they must be professional and skilled.

9. Flexibility: Housing Partnerships must have an approach that enables them to respond to changing rules and opportunities.

10. Development entity: the completion of partnership-supported housing projects depends on a capable development entity.

The extant literature is useful in providing insights into the factors affecting the performance of HPs in achieving their affordable housing goals. In summary, the literature highlights four major categories of factors: (a) financial capacity; (b) the nature of clients served; (c) programs and services rendered; and (d) internal organizational factors (for instance, leadership and staff skills). These four categories also broadly conform with the Balanced Scorecard framework outlined below. 


\subsection{Performance Evaluation}

a. Evaluation of Housing Partnerships

Russ-Eft and Preskill (2001) define performance evaluation as the following:

The process of determining the merit, worth, or value of something, or the product of that process. Terms used to refer to this process or part includes: appraise, analyze, assess, critique, examine, grade, inspect, judge, rate, rank, review, study, test...The evaluation process normally involves some identification of relevant standards of merit, worth, or value; some investigation of the performance of these standards; and some integration or synthesis of the results to achieve an overall evaluation or set of associated evaluations.

Performance evaluation began in the private sector to address the need for a system that would allow organizations to develop effective internal and external communication (Procurement Executives' Association (PEA), 1998). Performance evaluation evolved into a system that assists organizations in the identification of programs, protocols, plans that work and which of these do not. The ultimate goal of performance evaluation was to identify which processes/ programs to continue with, which to improve on, and which to repair or replace (Swanson, 1994; 2007). Subsequently, public and nonprofit organizations followed in the steps of the private sector and adjusted performance evaluation frameworks to their needs.

Evaluation frameworks are plans that can be used by all levels of the organization to support the mission and goals (Chapman, 2005). Riggin et al. (1992) highlight the 
challenges in evaluating the work of public-private partnerships undertaking housing and community development projects. They identified nine criteria for the evaluation of the partnerships under three broad categories. The categories and the criteria are: the need addressed by the partnership (magnitude of problem, duplication); the process of partnership implementation (planning implementation, partnership structure, management, resource acquisition), and the outcomes of the partnership (objectives attainment, other effects, project costs).

Russ-Eft and Preskill (2001) argue that evaluations should be viewed as a systematic process that should take place as a planned and purposeful activity. Evaluations should involve collecting data regarding issues in an organization or program. The evaluations should allow decision makers to gain the knowledge necessary to make appropriate decisions so that a program, process, product, system, or organization can be improved or refined. Finally, it is important to use what is learned through an evaluation of performance because it provides a better understanding of how an organization works and what could be done for improvement. Although evaluation is important, some organizations may not undertake it for various reasons, such as misunderstanding the purpose and role of evaluation, fear that the findings may produce negative impacts, lack of use of results, perception of evaluation as a time consuming task, perception of costs outweigh benefits, and bad prior experiences with evaluations.

\section{b. The Balanced Scorecard Framework}

Performance evaluations as well as rewards for performance should be tied to specific measures of success by linking financial and non-financial incentives directly to performance (PEA, 1998). In this, the Balanced Scorecard (BSC) is a useful framework 
that combines financial and non-financial measures effectively. It is a structured methodology of performance evaluation that helps organizations to set agreed-upon performance goals, allocate and prioritize resources, confirm or change current policy or program directions to meet these goals, and report on the successes of meeting those goals (PEA, 1998). The Balanced Scorecard framework is used for performance evaluation widely in both the practitioner and scholarly world (Bryson, 2004; Kaplan and Norton, 1996; Niven, 2003). The Balanced Scorecard framework of evaluation is used in this study because the factors associated with performance highlighted in the literature are well aligned with the BSC framework.

Kaplan and Norton (1996) developed the BSC framework for improving private sector performance, and Paul Niven (2003) adapted it for nonprofit organizations. The identification and evaluation of performance measures using BSC allow agencies to improve their processes. In order for agencies to improve using the BSC framework, they must align the factors found in all perspectives as affecting performance with the mission of the agency. The Balanced Scorecard framework has four perspectives that represent all aspects of the organization to "balance" financial and nonfinancial indicators of success. The Balanced Scorecard, as it was originally developed for the private sector, has an emphasis on financial measures of success. In nonprofits and government agencies, the emphasis of the BSC is on mission achievement to examine successful performance. However, regardless of the sector, finances affect the growth and overall performance of an organization. Financial measures have a role in organizational performance measurement because funding has an impact on the efficiency and efficacy of a program. As a result, the $\mathrm{BSC}$ retains financial measures as one of the perspectives. The other three 
perspectives cover non-financial issues affecting organizations in the short and long-term that traditional financial measures do not capture. Financial measures provide short-term performance solutions while non-financial measures capture drivers of long term success. Together these drivers are organized to balance external measures for stakeholders and customers, and internal measures of critical business processes, innovation, learning and growth.

The Financial Perspective emphasizes financial performance measures for cost effectiveness and efficient delivery of services to the customers. The $\underline{\text { Customer }}$ Perspective deals with the type of customers that organization's mission emphasizes. The Internal Business Process Perspective deals with issues relating to functions, activities, work process, and programs that organizations pursue to achieve their mission. The Employee Learning and Growth Perspective deals with skills, dedication, and alignment of the staff with the organization's mission. The perspectives affect each other in that all measures are part of a cause-and-effect relationship that improves performance (Kaplan and Norton, 1996). The four perspectives align well with the four major categories of factors identified in the literature on HPs, namely the financial capacity, the nature of clients served, their programs and services, and their internal organizational factors.

\subsection{Conclusion}

The available literature on Housing Partnerships is not deep. Nearly all extant research is derived from selected case studies. Thus, there is a gap in literature on systematic analysis of the factors that affect HP performance. There is also limited documentation of HPs as organizations delivering affordable housing and assisting in 
community development. The sparse research that exists indicates that the HPs play a significant role in the housing market, and it is important to reduce the literature gap. Although fewer in number, Housing Partnerships produced more affordable housing units in comparison to other affordable housing delivery and community development agencies and are significant entities nationwide affecting affordable housing delivery (Mayer and Temkin, 2007).

The primary mission of HPs is to deliver affordable housing through various programs and services such as housing construction and education. Housing Partnerships add, expand, or discontinue programs and services as they develop (Suchman et al., 1990). The extant literature is useful in providing insights into the factors affecting the performance of HPs in achieving their affordable housing goals. In summary, the literature highlights four major categories of factors: (a) financial capacity; (b) the nature of clients served; (c) programs and services rendered; and (d) internal organizational factors (e.g., leadership, staff skills).

Performance evaluation of Housing Partnerships is required to enhance their programs and services that meet the needs of the communities served. Performance improvement recommendations allow HP management to develop efforts that address their organizational goal of affordable housing (Swanson, 1994; 2007). My study uses the Balanced Scorecard as the framework for evaluation. It has been used widely in the private, government, as well as the nonprofit sectors. It has four perspectives capturing both financial and non-financial dimensions affecting performance. The four perspectives — namely, financial, customer, internal business process, and employee 
learning and growth - align well with the four core dimensions of evaluations suggested by extant research on the evaluation of Housing Partnerships. 


\section{RESEARCH METHODOLOGY}

\subsection{Introduction}

This chapter provides an outline of the research methods employed in my dissertation. The main objective of my dissertation is to identify the factors that lead to the successful performance of Housing Partnerships (HPs) in delivering affordable housing. The Balanced Scorecard (BSC) is used as a framework for this evaluation. In this context, the research design employs a mixed method, geared towards collating and analyzing the data related to HPs' performance using the Balanced Scorecard framework. The Balanced Scorecard framework is comprised of four perspectives: financial, customer, internal business process, and employee learning and growth. Data for these perspectives relating to HPs were obtained through a variety of sources. The Internal Revenue Service (IRS) Publication 78 was used as the main entry point to identify all HPs in the country. Then, the IRS Form 990 (required to be filed by nonprofits) from Guidestar formed the basis for the financial data I analyzed. The IRS Form 990 is titled "Return of Organization Exempt from Income Tax," and is submitted by tax-exempt organizations and nonprofit organizations to provide the IRS with annual financial information. The individual HPs' websites and secondary sources were used to obtain detailed background information about the Housing Partnerships. An open-ended questionnaire (using email and interviews) was used with selected HPs to gain deeper insights into their functioning. The Housing Partnerships' Form 990s, websites, secondary sources, and the answers of the open-ended questionnaires, assisted in the development of a close-ended survey. The close-ended survey was administered covering 
all four perspectives of the Balanced Scorecard framework. Descriptive and inferential statistics are used to analyze the data obtained through the IRS Form 990 and the surveys.

The rest of the chapter explains the research methods in detail. The next section outlines the research design. The major data sources are then identified. The chapter concludes with the major research methods adopted in the study and their limitations.

\subsection{Research Design}

The main purpose of this study is to identify the principal factors that contribute to the successful performance of Housing Partnerships in achieving their affordable housing mission. In this context, the main research question underlying the study is: What are the factors affecting the successful performance of Housing Partnerships? This is an exploratory research question. According to Creswell and Plano (2007), an exploratory research question is used when a study seeks to gain an understanding of a new topic that has not had much research on it before. My study employs a quasiexperimental design in arriving at answers to the question. The major data sources for this study are: the IRS Form 990, a federal tax return form required to be filed by all nonprofits; and a survey questionnaire sent to the Housing Partnerships. Agency specific data were also drawn from the organization's websites and secondary documents.

The emphasis in the exploratory analysis is to identify the factors that lead to the success of HPs with respect to achieving their mission of delivering affordable housing. Successful performance is conceptualized as the degree to which the Housing Partnerships have catered to affordable housing delivery (financing, construction, and other related services). Affordable housing is below market rate housing, usually 
constructed for the benefit of low and moderate-income households. The generally accepted definition of affordability is for a household to pay no more than 30 percent of its annual income on housing. Households that spend more than 30 percent of the income on housing are considered cost burdened.

The extant literature on Housing Partnerships provides insights into some of the factors affecting the performance of Housing Partnerships. These insights provide the basis for identifying preliminary factors for further analysis to answer the research question. As outlined in the previous chapter, the insights from extant literature are aligned with the Balanced Scorecard framework. Moreover, the BSC framework is widely used in the performance evaluation literature. Hence, this framework has been used for analyzing the performance of Housing Partnerships. The unit of analysis in the BSC framework is the organization, i.e., the Housing Partnership itself.

In conformity with the BSC framework, the main research question is examined from its four component perspectives, namely the financial, customer, internal business process, and learning and growth. The four perspectives put together represent all the aspects of organizations. The four perspectives together will provide insights into the factors along each dimension for the successful performance of Housing Partnerships. Therefore, answering the main research question. Therefore, answering the main research question. The sub-questions and the analytical methods to answer each question are outlined below. The hypothesis of each question is derived from the literature review.

\section{a. Financial Perspective}

The financial perspective emphasizes HPs' financial performance for cost effective and efficient delivery of affordable housing services (Niven, 2003) and this 
perspective will assist with the identification of HPs' financial performance factors. The sub-question from this perspective is: What are the financial activities of Housing Partnerships? The hypothesis is that Housing Partnerships are mainly oriented toward funding affordable housing related activities. Such activities could include providing funds for housing construction, loans, credit counseling, and other such programs. Diversity of public and private funding sources is an important issue for survival of nonprofits (Suchman, et. al., 1990). The financial data of HPs were obtained from the IRS Form 990 and the close-ended survey questionnaire. The data are analyzed for the HPs' diversity of sources, the various activities funded by them, and the trajectory of funding over time. Particular attention is also paid to how the HPs have responded to the housing market downturn.

\section{b. Customer Perspective}

The customer perspective deals with the customers emphasized by the HP's mission (Niven, 2003). This perspective will thus assist with identifying the customer related factors affecting Housing Partnership performance, such as the type of customers served by the HP and their satisfaction with the HP's services. The research question from this perspective is: Who are the main clientele of Housing Partnerships? The hypothesis is that the clientele of the HPs are mainly low and moderate-income households. If HPs are oriented toward affordable housing development, they should be considered successful if low and moderate-income households form a majority of their customers. The data on the customers served are derived from the IRS Form 990s and the survey questionnaire. The data are then analyzed for the income groups served by the Housing Partnerships and the customers' satisfaction with the HP services. 


\section{c. Internal Perspective}

The internal business process perspective deals with issues relating to the programs that HPs have pursued to achieve their mission (Niven, 2003). This perspective will assist with identifying programmatic factors that affect HP performance, such as type of programs and services. The research question from this perspective is: What are the programmatic activities of Housing Partnerships? The hypothesis is that the Housing Partnerships undertake programmatic activities that contribute toward increasing affordable housing options. Such activities include: affordable housing construction, affordable rental housing, loans, and credit counseling. The data on programmatic activities are drawn from the IRS Form 990s and the survey questionnaire. The data are then analyzed for the types of programs and the income groups that these programs target.

\section{d. Employee Learning and Growth Perspective}

The employee learning and growth perspective deals with the skills and the capacity of the staff to achieve the HPs' mission (Niven, 2003). This perspective will assist with identifying the staff-related performance factors such as their expertise in conducting the HP activities. The research question from this perspective is: What are the organizational capacities of Housing Partnerships? The hypothesis is that successful partnerships have a committed leader, high degree of involvement of a board of directors, and the requisite staff trained in affordable housing issues. The lack of organizational capacity is often a limitation for nonprofits to deliver their services (Fredericksen and London, 2000). The data on organizational capacities were mainly obtained from the 
survey questionnaire. The data are analyzed for the staff skills, the composition of board members, and the leadership qualities.

\subsection{Data Sources}

The major data sources for this study are: the IRS Form 990, and the close-ended survey questionnaire sent to the nonprofit Housing Partnerships identified in the United States using Publication 78 of the Internal Revenue Service. The data for specific agencies were derived from the organizations' websites and secondary documents. Prior to obtaining the data through these sources, I conducted a preliminary open-ended email and phone interview of selected Housing Partnerships to gain insights into their functioning. In early 2009, I emailed the open-ended questionnaire to the Chief Executive Officers or Executive Directors of 20 selected Housing Partnerships. The preliminary questionnaire included six questions asking the leaders about the factors affecting the performance of Housing Partnerships (Appendix 1). Six HPs responded to the questionnaire. These responses and the factors identified in the literature were aligned with the BSC framework to develop the close-ended survey for this study. The process of collecting data from the IRS Form 990 and the close-ended survey are explained below.

\section{a. IRS Form 990}

The first step in the data gathering consisted of identifying all the nonprofit HPs in the United States. The nonprofit HP database was compiled using the online version of Publication 78 of the IRS (Cumulative List of Organizations described in Section 170(c) of the Internal Revenue Code of 1986). The Publication 78 is a comprehensive list of all the organizations that are tax-exempt under section 501(c)(3) of the Internal Revenue 
Code (i.e., these are nonprofit organizations, also called 501(c)(3) organizations). The Housing Partnerships were identified on the basis of the definition that they are broad coalitions of private, public, and nonprofit organizations to provide housing related services. Since the HPs are formally structured as partnerships, networks, coalitions, and alliances, the organizations that had such structure in the Publication 78 were shortlisted. The short listing gave a total of 381 Housing Partnerships in the country.

Nonprofit organizations are expected to submit their tax returns (Form 990, titled "Return of Organization Exempt from Income Tax") to the IRS, especially if their total annual revenues are over $\$ 25,000$. These tax returns are in the public domain. The forms are available through Guidestar, which is an online data source for information on nonprofits (http://www2.guidestar.org). After the Housing Partnerships were identified from IRS Publication 78, their IRS Form 990s were collected from the Guidestar website for four consecutive years $(2005,2006,2007$, and 2008) from HPs that filed tax returns for these years. These years were selected since these were the latest years for which the data were available. The Guidestar website also provides other basic information on nonprofits, such as the year of nonprofit's founding, their programmatic activities determined by the North American Industry Classification System (NAICS), staff size, activities, and awards.

As indicated by Froelich (1997), the IRS Form 990 tax return has been the primary source of data on nonprofit agencies. Much of the scholarly research on nonprofits is derived from the data collected from these forms. Indeed, the form gives much required financial and some non-financial data on Housing Partnerships. The form provides audited financial data (revenues and expenditures), the organizational mission, 
programs and activities undertaken, and other organizational information (such as, the use of volunteer labor). Hence, the IRS Form 990 is an excellent source of information for analyzing Housing Partnerships. The data fields that would be useful for answering the research questions were identified from the IRS Form 990. The database of the list of HPs previously identified was then populated with these data fields. The data fields are listed in Table 3.1. The missing data fields were completed from secondary information from the Housing Partnerships' websites and other secondary sources (including the Guidestar website). Comprehensive data for 238 of the 381 Housing Partnerships were collated in this manner.

Although the IRS Form 990 is a good source for data on nonprofits, it also has its limitations. The Internal Revenue Service requires the form to be submitted for nonprofits which have over $\$ 25,000$ in revenues annually. Hence, this threshold exempts organizations from inclusion in the database for analysis. About $30 \%$ of nonprofits in general meet the minimum revenue threshold. However, HPs are likely to have higher revenues than the threshold because of the inherent costly nature of their activities (construction, financing, training, etc.). Hence, the threshold limit may not be a major barrier to the analysis of Housing Partnerships. However, some HPs with revenues over $\$ 25,000$ may have not filed their returns in time. For instance, filed an extension or did not file. The research on the filing of Form 990s also indicates that there could be errors in the filling the fields in the form (Froelich, 1997; Froelich, Knoefle, and Pollak, 2000). Moreover, according to Frumkin and Kim (2001), the IRS Form 990 may not be accurate because the reporting categories are often vague and audits of nonprofit organizations are rare. In addition, Froelich, Knoefle, and Pollak, (2000) and Froelich (1997) argue that 
Form 990 could be a problematic source of longitudinal financial information because of the inherent fickleness of nonprofits — organizations merge or cease operations. As a result of these data gathering limitations, the net number of HPs with comprehensive information is smaller than the total number of identified Housing Partnerships.

Table 3.1: Data fields from IRS Form 990

\begin{tabular}{|l|}
\hline \multicolumn{1}{|c|}{ LINE ITEMS } \\
\hline Line C- Organization name \\
\hline Location: address, city, state \\
\hline Line E- Telephone number \\
\hline Line F- CEO name \\
\hline Line I- Tax exempt status \\
\hline Line L- Year of formation \\
\hline PART I: Summary \\
\hline Line 1- Mission \\
\hline Line 5- Number of employees \\
\hline Line 12- Total Revenue \\
\hline Line 19- Total Expenses \\
\hline PART III: Statement of Program Service Accomplishments \\
\hline Lines 4a- 4d- Programs and activities \\
\hline
\end{tabular}

Survey questionnaire

While the IRS Form 990 is a good source of information required for the basic information required for analysis using the BSC framework, it does not give all the data required for the analysis. For example, the number of households assisted and the size of the workforce is provided in a number range instead of an exact figure. In addition, Form 990 does not provide information on training, trends and changes. To supplement the Form 990 data, and for a fuller set of data fields required for analysis using the BSC framework, I conducted a survey of the Housing Partnerships. The close-ended survey questionnaire was built on the review of extant literature and the insights gained from the 
preliminary open-ended questionnaire and interviews with chiefs of selected HPs (as alluded to earlier). The close-ended survey consisted of 35 questions (Appendix 2). The questions were structured in six sections, in alignment with the Balanced Scorecard framework:

(a) Overview section, with five questions on the overall activities of Housing Partnerships (for example, the mission statement);

(b) Financial Perspective section, with six questions on the financial activities of Housing Partnerships (for example, allocation of funds);

(c) Customer Perspective section, with six questions on customer oriented activities (for example, income breakdown of households assisted);

(d) Internal Business Perspective, with four questions on the programmatic activities of Housing Partnerships (for example, program size changes);

(e) Employee Learning and Growth Perspective, with 10 questions on the Board of Directors, and staff capabilities (for example, the types of training opportunities available to staff); and

(f) Background section, with four questions on the organizational and demographic background of the Housing Partnership. The key Balanced Scorecard variables from each perspective in the survey are listed in Table 3.2. 
Table 3.2: BSC Variables based on Survey Questionnaire

\begin{tabular}{|c|c|c|}
\hline PERSPECTIVE & VARIABLE & VALUES \\
\hline \multirow{3}{*}{$\begin{array}{l}\text { FINANCIAL } \\
\text { PERSPECTIVE }\end{array}$} & Sources of revenue & Private, government, service fees, other \\
\hline & Budget change & Decrease/ increase \\
\hline & $\begin{array}{l}\text { Impact of current } \\
\text { economic crisis }\end{array}$ & $\begin{array}{l}\text { Reduced programs, Laid off staff, Increased loan } \\
\text { remodifications, Purchase foreclosed properties, } \\
\text { other }\end{array}$ \\
\hline \multirow{5}{*}{$\begin{array}{l}\text { CUSTOMER } \\
\text { PERSPECTIVE }\end{array}$} & Households assisted & \# of households assisted \\
\hline & $\begin{array}{l}\text { Change in household } \\
\text { assist }\end{array}$ & Decrease/ increase \\
\hline & $\begin{array}{l}\text { Income bracket of } \\
\text { households served }\end{array}$ & $\begin{array}{l}\% \text { AMI. } \% \text { very-low-income, } \% \text { low-income, } \% \\
\text { moderate, } \% \text { middle, } \% \text { high }\end{array}$ \\
\hline & Populations served & Elderly, homeless, veterans, other \\
\hline & Feedback mechanisms & $\begin{array}{l}\text { Annual meetings, Periodic visioning meetings, } \\
\text { Customer input in strategic planning, Informal } \\
\text { input from customers, other }\end{array}$ \\
\hline \multirow{5}{*}{$\begin{array}{l}\text { INTERNAL/ } \\
\text { BUSINESS } \\
\text { PERSPECTVE }\end{array}$} & Types of programs & $\begin{array}{l}\text { Affordable housing construction, lending, } \\
\text { education, counseling }\end{array}$ \\
\hline & $\begin{array}{l}\text { Performance of } \\
\text { programs and services } \\
\text { during the last three } \\
\text { years }(2006-2008)\end{array}$ & Percentage \\
\hline & $\begin{array}{l}\text { Mechanisms to attract } \\
\text { customers }\end{array}$ & $\begin{array}{l}\text { Through radio advertisements, newspaper } \\
\text { advertisements, referral, word of mouth, other }\end{array}$ \\
\hline & $\begin{array}{l}\text { Change in program or } \\
\text { services offered }\end{array}$ & Decrease/ increase \\
\hline & $\begin{array}{l}\text { Improvement of internal } \\
\text { management systems }\end{array}$ & \\
\hline \multirow{9}{*}{$\begin{array}{l}\text { EMPLOYEE } \\
\text { LEARNING } \\
\text { AND } \\
\text { GROWTH } \\
\text { PERSPECTIVE }\end{array}$} & Distribution of the board & $\begin{array}{l}\text { Local government \#, Local community group \#, } \\
\text { Local businesses \#, Local university representatives } \\
\text { \#, Representatives from organizations outside the } \\
\text { local area \#, Other \# }\end{array}$ \\
\hline & $\begin{array}{l}\text { Communication of the } \\
\text { Board of Directors }\end{array}$ & Meeting \# per year \\
\hline & Size of workforce & \# of Full time employees \\
\hline & FTE employee change & Decrease/increase \\
\hline & Turnover rate & $0 \%$ to $100 \%$ per year \\
\hline & Employee development & $\begin{array}{l}\text { Offering of programs such as Skills specific } \\
\text { training, tuition waivers }\end{array}$ \\
\hline & $\begin{array}{l}\text { Training of the } \\
\text { workforce }\end{array}$ & educational background (HS \%, College $\%$, other) \\
\hline & Background of CEO & Yrs of education, yrs of experience, \\
\hline & Maturity of organization & \# of yrs in operation \\
\hline
\end{tabular}


Two forms of the survey were developed: mail-in and online (using Survey Monkey). The survey was undertaken between May two thousand ten and January two thousand eleven. In May 2010, the survey was e-mailed to 164 Housing Partnerships (for which emails of Chief Executive Officers were available). It was then followed up with a mail-in survey (with pre-paid return envelopes) in June 2011 to all the 381 Housing Partnerships identified through the IRS Publication 78. About 46 envelopes were returned by the postal service since the Housing Partnerships were not at the physical address because they no longer exist, merged, or were never operational at the location. I sent a postcard reminder to the rest 335 Housing Partnerships in August 2010. I also followed up with emails to respond to the survey in September two thousand ten, October two thousand ten, and in January two thousand eleven. Such repeated attempts are required for increasing the survey response (O'Sullivan, Rassel, and Berner, 2003).

After all of the above attempts, there were a total of 70 responses. Of these, 10 indicated that they do not qualify as Housing Partnerships in the terms intended by the survey. Hence, there was a net of 60 (18 through postal mail, 42 through Survey Monkey) usable responses out of the population of 325 Housing Partnerships. I input all the postal responses into the Survey Monkey manually for a comprehensive analysis. The response rate was 18.5 percent of the agencies contacted. Although the response rate appears low, the sample size is adequate — the highest statistical margin of error is \pm 10.3 percent at 95 percent confidence level. After completing the survey, I conducted follow-up inquiries over email with some of the Housing Partnerships to gain deeper insights into some of the questions. 


\subsection{Limitations and Conclusion}

The proposed research design used for the dissertation hinges on two independent data sources - the IRS Form 990 and the survey instrument. Prior to administering the survey instrument, I also conducted a preliminary interview with selected Housing Partnerships. The triangulation of data sources allows for controlling bias and errors and increasing the reliability and validity of the analysis. The data sources have a few limitations though.

First, The IRS Form 990 is available mainly for nonprofits whose total annual revenues exceed $\$ 25,000$. Hence, the analysis derived from this data source is applicable for large Housing Partnerships. This may not pose a significant limitation since the activities of HPs, such as construction and loan origination, by their very nature, require high revenues. Hence, the HPs are likely to have annual revenues exceeding $\$ 25,000$. Second, the response rate for the survey was 18 percent. Although this is a bit on the low side, the survey analysis is reasonably adequate, with a margin of 10.3 percent at 95 percent confidence level. Third, a broader aspect of this dissertation research is that it is undertaken at a time of downturn in housing market, and a severe economic recession. The broader economic conditions have affected the performance of Housing Partnerships in general. This is addressed directly by including the housing market downturn in the analysis. For instance, survey questions examine organizational changes from two thousand seven to two thousand nine. 


\section{HOUSING PARTNERSHIPS: A NATIONAL OVERVIEW}

\subsection{Introduction}

This chapter provides an overall analysis of the national growth and role of Housing Partnerships (HPs) in the United States. The analysis focuses on the review of the IRS Form 990s filed by the partnerships and the overview section of the survey responses. In essence, the chapter shows how Housing Partnerships have evolved since the eighties. The Housing Partnerships grew significantly across the country in the 1990s and the early 2000s; however, they have been adversely affected by the economic downturn and the declining housing market. The role of HPs has also evolved over time. In their early years, the HPs mainly financed and constructed housing for low-income households. Over the years, the HPs have taken on additional supportive roles to assist in affordable housing.

The next section outlines the national growth of Housing Partnerships. Then, the geographical pattern of the HPs activities by state is examined. Next, the functional roles played by the HPs are analyzed using the HPs' mission statements. The last section concludes with the major aspects of the HPs' national growth and roles.

\subsection{Growth of Housing Partnerships}

Housing Partnerships emerged in the eighties as local solutions to affordable housing delivery in major urban areas. While they grew slowly during the eighties, they became more prominent since the beginning of the nineteen-nineties. Table 4.1 summarizes the Housing Partnerships by the decade they were started. Four periods are identified in the table: before $1980 ; 1980$ to 1989 ; 1990 to 1999 ; and after two thousand- 
nine. As the table shows, a small percentage (3.8 percent) began before nineteen eighty. About one-third of the HPs were formed in the eighties. The majority (45.4 percent) emerged in the nineteen-nineties. About 17.4 percent were formed in the 2000 s, partly due to the downturn in the housing market.

Table 4.1: Housing Partnership Formed by Decade

\begin{tabular}{|l|c|c|}
\hline Year & Number formed & Percent \\
\hline Before 1980 & 15 & $3.8 \%$ \\
\hline 1980 to 1989 & 127 & $33.4 \%$ \\
\hline $1990-1999$ & 173 & $45.4 \%$ \\
\hline 2000 and later & 66 & $17.4 \%$ \\
\hline & 381 & $100.0 \%$ \\
\hline
\end{tabular}

Figure 1 summarizes the five-year interval growth in the number of Housing Partnerships, between nineteen eighty and two thousand-nine. As the figure shows, the formation of new Housing Partnerships increased rapidly since nineteen eighty to nineteen eighty-nine and reached its peak from nineteen ninety to nineteen ninety-four. The formation of new Housing Partnerships decelerated since then, to reach a low rate in two thousand five to two thousand nine. 
Figure 4.1: Five-year Interval Growth in Number of Housing Partnerships, 19802009

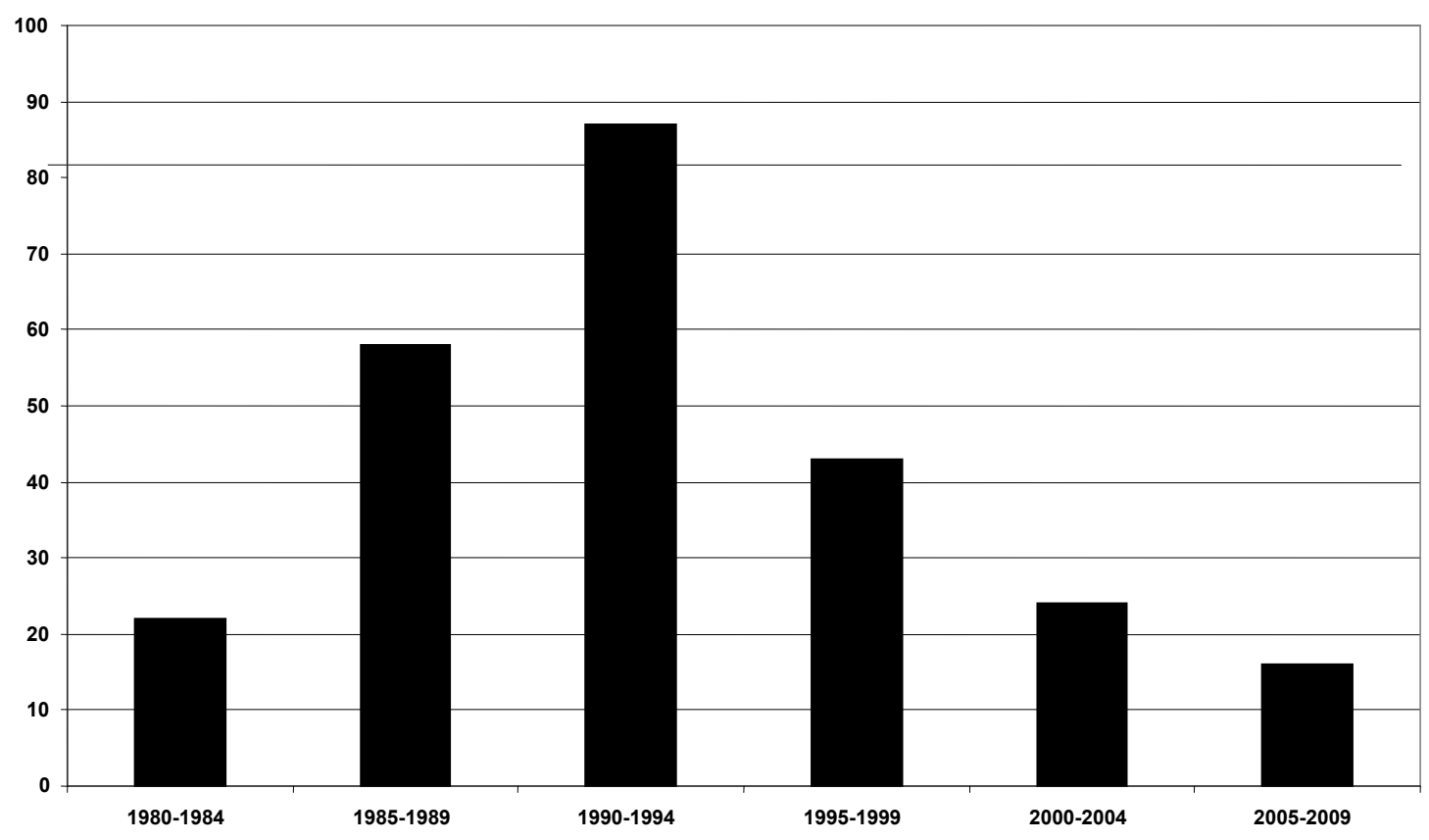

The growth in the activities is not indicated by the number of Housing Partnerships alone. Such growth is also indicated by the growth in their funding and the number of housing units constructed by Housing Partnerships. Although the details of finances and number of housing units are not available annually, Mayer and Temkin (2008, p. 3) indicate in their 2008 report that the HPs served over 80,000 people, and financed over $\$ 1.1$ billion for over 240,000 affordable housing units. The summary profile of the HPs' total revenues and expenses between 2005 and 2008 is given in Figure 4.2. As the figure indicates, the HPs' revenues decreased between 2005 and 2009 from \$377.8 million to \$353.3 million. Yet, the HPs expenses rose during this period, from \$306.6 million to \$328.9 million. The expense increase despite revenue decrease shows that the HPs have increased their financial activities, even in the face of decreasing revenues during the recent housing market downturn. 
Figure 4.2: Housing Partnerships' Total Revenues and Expenditures, 2005 to 2008

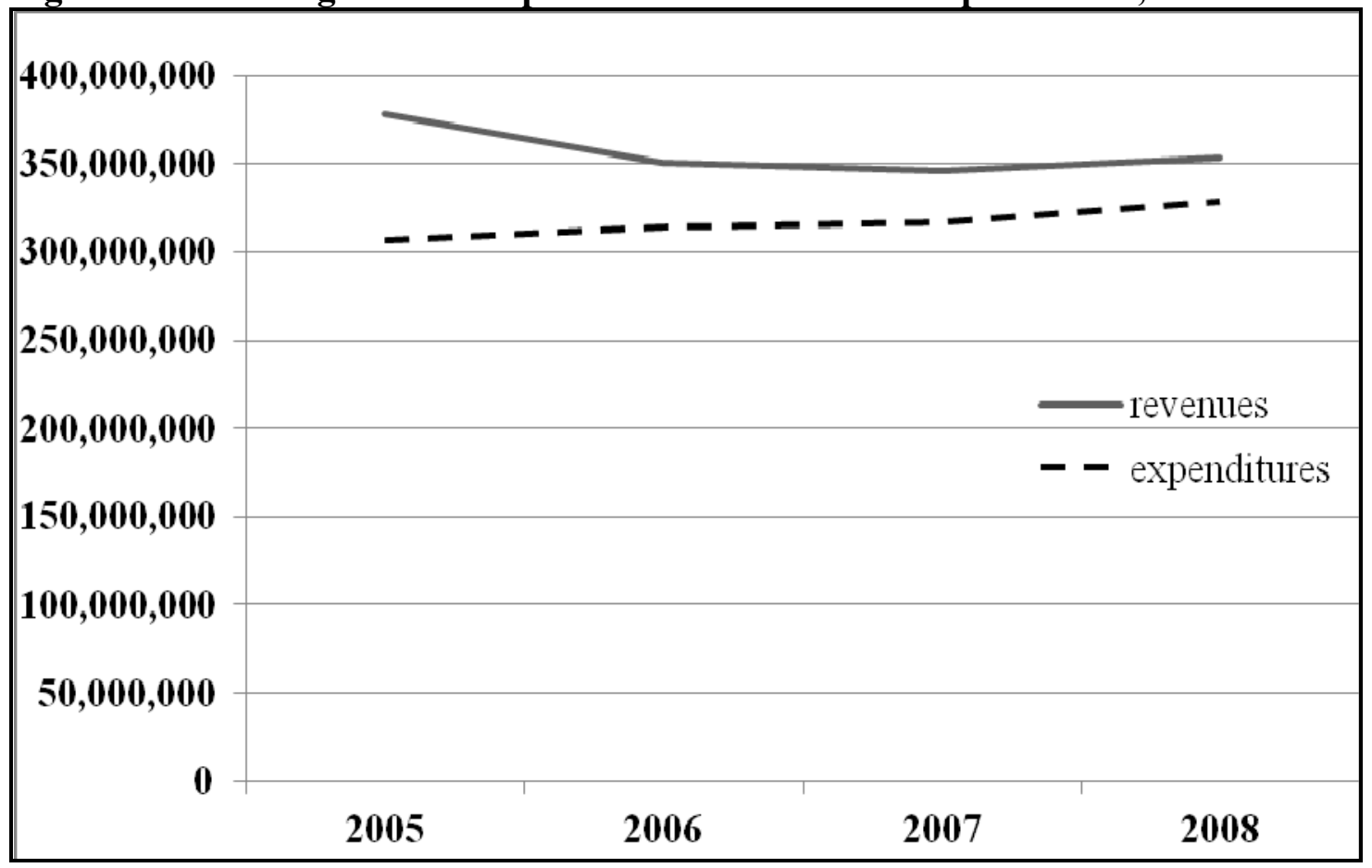

Analysis of the average revenues and expenses of the Housing Partnerships reveals a steady decline in their revenue between two thousand-five and two thousandeight, from $\$ 1.4$ million to $\$ 1.3$ million (Figure 4.3). During this period, on average, the Housing Partnerships increased their expenses from $\$ 1.1$ million to $\$ 1.25$ million. Although the average trendlines are likely to mimic the total trendlines depicted before, the interesting point is that the average size of the Housing Partnerships is large, with over $\$ 1$ million in revenues and expenses. They are much larger than the average nonprofits in general - about one-third of nonprofits are below $\$ 25,000$ in annual revenues. The Housing Partnerships are large in size and have revenues of over $\$ 25,000$ since their activities are typically more capital intensive (e.g., housing construction, providing loans). 
Figure 4.3: Housing Partnerships' Average Revenues and Expenses, 2005 to 2008

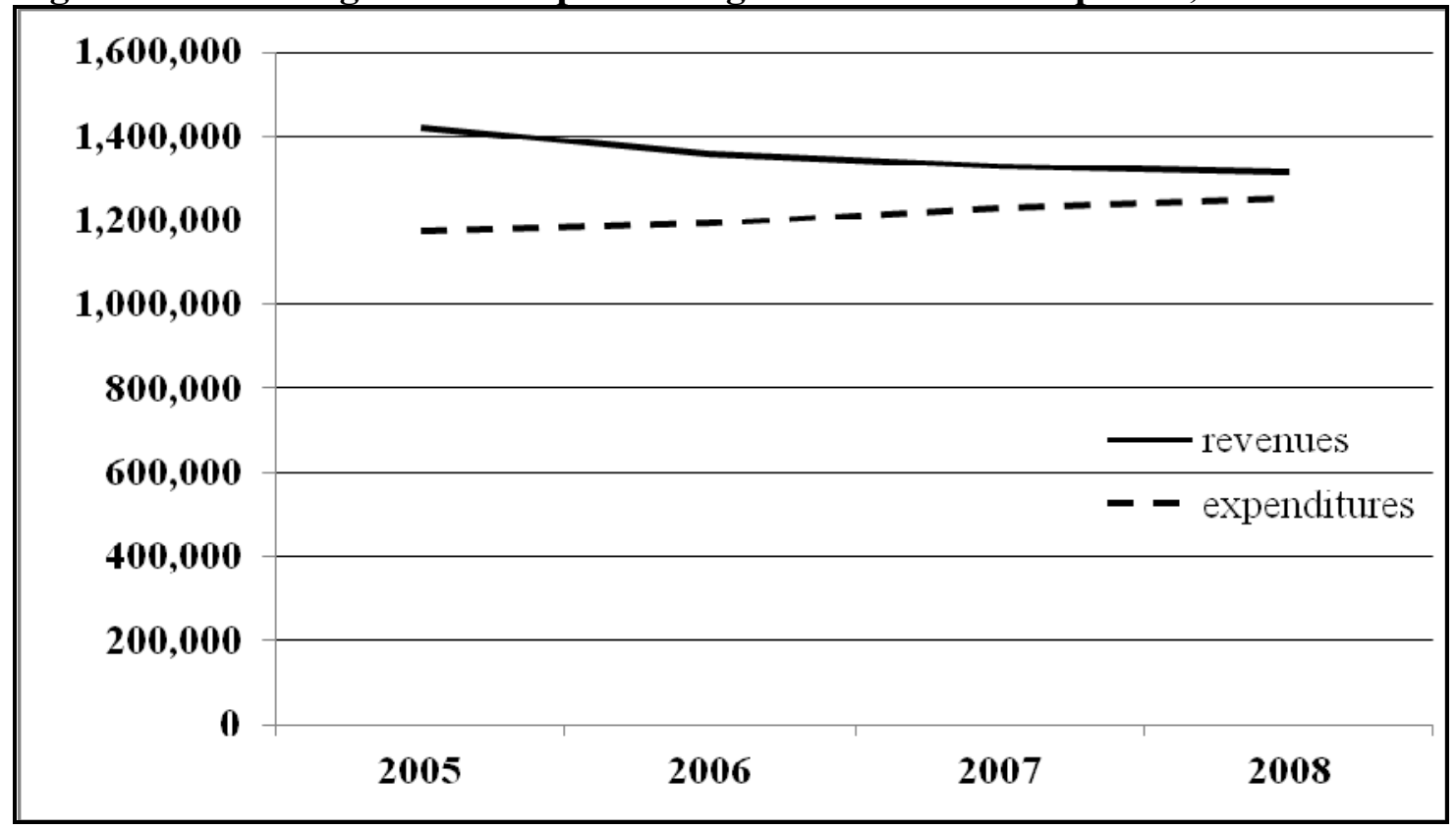

Cross-tabulation analyses of the year of formation and revenues provide interesting insights into how the age of Housing Partnerships relates to their finances. The results of the cross-tabulation are summarized in Table 4.2. The $\mathrm{P}$ values indicate that the emergence years are strongly associated with the revenues of 2005, 2006, 2007, and two thousand-eight. The gamma values for 2005 (-0.468), $2006(-0.374), 2007$ (-0.375), and 2008 (-0.364) are moderately negative, indicating inverse relationships. These results indicate that as the years of emergence increase, HP revenues decrease.

Table 4.2: Cross-tabulation of Emergence Year with Annual Revenues (2005 to 2008)

\begin{tabular}{lccc}
\hline Variable Association & $\begin{array}{c}\text { Pearson Chi-squared Test } \\
\text { (P Value) }\end{array}$ & Gamma & N \\
\hline Emergence Year by 2005 Revenue & $<.001$ & -.468 & 198 \\
Emergence Year by 2006 Revenue & .006 & -.374 & 203 \\
Emergence Year by 2007 Revenue & .002 & -.375 & 211 \\
Emergence Year by 2008 Revenue & .003 & -.364 & 208 \\
\hline
\end{tabular}


In terms of geography, Housing Partnerships are unevenly distributed across the United States. Figure 4.4 shows the geographical distribution of the Housing Partnerships; Table 4.3 gives the regional breakdown by the five Census Bureau regions. As the figure and the table show, the Housing Partnerships have been most prominent in the northeast region, particularly in New York, Virginia, and Pennsylvania. The Midwest region comes a close second, with the HPs' activities in Ohio, Milwaukee, Wisconsin, and Minnesota. The Housing Partnerships also spread to a few states in the West (especially California) and Southeast (especially Florida) regions. Very few Housing Partnerships emerged in the Southwest region.

Figure 4.4: Distribution of Housing Partnerships by State

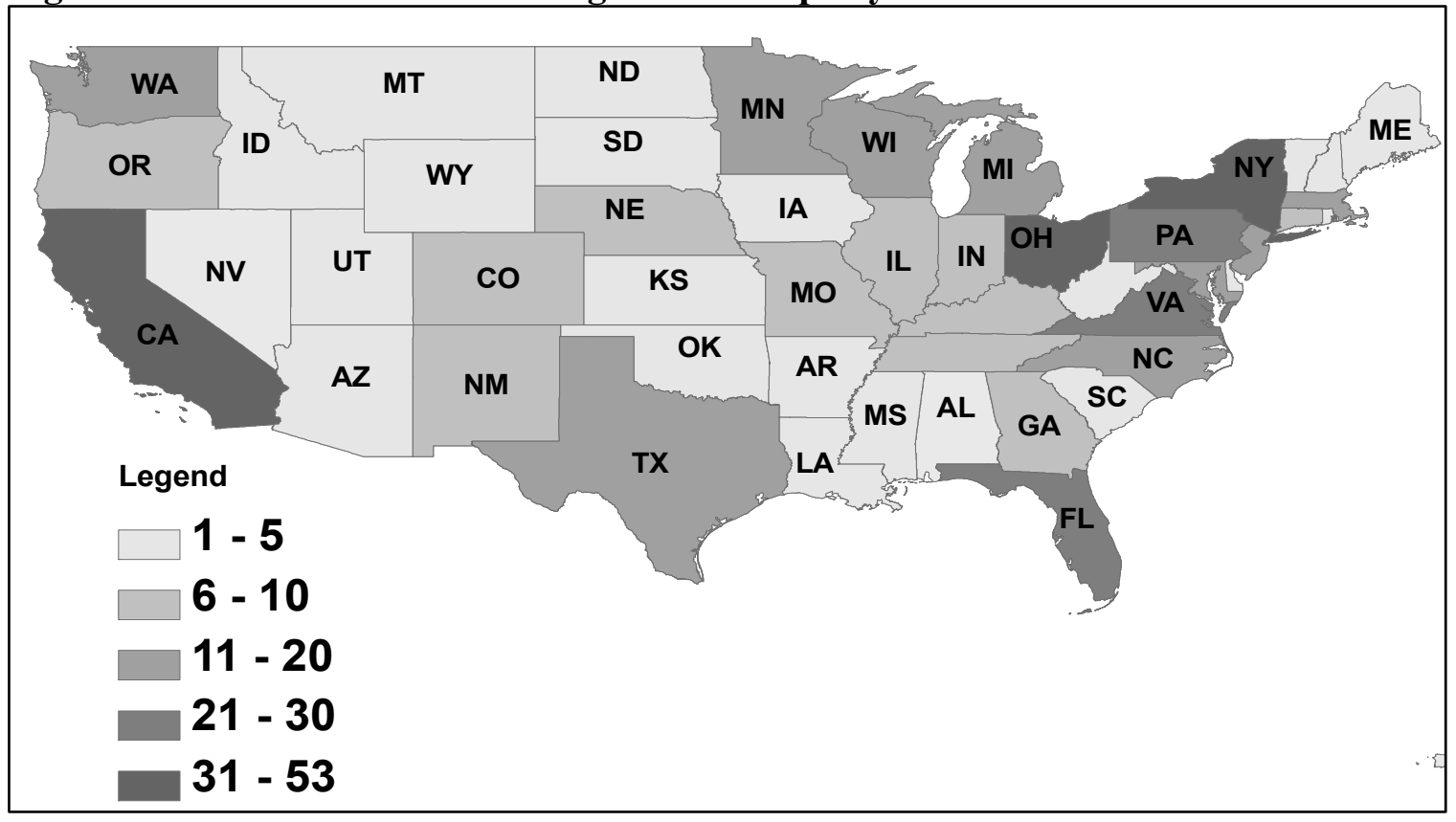

Table 4.3: Distribution of Housing Partnerships by Census Bureau Regions

\begin{tabular}{|l|c|}
\hline Census Region & Percent \\
\hline Southeast & $18 \%$ \\
\hline Northeast & $33 \%$ \\
\hline Midwest & $29 \%$ \\
\hline West & $15 \%$ \\
\hline Southwest & $4 \%$ \\
\hline
\end{tabular}




\subsection{Mission of Housing Partnerships}

The main mission of Housing Partnerships is to provide affordable housing. However, the examination of the mission statements of the HPs show the different related activities undertaken by them. The clarity and conciseness of mission statements are important for the performance and success of organizations (Lansberry, Litwin, and Slotnik, 1995). Mills (1991) argues that organizational missions are significantly associated with goals and strategies by providing the information to answer the questions: what type of programs/services are provided?, who receives services?, and how will these services be delivered? The mission statement is also important for funding agencies in order for them to provide financial resources (Lansberry, Litwin, and Slotnik, 1995).

Mission statements of 200 Housing Partnerships (i.e., about 52.5 percent of the population) were available from the IRS Form 990s. The mission statements were analyzed for HPs' principal activities. The mission statements revealed a range of activities (Table 4.4), all related to the delivery of affordable housing. Such services include construction, education, rehabilitation, and advocacy efforts. Some HPs take a comprehensive approach that includes activities such as rental assistance and management, counseling, and other services, so that they are one stop centers for housing services. One stop centers assist clients who require multiple housing-related services in order to purchase, rent or keep their home. Such clients may require, credit counseling, first time home buyers education, rental and homeownership down payment assistance, or other services and programs. However, not all HPs have comprehensive approaches; they could specialize in a few programs/activities. 
Table 4.4: Range of Activities Performed by Housing Partnerships

\begin{tabular}{|l|}
\hline Affordable housing construction \\
\hline First time homebuyers education courses \\
\hline Homebuyers financial assistance \\
\hline Affordable rental housing construction \\
\hline Affordable rental housing \\
\hline Financial down payment assistance (rent/ownership) \\
\hline Credit counseling \\
\hline Loan re-modification assistance \\
\hline Foreclosure education \\
\hline Foreclosure financial assistance \\
\hline Financial management/budgeting education \\
\hline Housing rehabilitation \\
\hline Weatherization or accommodations \\
\hline Public education \\
\hline Advocacy \\
\hline Policy formulation \\
\hline Research \\
\hline
\end{tabular}

These organizational activities were then classified into five categories, by coding the mission statements. Table 4.5 indicates the five categories and the distribution of the HPs according to these categories. The table indicates that most HPs have been involved in a combination of "low-income assistance, affordable housing, and location receiving assistance." About a quarter deal with homeless or low-income assistance. A smaller percentage (13.5 percent) has been involved directly in affordable housing construction and delivery. About 10 percent has been involved in low-income assistance and affordable housing delivery.

Table 4.5: Housing Partnerships' Activities Based on Mission Statements

\begin{tabular}{|l|c|}
\hline Activities & Percent \\
\hline Homeless or low income assistance & $25.0 \%$ \\
\hline Affordable housing development & $13.5 \%$ \\
\hline Low-income assistance and affordable housing delivery & $10.0 \%$ \\
\hline Low-income assistance, affordable housing, and the location receiving assistance & $28.5 \%$ \\
\hline Mission stating the HP advocates, promotes, or is a voice for affordable housing & $23.0 \%$ \\
\hline Total & $100.0 \%$ \\
\hline
\end{tabular}


The mission statements of HPs emphasize the delivery of affordable housing. Several HPs who highlight that their mission is to deliver affordable housing also specify the income group that their services are intended for. The sentiment is illustrated in the following representative mission statements:

"To provide stable, vibrant, healthy communities by developing, financing and managing quality, affordable housing for those who cannot afford market rate housing,"

"To provide safe, decent, affordable, accessible housing to low income households and persons with special needs,"

"To provide decent and safe affordable housing opportunities to those who could not afford housing in the open market."

Housing Partnership mission statements generally indicate the jurisdiction and income of the population that will be assisted by the organizations. For example, the St. Johns Housing Partnership (SJHP) mission statement indicates it is committed to promoting safe, decent and affordable housing in St. Johns County, Florida by creating links between the public and private sectors on projects that create low- and moderateincome housing, rebuild neglected homes and neighborhoods, thus benefiting disadvantaged areas and enhancing community economic and social development. The Community Housing Partnership of Williamson County, Tennessee seeks to establish a public/ private partnership as the County's leading agency in achieving quality affordable housing for elderly, low income, disabled and work force families through housing alternatives to create, supply and maintain appropriate housing by rehabilitation, maintenance and restoration. The Massachusetts Housing Partnership (MHP)'s mission is 
to push beyond business as usual to find creative new solutions that are responsive to community needs and the ever-changing marketplace. The Massachusetts Housing Partnership (MHP) is a privately-funded public nonprofit organization that works with state government and with business, civic and community leaders across the Commonwealth to increase the supply of affordable housing to the region. The Housing Partnership of the Fox Cities seeks to be the low cost provider of quality affordable housing to low-income families in the Fox cities (Appleton, Neenah, and Menasha) and to provide families, adults, and children the opportunity to realize their potential and make a lasting contribution to society. The Community Housing Partnership creates, implements and demonstrates solutions to homelessness by working in partnership with people in San Francisco who would otherwise be without a home. The Community Housing Partnership develops and operates high quality permanent affordable housing, integrating optional support services, job training and community organizing. They strive to break the cycle of homelessness by strengthening community, encouraging selfdetermination and involving tenants in every aspect of the organization.

I conducted one-way Analysis of Variance (ANOVA) tests to evaluate the relationship between the activities derived from the mission statements and revenues of Housing Partnerships. The ANOVA test indicates a significant relationship between the mission and the function (Table 4.6). Post hoc examination using the Tukey range test, and the Dunnett $\mathrm{C}$ test highlighted the nature of this association. For the most part HPs with mission statements stating a combination of low-income assistance, affordable delivery, and the location receiving the assistance have functions with comprehensive 
approaches to affordable housing delivery that include rental construction, management, unit rehabilitation, financial, advocacy, and education assistance.

Table 4.6: Relationship Between Mission and Revenues: ANOVA Results

\begin{tabular}{lllc}
\hline ANOVA & F & P & N \\
\hline Mission and Functions /Activities (dependent) & 7.885 & $<.001$ & 179 \\
Mission and 2005 Revenue (dependent) & 3.591 & .008 & 186 \\
Mission and 2006 Revenue (dependent) & 3.258 & .013 & 189 \\
Mission and 2007 Revenue (dependent) & 3.457 & .009 & 196 \\
Mission and 2008 Revenue (dependent) & 3.556 & .008 & 193 \\
\hline
\end{tabular}

Analysis of the Housing Partnerships' mission across regions also offers interesting insights (Table 4.7). Housing partnerships in the Southeast, Northeast, and West regions of the United States are associated with the high percentages of HPs with advocacy as the main function. In addition, Housing Partnerships in the Southeast are also associated with comprehensive approaches function (one stop for housing services). The Southwest region is associated with a high percentage of Housing Partnerships that undertake construction as their main function. The Midwest region is associated with Housing Partnerships that do not undertake construction or advocacy. The majority of HPs in the Midwest region provide support and property management services. Regarding the relationship between location and 2006 revenue, Housing Partnerships located in the Southeast, Midwest, and Southwest regions are associated with high revenues for that year when compared to other regions. 
Table 4.7: Relationship Between Mission and Census Regions

\begin{tabular}{|l|r|r|r|r|r|}
\hline Function/Activities & SE & NE & MW & W & SW \\
\hline $\begin{array}{l}\text { Affordable homeowner or rental } \\
\text { construction }\end{array}$ & $3.4 \%$ & $12.1 \%$ & $12.5 \%$ & $6.9 \%$ & $42.9 \%$ \\
\hline $\begin{array}{l}\text { Home and or neighborhood rehabilitation } \\
\text { weatherization, adaptations, or other }\end{array}$ & $24.1 \%$ & $3.0 \%$ & $5.4 \%$ & $3.4 \%$ & $.0 \%$ \\
\hline $\begin{array}{l}\text { Only management, property maintenance } \\
\text { with some supportive services (no } \\
\text { construction) }\end{array}$ & $17.2 \%$ & $22.7 \%$ & $35.7 \%$ & $24.1 \%$ & $14.3 \%$ \\
\hline $\begin{array}{l}\text { Advocacy, education, and counseling } \\
\text { (with some financial assistance) }\end{array}$ & $27.6 \%$ & $43.9 \%$ & $25.0 \%$ & $48.3 \%$ & $28.6 \%$ \\
\hline $\begin{array}{l}\text { Homeowner and rental construction, } \\
\text { management, delivery, rehab, financial, } \\
\text { and advocacy, education, counseling (one } \\
\text { stop center for housing) }\end{array}$ & $27.6 \%$ & $18.2 \%$ & $21.4 \%$ & $17.2 \%$ & $14.3 \%$ \\
\hline
\end{tabular}

\subsection{Housing Partnerships' Characteristics}

The characteristics of the Housing Partnerships nationwide were obtained from the "overview" section of the survey. The "overview" section included five broad questions, of which four are relevant to the overall characteristics of Housing Partnerships. There were 60 HPs who responded to the survey. The first main question relevant to overall characteristics is, "What is the main mission of the Housing Partnership?” All 60 respondents answered this survey question. The responses were collated into five categories (Figure 4.5). The largest group (43 percent) indicated that their main function is to advocate regarding issues dealing with housing affordability. They do so through education, research, counseling, and technical assistance. Sometimes, these HPs have funds set aside for down-payment assistance. The second largest group (40 percent) is that of HPs that are "one-stop agencies" for housing-related issues. The functions/activities of one-stop HPs are affordable homeowner and rental unit construction and management, housing rehabilitation, counseling, education, advocacy, 
and technical assistance. Other functions/activities include home and neighborhood revitalization (nine percent), affordable home construction (seven percent), and property management (two percent).

Figure 4.5: Overview of Housing Partnerships' Functions/Programs

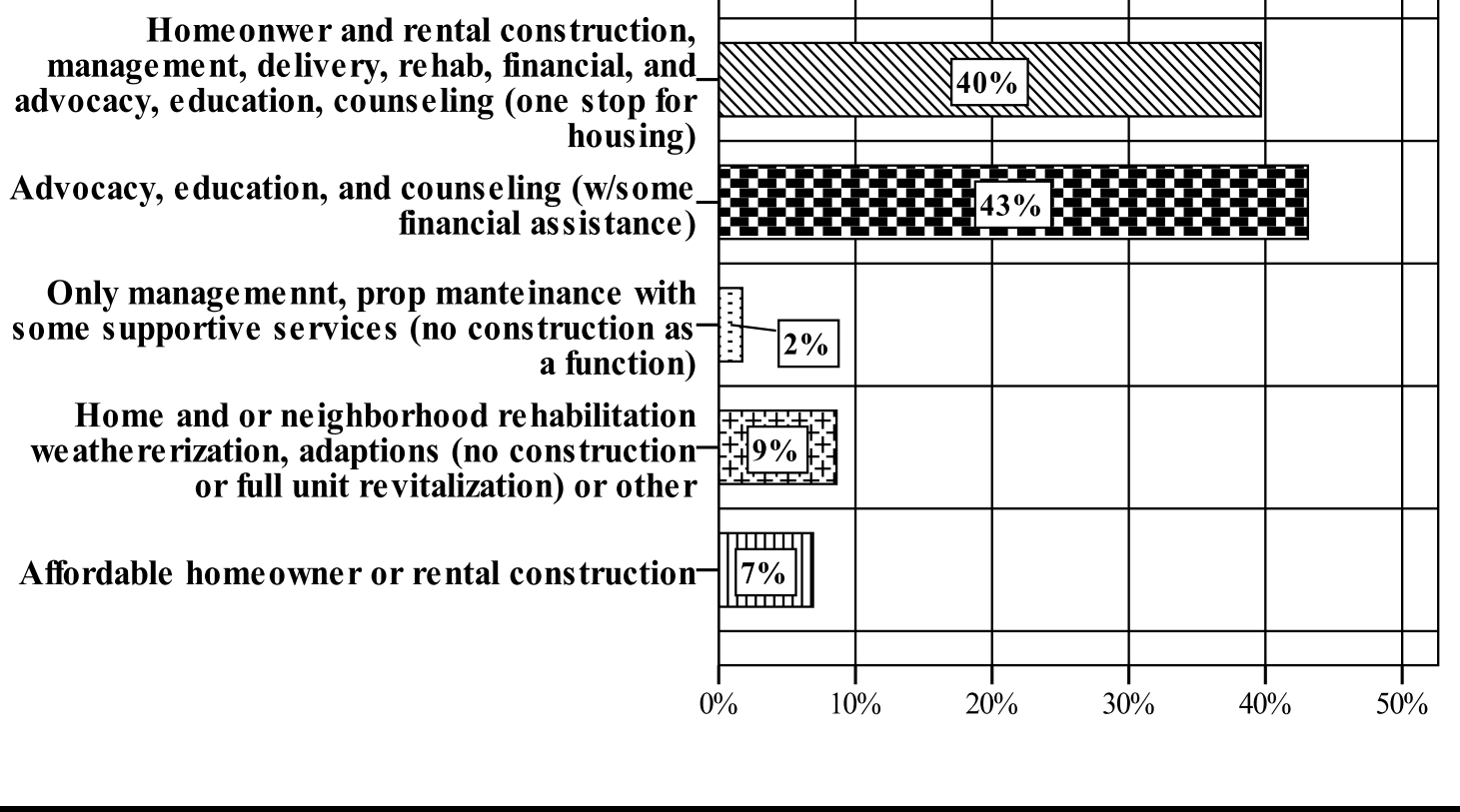

The missions were also grouped in the categories similar to those in the analysis of the Form 990 database. Such grouping is summarized in Figure 4.6. Analysis shows that the missions derived from the survey questionnaire reveal a pattern similar to that obtained from Form 990s; hence the close-ended survey can be argued to be fairly representative of the Housing Partnerships. As the figure suggests, most respondents (43 percent) were HPs whose mission statement indicates that their main purpose is to advocate, promote, educate, and "other" housing information issues such as research. A representative mission statement in this group is, "To promote and facilitate healthy safe and affordable housing through advocacy, education, and resource development for low 
and very-low-income residents of the county." The second largest category (38 percent)

is that of HPs whose main purpose is to deliver affordable housing to low-income

individuals in a specific area. An example of mission statement in this category is the following:

To be the low cost provider of quality affordable housing to low-income families in the fox cities (Appleton, Neewah, Menasha) and to provide families, adults, and children the opportunity to realize their potential and make a lasting contribution to society.

The other categorical groups are both affordable housing development and low-income assistance (ten percent), affordable housing construction (five percent), and homeless or low-income assistance (three percent).

Figure 4.6: Housing Partnerships' Missions (Based on Survey)

Advocacy, promotion, education of housing related issues, and "other"

Affordable housing delivery for low income of a location

Both affordable housing development and low income assistance

Affordable housing $5 \%$ (development/construction)
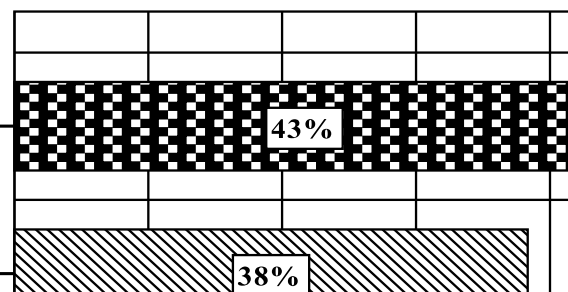

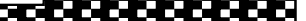

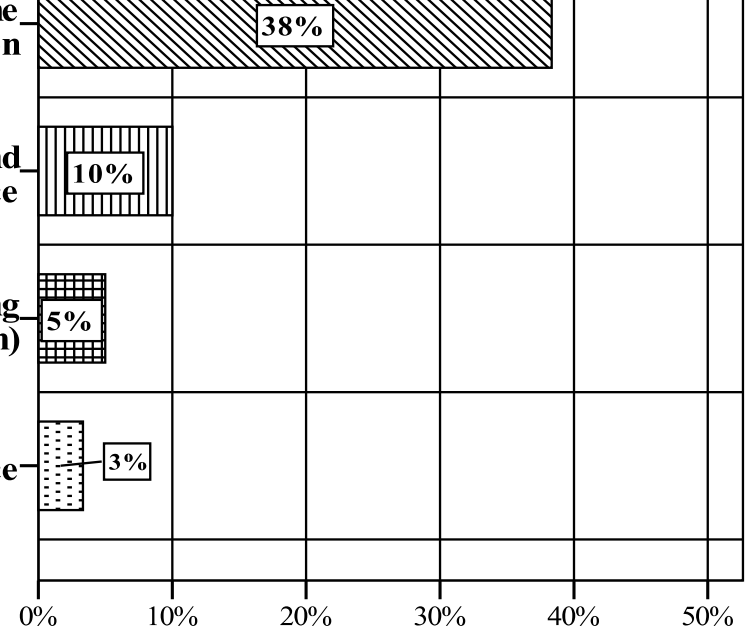

Homeless or low income assistance 
The next overview question in the survey was, "What percentage of the above mission's targets was achieved overall in 2009?" The question was aimed at examining the target of affordable housing delivery by Housing Partnerships. The answer choices were five percentage categories: 0 to 20 percent; 21 to 40 percent; 41 to 60 percent; 61 to 80 percent; and 81 to 100 percent. Figure 4.7 summarizes the percentage share of the survey respondents in each category. As the figure shows, about 67 percent of the respondents reported achieving 81 to 100 percent of the mission's target for two thousand nine. Thus, despite the housing market downturn, an overwhelming share of Housing Partnerships continued to maintain their activities to meet their targets. In this context, it is not surprising that the expenses of the Housing Partnerships continued to increase, even as their revenues fell between two thousand-five and two thousand-eight. Among the other categories, twelve percent and ten percent of the Housing Partnerships reported having achieved 61 to 80 percent and 41 to 60 percent of their mission's targets respectively. Eleven percent of the Housing Partnerships reported having achieved 0 to 40 percent of their mission's targets. 


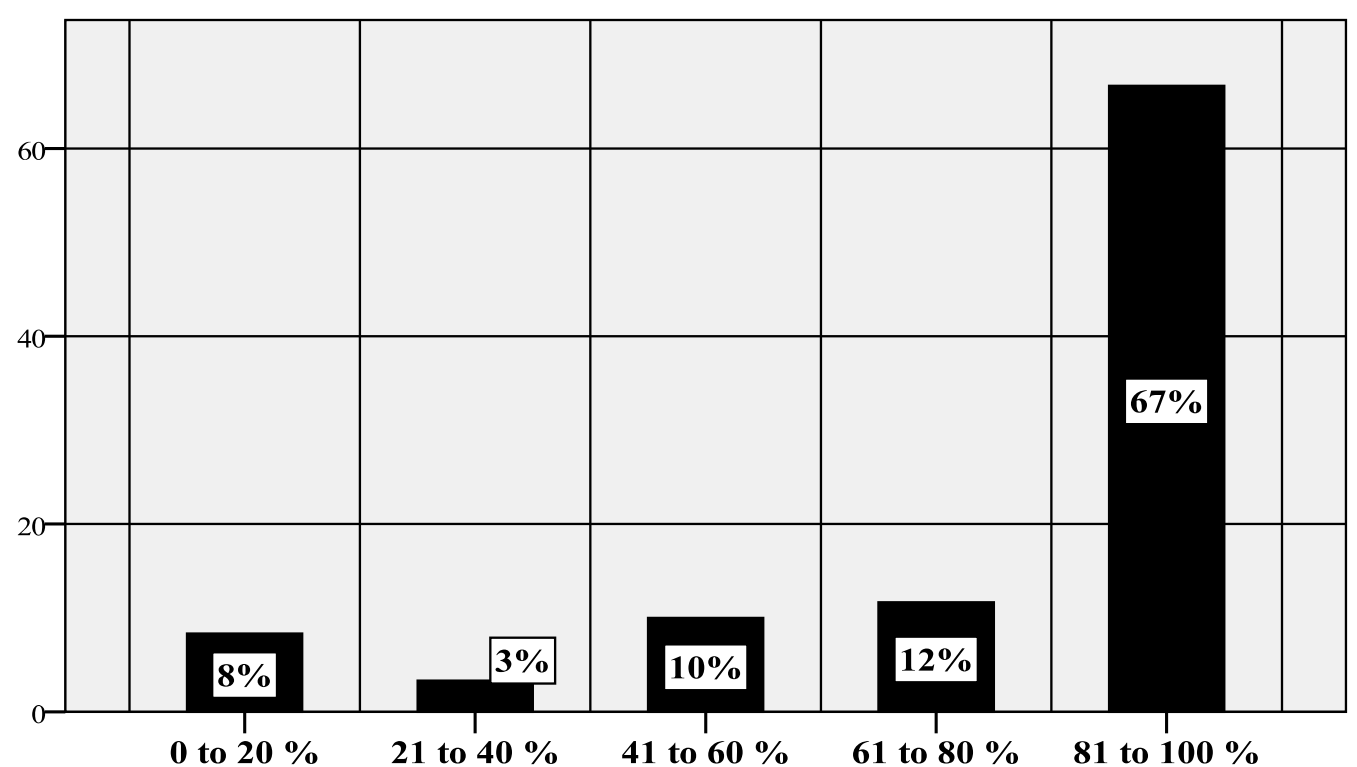

The subsequent survey question in the overview section was, "What is the principal jurisdiction served by the partnership?" The question was aimed at providing a profile of the coverage of the HPs' activities. The answer choices were: neighborhood, county, city, state, and other. Most respondents (43percent) indicated that their activities were in the "other" category (Figure 4.8). Further examination of the specific areas indicated under the "other" category reveals that the HPs served combinations of cities and counties, state and county, and multiple cities/regions. A few even indicated regions that span states. About 20 percent indicated that they are state-wide, and 28 percent indicated that they serve at the county level. A small percentage (nine percent) indicated that they served at the neighborhood or the city level. Undoubtedly, the HPs serve a large jurisdiction. This is characteristically different from the Community Development Corporations (CDCs), which serve mainly at the neighborhood or the city level. Housing 
Partnerships provide a complementary service for affordable housing at a more macro level than the Community Development Corporations.

Figure 4.8: Principal Jurisdiction Served by Housing Partnerships

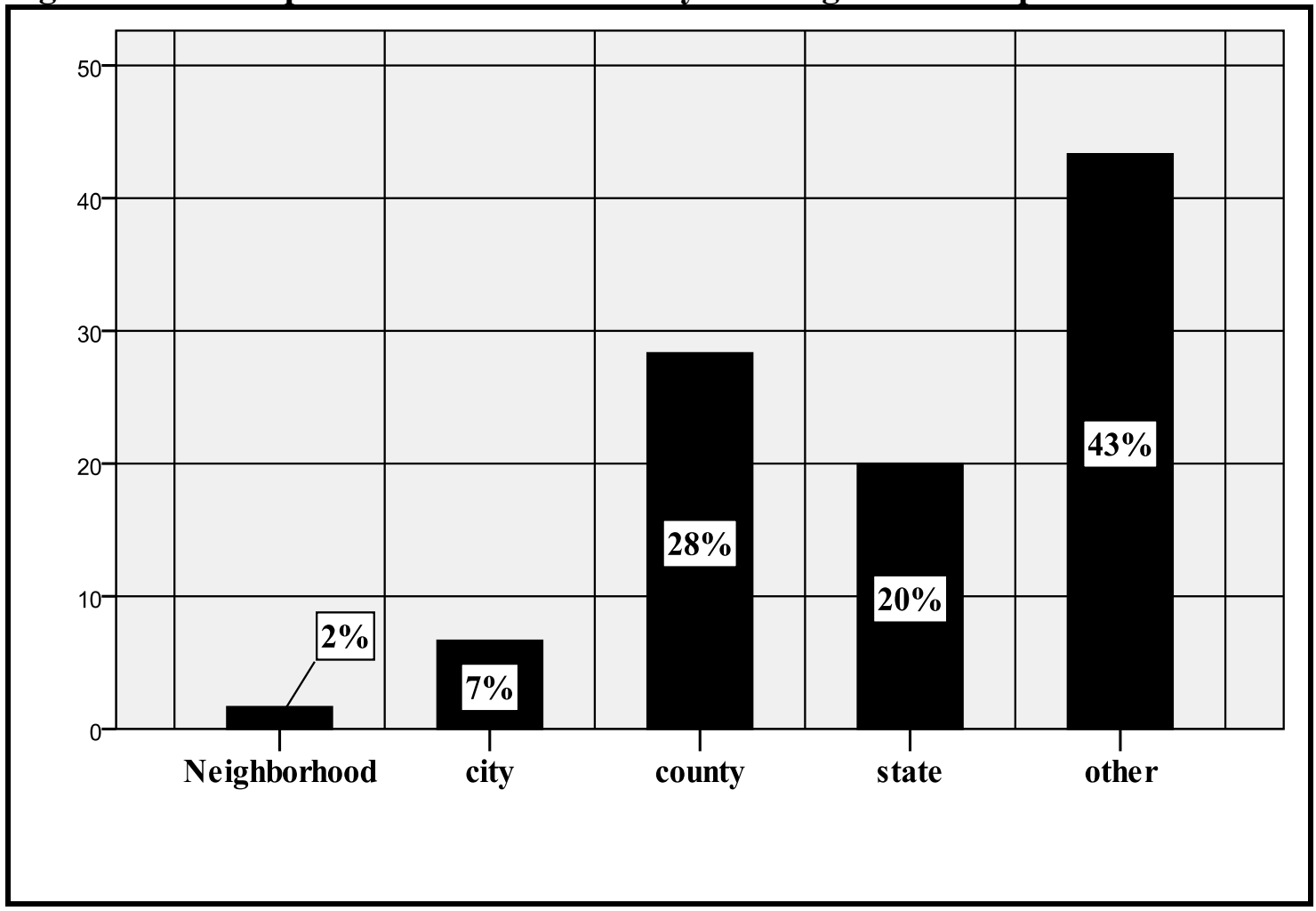

The last survey question in the overview section asked, "How many organizations are affiliated with the Housing Partnership?" Responders were asked to indicate the number of public agencies, private firms, nonprofits, and "other" organizations in the partnership. The survey explicitly clarified that the affiliates are organizations "which support the HP with funding or other tasks." According to the survey responses, an average HP has 35 partner organizations; however, the number of partners vary significantly, ranging from three to 230 (standard deviation=52). Figure 4.9 summarizes the average number of partner organizations in the Housing Partnerships. As the figure 
indicates, private firms and nonprofit agencies form the majority (17 and 18 respectively). Public agencies come last (six on average). The "other" organizations are eight on average, and this category includes churches, universities, and hospitals. Housing Partnerships thus represent coalitions among the private, nonprofit, and other sectors; public organization representation is relatively small as compared to others.

\section{Figure 4.9: Number of Affiliate Organizations}

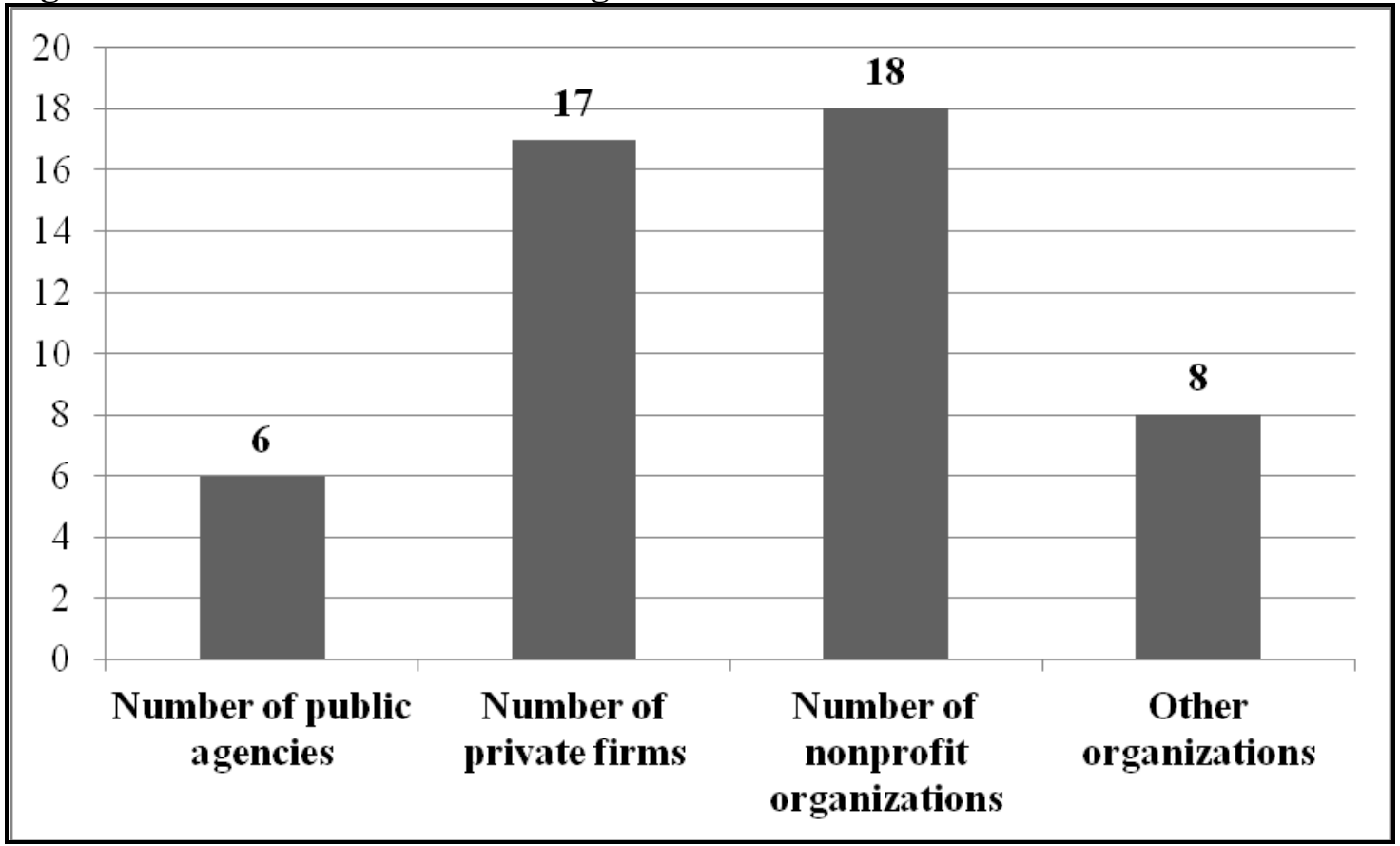

\subsection{Conclusion}

This chapter provided an overview of Housing Partnerships, derived from the IRS Form 990 and the overview section of the survey. Housing Partnerships emerged in the eighties as local solutions to affordable housing delivery in major urban areas. While they grew slowly during the eighties, they became more prominent during the nineteennineties. Their growth peaked from nineteen ninety to nineteen ninety-four and decelerated and dropped to a low growth rate from two thousand-five to two thousand- 
nine. In terms of their finances, the HPs' expenses increased despite revenue decrease from two thousand-five to two thousand-eight. Revenues decrease and expenses increase shows that the HPs have indeed increased their financial activities, even in the face of decreasing revenues during the recent housing market downturn. The HPs are also large on average, with over $\$ 1$ million in annual revenues. In terms of geography, Housing Partnerships are unevenly distributed across the United States. They have been most prominent in the Northeast and Midwest regions, and are also spread across a few states in the West and Southeast regions. Very few Housing Partnerships emerged in the Southwest region. Housing Partnership prominence in the Northeast can be a result of their first origins in this region, and thus more time to increase the knowledge of their role in affordable housing delivery in this area. Few HPs in the Southwest region might be caused by demographic characteristics of these communities and government involvement in the affordable housing of this area.

Analysis of the missions stated in the 990 forms shows that the HPs perform a range of affordable housing activities. Such services include construction, education, rehabilitation, and advocacy efforts. Some HPs take a comprehensive approach that includes activities such as rental assistance and management, counseling, and other services, so that they are one stop centers for housing services. Most HPs, have been involved in a combination of "low-income assistance, affordable housing, and location receiving assistance.”

Analysis of the missions described in the survey questionnaire reveals a pattern similar to that obtained from Form 990s in terms the HP activities. Sixty-seven percent of the respondents reported achieving 81 to 100 percent of the mission's target for two 
thousand-nine. Thus, HPs have arguably filled a gap in the housing market downturn by increasing their activities to meet their targets. Housing Partnerships also serve a large jurisdiction, which is characteristically different from the Community Development Corporations, which serve mainly at the neighborhood or the city level. It could be argued that the HPs provide a complementary service at the macro level of county, state, and even across states. Lastly, HPs are partnerships with private and nonprofit participation; public sector participation is comparatively less. 


\section{THE FINANCIAL PERSPECTIVE}

\subsection{Introduction}

Factors that affect organizational profitability are used to create financial objectives. In the Balanced Scorecard, financial objectives are translated into measures. These measures summarize the economic situation and indicate whether an organization's strategy, implementation, and execution are contributing to financial improvement (Kaplan and Norton, 1996). The financial perspective examines the use and access to public and private sources in Housing Partnerships. The examination of the uses of public, private funds and service fees by Housing Partnerships highlights the need for HPs to have diversity in their sources of funding in order to have sufficient resources that support housing production as well as housing-related support services.

Although profitability and long-term financial growth are not the main purposes of nonprofit HPs, Niven (2003) states that "no organization, regardless of its status, can successfully operate and meet customer requirements without financial resources." In other words, financial performance indicators have to be examined in tandem with nonfinancial factors to assess the overall performance of organizations. Affordable housing delivery is the main purpose of Housing Partnerships. Revenue must be sufficient to conduct activities that assist HPs to achieve their mission by addressing community affordable housing needs.

The financial perspective assists in identifying financial-related success factors, such as the type of funding used that affects HP performance. The question raised for the financial perspective is: What are the financial activities of successful Housing 
Partnerships? The hypothesis is that Housing Partnerships are mainly oriented toward funding affordable housing related activities. Such activities could include providing funds for housing construction, loans, credit counseling, and other such programs. Diversity of public and private funding sources is an important issue for survival of nonprofits (Suchman, et. al., 1990). Therefore, nonprofit HPs should pursue funding diversity for successful financial performance. This chapter examines the HPs from the financial perspective derived from the six questions in the financial section of the survey.

\subsection{Financial sources of Housing Partnerships}

The following quote by Patricia Garret, CEO, Charlotte-Mecklenburg Housing Partnership, Inc. illustrates how some HPs build financial accountability when dealing with a public-private arrangement in order to assist a community in the delivery of affordable housing. "We are successful because we deliver what we promise. We are accountable for our funds and do not hide what we do. Our approach is comprehensive whether we are revitalizing a neighborhood or providing pre-homeownership counseling." Emphasizing the need for nonprofits to develop a financial accountability framework, Keating and Frumkin (2003) indicate that such a framework improves and benefits the nonprofit sector by providing the public and policy makers with information regarding the financial needs to meet an organizational goal. They argue that a nonprofit financial reporting framework should be reliable and relevant in order for policy makers to make informed decisions.

The financial accountability of HPs is multidimensional. They need to be accountable to public and policy makers regarding their financial activities for the 
betterment of the community. Housing Partnerships also have to be accountable to their private partners and other stake holders. Consequently, the financial accountability of HPs would have to meet the needs of different sectors. As such, a performance and reporting framework for public-private HPs is difficult because of funding sources that follow different requirements and reporting standards. These sources cannot be commingled to obtain a performance and reporting framework that encompasses different needs, goals, and outcomes. In order to deal with this issue, with the increase of publicprivate collaborative agreements such as HPs, some entities provide financial information in formats that are easily accessible and comprehensible to the general public. Since a framework that combines the sectors is not feasible, reports are generally-sector specific. In the financial perspective analysis, revenue diversification is taken as a major factor for successful performance because it allows HPs to adapt their finances to changes. Amy Klaben, the CEO of Columbus Housing Partnership, states that revenue diversification is a tool that allows HPs to face financial challenges of the current economic environment.

We expanded our foreclosure prevention activities to meet the needs of people in our community as the crisis has had a huge impact locally. This has raised our profile as a competent leader in the industry. The housing crisis has had a serious financial impact on our organization as we are not selling houses that we have in our inventory. This has required that we look over programs to fill needs in the community and help us bring in fees. 
Funding diversity help HPs financially in various ways. It allows HPs to leverage funds and to not rely financially on just one source, sector or method. According to Kate Barr, Executive Director, Nonprofits Assistance Fund, nonprofits should have more than one source of income as a financial strategy. Funding diversity assists nonprofits to avoid the risk of a major reduction in income if a source of income reduces or stops. Reliance on one or few partners can translate into budgetary or financial problems for Housing Partnerships. For instance, an HP partner may provide a lower allocation of funds or might no longer exist. If the HP relies on this partner for a high percentage of funding, then such financial shortage could result in negative implications for the HP, such as the termination of services, laying off of staff, and in some occasions, ceasing operations.

Carroll and Jones Stater (2008) argue that revenue diversification decreases the financial vulnerability of nonprofits. Greenlee and Trussel (2000) and Greenlee (2002) indicate that greater revenue diversification provides nonprofits with higher operating margins, decreasing the likelihood that it would cut program expenses or services as a result of the loss of one revenue stream. In the case of nonprofit HPs, diversification is a financial strategy which allows for the steady income and constant revenues regardless of factors such as an economic recession or the absence of a funding source. Housing Partnerships have the financial ability to continue activities already in progress such as the construction of a building and the adoption of new or expanding activities, such as foreclosure assistance (White, 1983). Consequently, one of the goals of public-private HPs is to have diversification of resources from private and public sources. Wylde (1986) and Lederman (1983) indicate that the ability of HPs to bring together various resources from the private sector, such as banks and realtors, the public sector, such as housing and 
government officials, and nonprofit entities, allow them to maximize resources in which knowledge and funds work together in order to achieve a collective housing goal.

The financial diversity of the HPs is captured by the first question in the financial section of the survey instrument: What percentage of the Housing Partnership's funding came from the following sources in 2009 ? Respondents were required to put the percentage amounts under four categories (summing to 100 percent): private, government, service fees, other. Among these categories, government funding in 2009 (41 percent) comprised the largest funding source for Housing Partnerships. According to follow-up information to the close-ended survey, higher government assistance is reported in this year because of new or expanding government programs developed to assist communities to lessen some of the effects of the current economic downturn on housing. These programs provide funds to housing services providers, such as HPs for new or expanding services. For instance, Metro Housing Partnership, an HP located in a metropolitan area hard hit by the economic downturn explained how the public sector allocated several funds to HPs in order to assist communities and households in these areas. Metro Housing Partnership explained that community assistance in the form of public funding is provided generally through the Community Development Block Grant (CDBG). Local governments, such as counties, receive allocations of these funds through a formula that takes into account issues such as foreclosure rates in a region. The rise in foreclosures in some jurisdictions have resulted in increase of the monetary amounts of CDBG allocations. Another form of public funding that became available recently is the Homelessness Prevention and Rapid Re-Housing Program (HPRP). It is part of the federal stimulus developed to assist individuals and communities to recover from some of 
the negative effects from the current economic crisis. The funds are distributed on the basis of the allocation formula of the Emergency Shelter Grants (ESG) program. These funds can be used to directly assist households in need. The explanations regarding the allocation of these funds by the follow-up responses suggest that these are temporary funding sources.

\section{Figure 5.1: Housing Partnerships' Funding Sources}

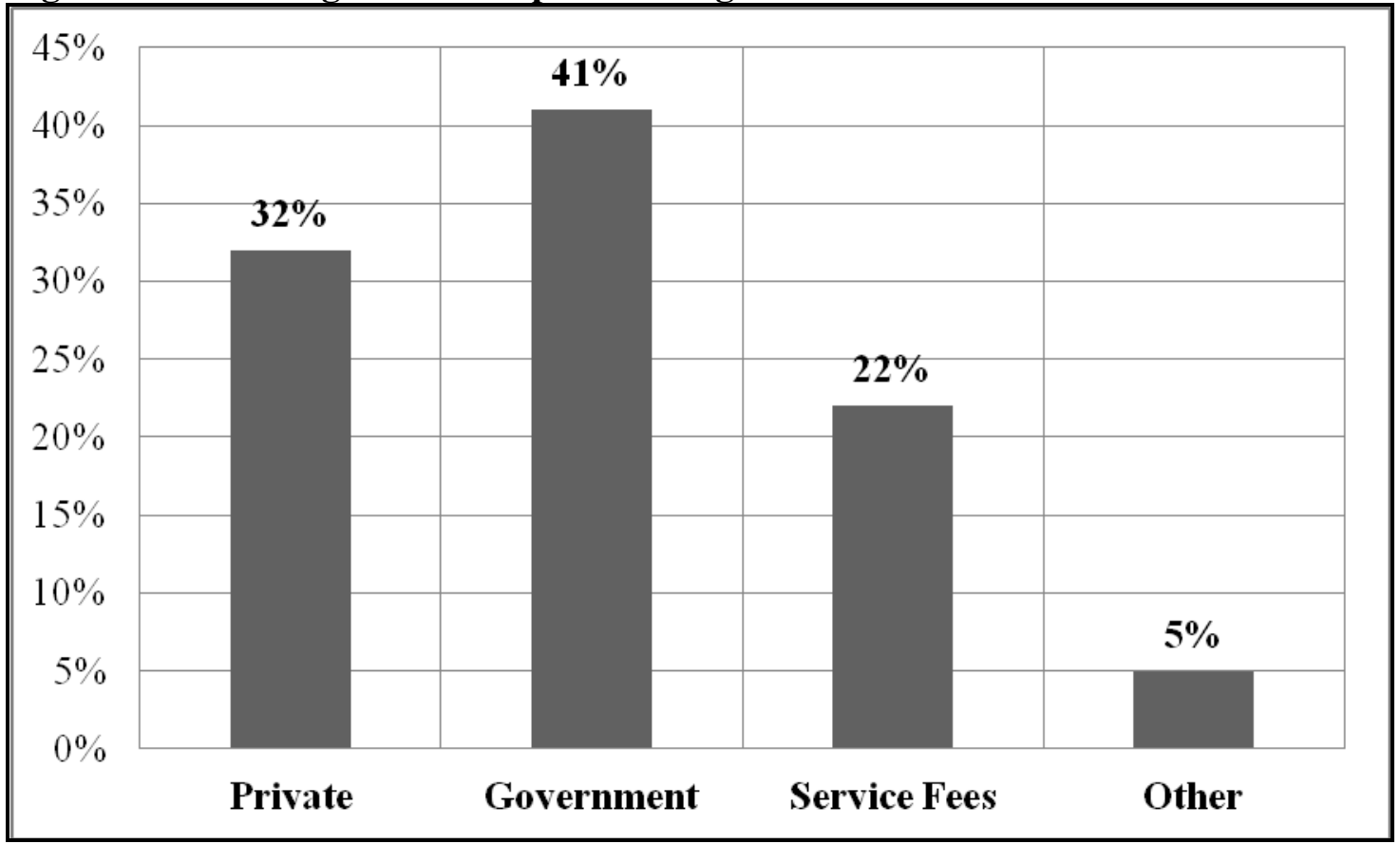

Funding from private sources comprised 32 percent of the annual revenue in two thousand nine. According to follow-up responses, the private funding stream was higher in the previous years and the government percentage was lower. Housing Partnerships indicated that private funding is mostly in the form of loans and interest and the majority of private funding sources and partners are banking and lending institutions. Service fees amounted to 22 percent of the total revenue in two thousand nine. Housing Partnerships indicated that service fees fund or supplement funding to new or increasing services, such 
as credit counseling or technical assistance. Service fees serve as gap financing when public/private funds do not provide the full monetary amount to cover all expenses. New services or programs involve new expenses, such as staff training, new hiring, and additional space. Often, these are expenses that occur after budgets are in place and funding allocation is set. Through service fees, expenses brought by new services or programs are funded. "Other" funding comprised five percent, mainly from philanthropy and donations, fundraising events, and churches.

In 2009, HPs received a higher percentage of funding from government sources through federal programs and grants to lessen the effects on housing by the current economic downturn. Increases of funding from governmental sources are, however, temporary. Even if some of these funds were permanent, government grants and programs, such as $\mathrm{CDBG}$, have use restrictions. For instance, government funds cover education and social services and not construction. As a result, it is necessary to have various funds in order to cover all HP activities. Housing Partnerships diversify their incomes by adding private funding and service fees to supplement public funds.

According to follow-up information from this section of the survey, on average, the percentage of revenues from private funding is about the same as for public funds. Service fees are a smaller funding percentage than public and private funding. However, HPs explained that the use of service fees increased because of limited resources and higher expenses from new or expanding services. By increasing the use of service fees, HPs altered and diversified their funding bases from relying on public and private funding to a comprehensive approach for long term financial stability (Frumkin and Kim, 2001; Hodge and Piccolo, 2005; Gou, 1997). A comprehensive approach that ensures 
long term financial stability assists in the achievement of mission-related goals. Financial health makes the survival of any type of organization more certain. Funding source diversity is important because it creates organizational sustainability when a source declines (Carroll and Jones Stater, 2008). For HPs, comprehensive financial approaches allow program and service adaptation to address new needs. Housing Partnerships with diversified funding streams are able to adapt financially to current challenges in the development and delivery of affordable housing.

\subsection{Financial activities of Housing Partnerships}

Changing needs in the population require HPs to adjust, expand, and/or discontinue some activities, services, and programs. For example, several HPs decreased their construction activities because of the housing market downturn. On the other hand, some of these HPs expanded or began credit counseling or foreclosure assistance programs. To examine the financial activities, the central question in the survey was: What percentage of the Housing Partnership's funds was spent on the following activities in 2009? The response options were: affordable ownership housing construction, provision of affordable rental housing, loan provision, homeless assistance, and "other." The responses are summarized in Figure 5.2.

The responses indicate that the provision of affordable rental housing is the main activity in which HPs spent the majority of their funding (36 percent) in two thousand nine. Housing construction and "other" categories were the next categories, (about 22 percent). Homeless assistance and loans formed fourteen percent and five percent of the expenses. According to survey responses, the "other" activities included research, 
education, training, technical assistance and counseling. The "other" category also included support costs, such as administrative costs, training, and technology. The following follow-up responses to the survey illustrate the types of activities that HPs contribute some of their funds to:

"We spent a high percentage of funds in our property management, and supportive housing activities. Administrative costs were part of our expenses."

"Twenty percent of funds go to educational purposes, that being either the community or the staff. We fund community programs as well as an academic scholarship fund."

\section{Figure 5.2: Percentage of Funds Spent in Various Activities by HPs in 2009}

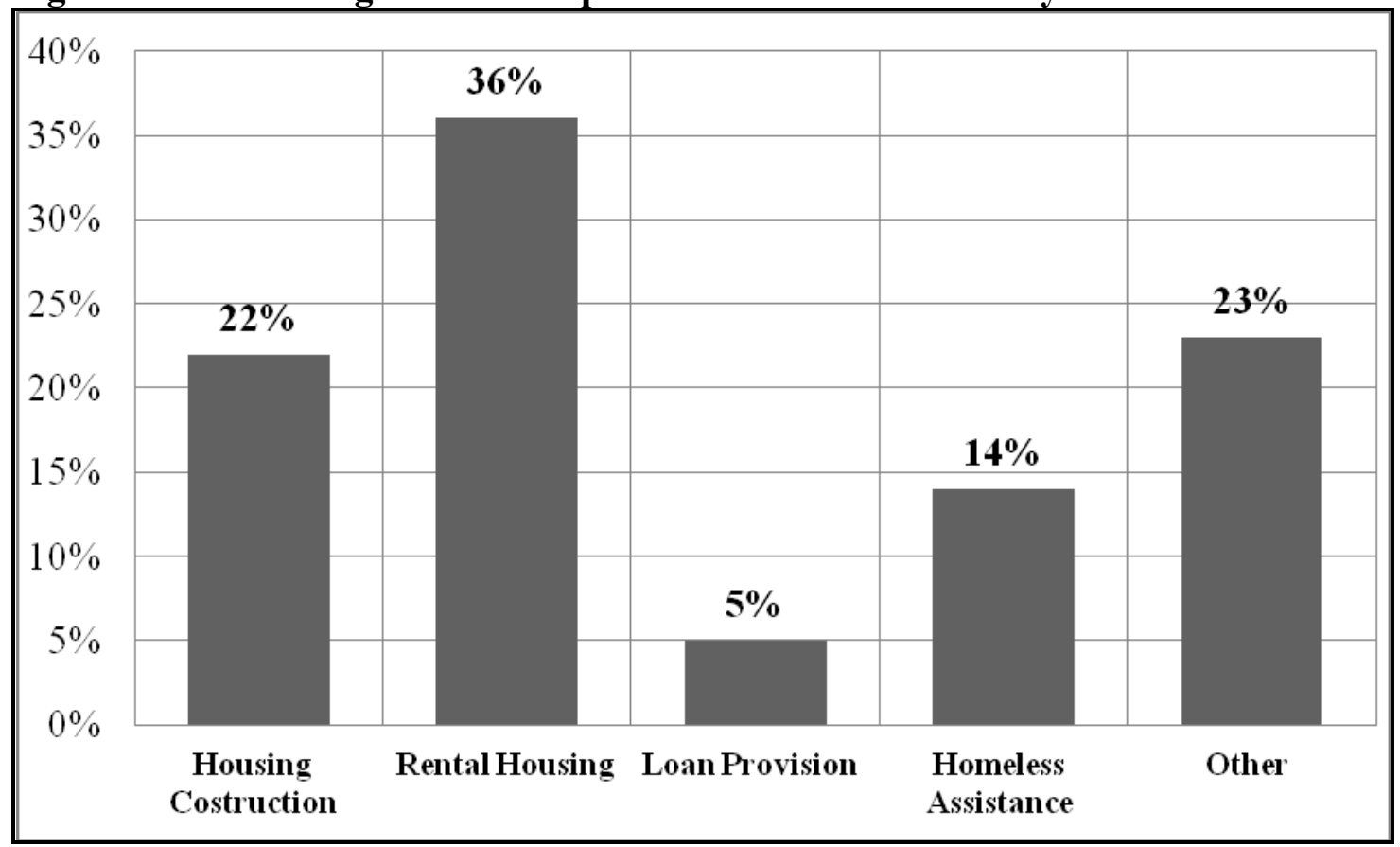

According to follow-up responses, some activities that were funded in the previous years were not funded in two thousand-nine because of financial challenges and 
changing community needs. The following quote provided by Mr. Tom Merkel, CEO, The Impact Group, explains some of the challenges that prevented many Housing Partnerships from funding activities. He stated, "We are having difficulty with equity investors and the reduced amount of investment they are willing to put into a project. Construction costs are very difficult to pin down and some of our tenants are having difficulty paying their rent and we have a higher vacancy rate than we should have."

To follow-up on the Housing Partnerships' ability to raise their funding in a difficult year, the next question in the financial section was: What percentage of the financial target did the Housing Partnership raise in 2009? Nearly fifty-five percent of the Housing Partnerships reported meeting eighty-one percent to one hundred percent of their financial target. About twenty-six percent of the Housing Partnerships raised sixty-one percent to eighty percent of their financial target, twelve percent had met forty-one percent to sixty percent of their target, and seven percent had reached under forty percent of their financial target. The survey responses show that although the economic downturn affected the Housing Partnerships financially, the overwhelming majority of them (eighty-one percent) had met more than sixty percent of their financial target. 
Figure 5.3: Financial Target met in 2009

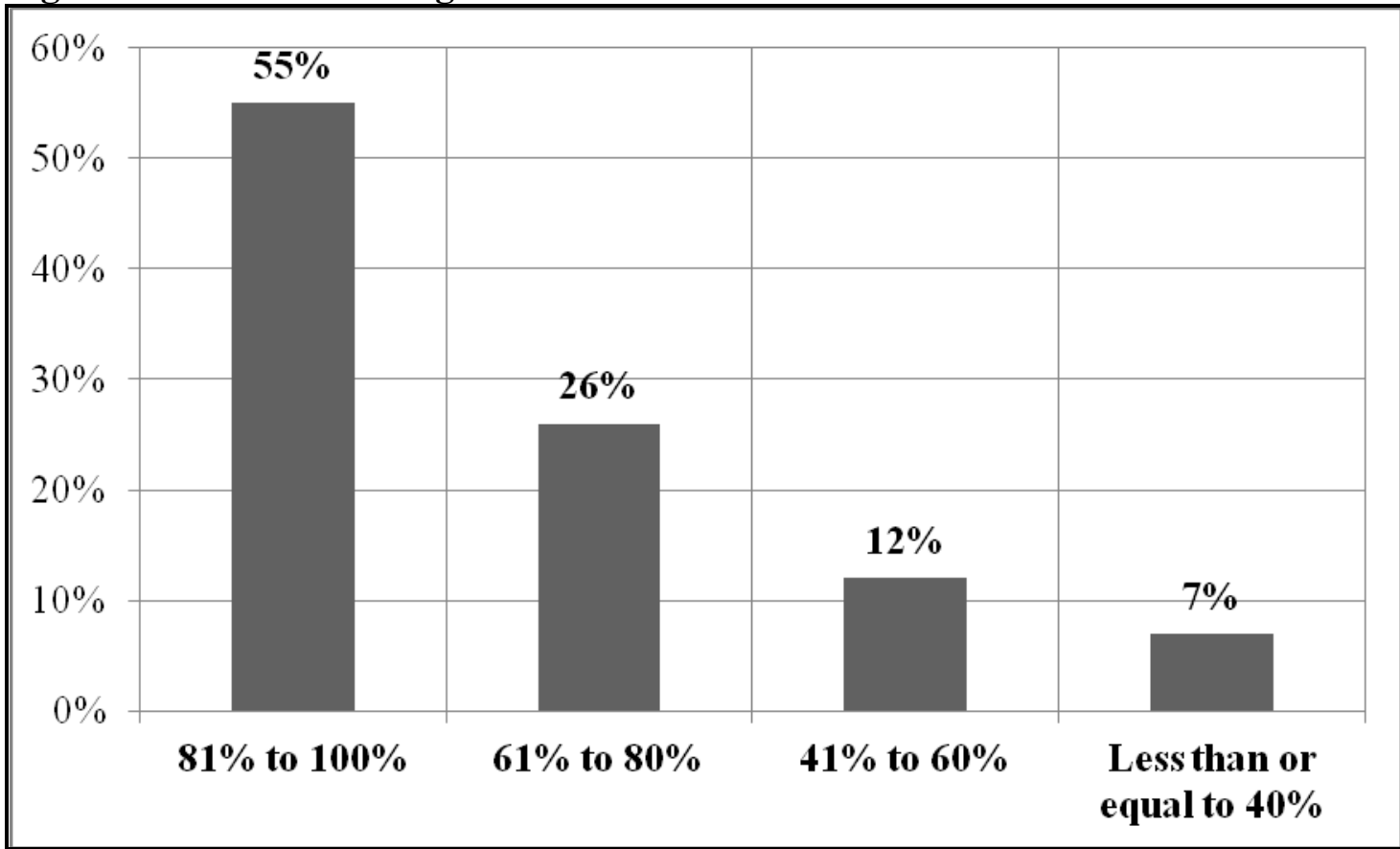

To further examine the impact of the economic downturn on the Housing Partnerships, the next question in the financial section was: If the Housing Partnership is three years or older, how did the budget change from 2007 to 2009? The expectation is that the economic environment would adversely affect the budget over the three years. Yet, almost half of the respondents (forty-nine percent) indicated budget increases from two thousand-seven to two thousand-nine (Figure 5.4). About twenty-seven percent indicated no increase or decrease. Only twenty-four percent reported a decrease in their budget during the period. Clearly, most HPs maintained their or increased their budget despite the economic downturn. Housing Partnerships have been able to raise or maintain their funding in a difficult economic environment. 
Figure 5.4: Housing Partnership Budgetary Changes from 2007 to 2009

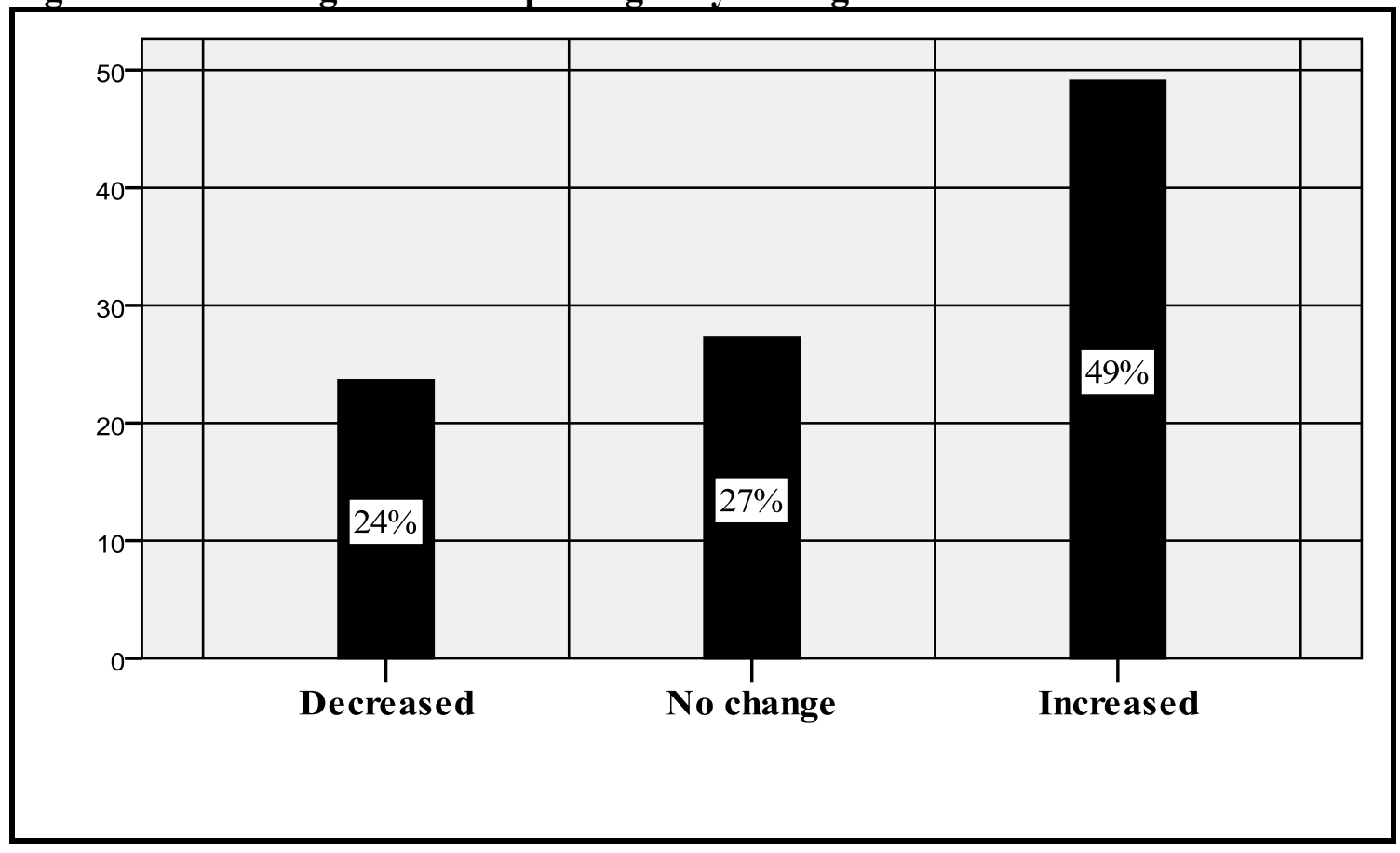

The next question in the financial section was: Out of the customers who sought financial assistance from the Housing Partnership in 2009, what percentage actually received the assistance? The majority of HPs (65 percent) indicated that they did not provide direct monetary assistance to clients. Survey follow-up information highlights various reasons for not providing direct monetary assistance. Some HPs explained that the organization had negative issues with direct monetary assistance previously and decided the organization no longer carries the activity. Of the HPs providing direct monetary assistance, 15 percent indicated that they gave financial assistance to 81 percent to 100 percent of their customers (Figure 5.5). About 60 percent indicated that they served 61 percent to 80 percent of their customers. Survey results indicate that the majority of the HPs (75 percent) that provided loan assistance have been able to assist individuals with direct monetary assistance even during changes to revenues and budgets. 
Figure 5.5: Percentage of Customers Receiving Financial Assistance

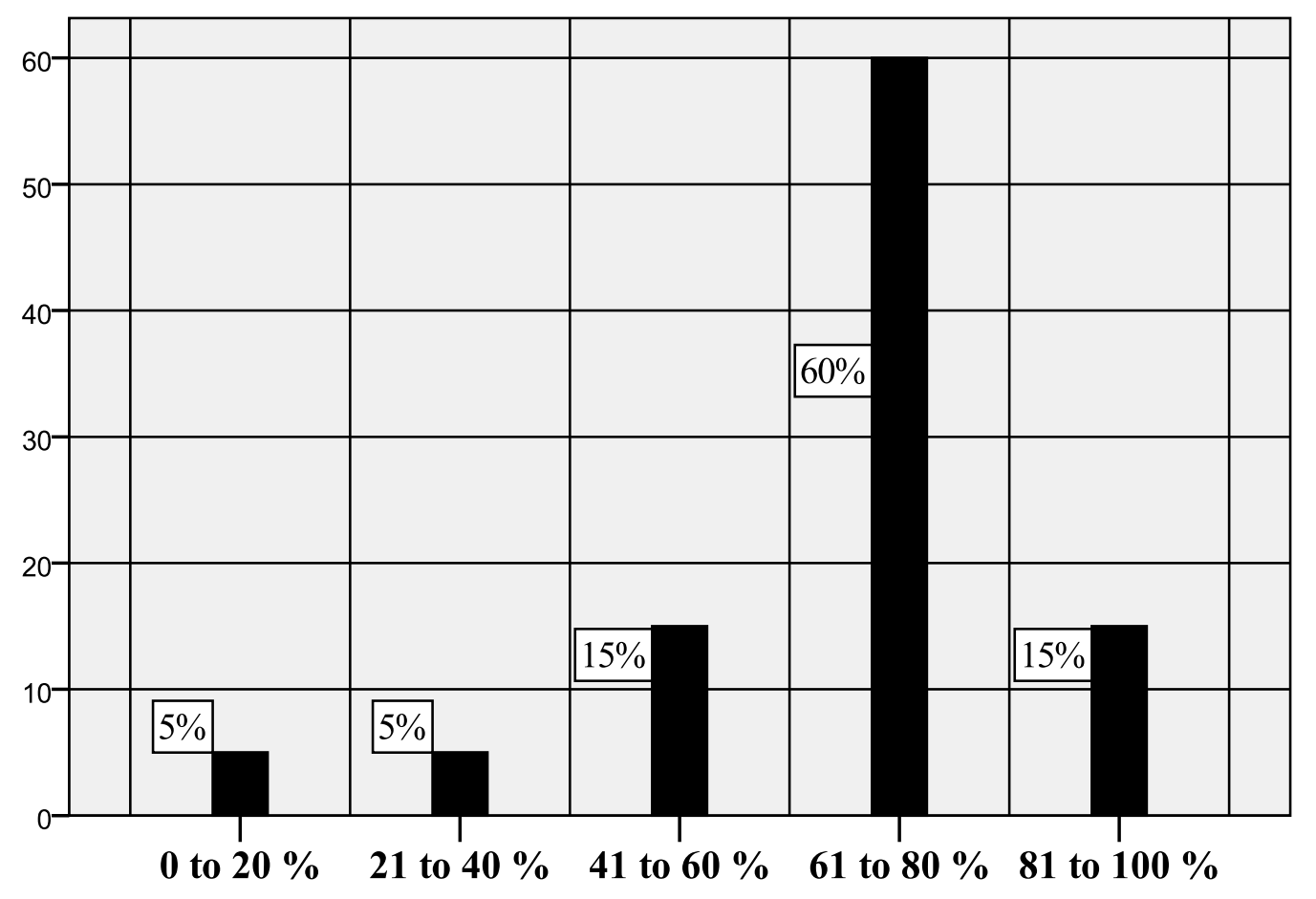

The last question in the financial section of the survey was related directly the HPs activities in the face of the economic downturn: What was the financial impact of the economic crisis on the Housing Partnership in 2009? The respondents were asked to select from the following options: Housing Partnership reduced programs, laid off staff, purchased foreclosure properties, and "other." Figure 5.6 summarizes the responses. About 32 percent of the survey respondents reported reducing their programs as a result of the economic crisis. About 21 percent reported laying off staff and purchasing foreclosed properties. A larger percentage (29 percent) reported "other" impacts. A more detailed analysis of the "other" category reveals mixed effects, both increase and decrease in the sizes of their business, staff, and funding. In addition, modification of work hour and wages was reported by some Housing Partnerships as other. 
Figure 5.6: Financial Impact Issues

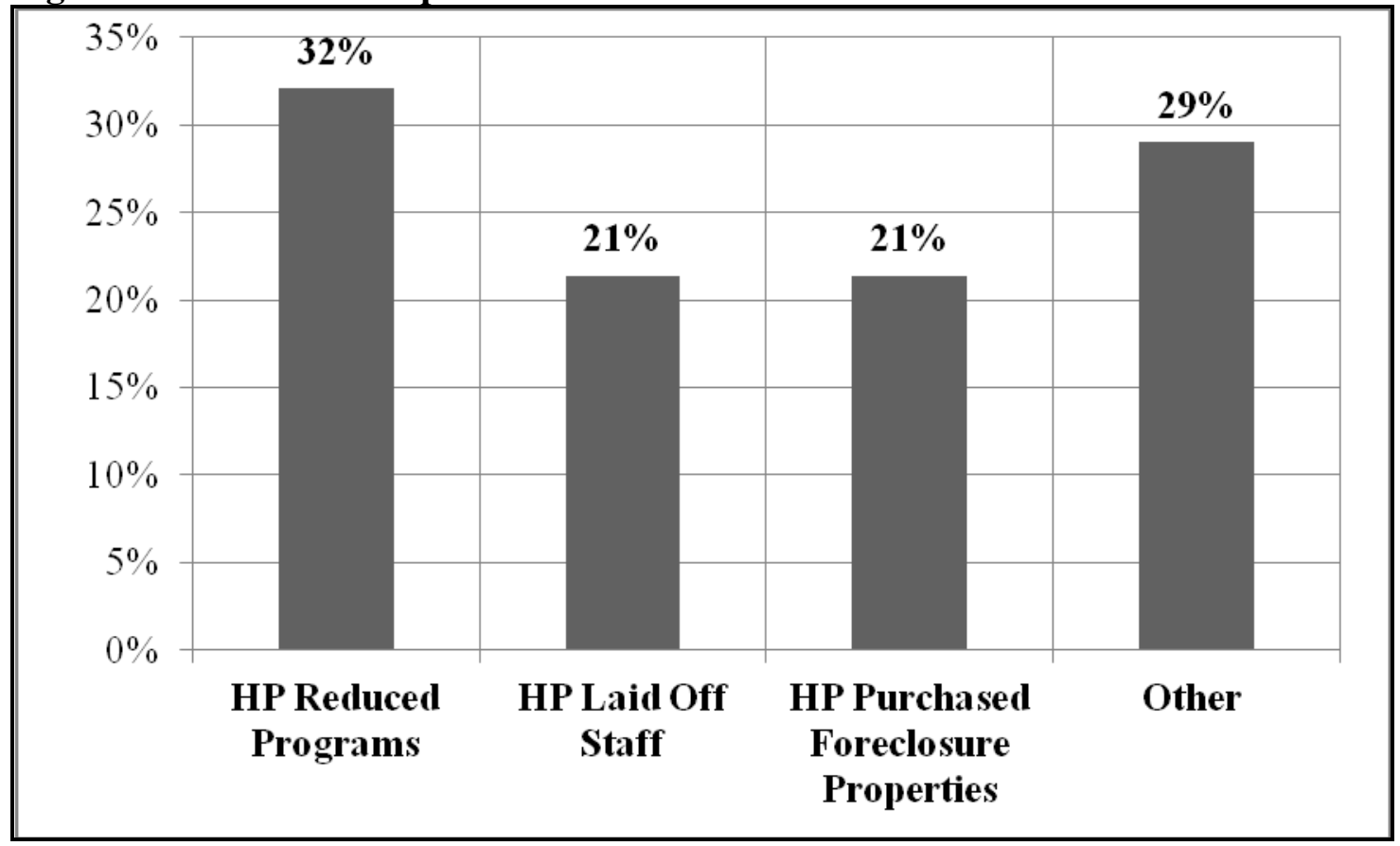

Housing Partnerships with comprehensive approaches including programs such as homeowner construction, rental assistance, counseling, education, and advocacy are associated with budget increases. Allocations resulting from expertise, because programs are already in place, allow HPs with comprehensive approaches to have budgetary increases. In addition, program variety allows HPs to charge service fees, thus increasing their budgets.

\subsection{Cross-Tabulation Analysis}

To gain further insight into the success factors from the financial perspective, I conducted a cross-tabulation of the survey answers in the financial perspective section. Upon identification of significant relationships, the direction and strength between variables are explored by examining the measures of association such as Goodman and Kruskal's Gamma and two-way table's row/column percentages. Gamma is used to 
explore the relationships because explained variables are ordinal and the explanatory variables are categorized as either dichotomous or interval variables. The cross-tabulation analyses between funding streams (private, government, service fees) and the financial responses indicate strong associations.

The relationship between service fees and nonprofit affiliates is significant (0.003), indicating that the nature of affiliates (public, private, nonprofit) is associated with the type of funding used by Housing Partnerships. Though significant, the association is very weak (0.031) as affiliates do not have a very close role with funding and HP finances. Government funding and the financial allocation of the rental program are significantly (0.016) associated. The strength of this relationship is moderate with a negative or inverse direction among variables $(-0.370)$, suggesting that as government funding increases, less funding is allocated to rental related activities (Table 5.1). The relationship between government funding stream and the financial allocation to the homeless program is significant $(0.006)$, indicating that government funding is associated with the type of funding allocation to programs. Though significant, the association is weak as other factors, such as the needs of a community, influence program funding.

\section{Table 5.1: Funding Streams Cross-Tabulations}

\begin{tabular}{lccc}
\hline Variable Association & $\begin{array}{l}\text { Pearson Chi-squared Test } \\
\text { (P Value) }\end{array}$ & Gamma & N \\
\hline $\begin{array}{l}\text { Funding stream (gov) by Program } \\
\text { Funding Allocation (rental) }\end{array}$ & 0.016 & -0.370 & 56 \\
& 0.006 & 0.236 & 56 \\
$\begin{array}{l}\text { Funding stream (gov) by Program } \\
\text { Funding Allocation (homeless) }\end{array}$ & & & \\
\hline
\end{tabular}


Cross-tabulation analyses of the financial target raised by HPs in 2009 indicate meeting the target is significantly related to HP mission achievement $(0.003)$ and jurisdiction (0.019) (Table 5.2). The relationship between the percentages of the financial target raised in 2009 and mission achievement is strong (.545) with a positive direction. High (81 percent to 100 percent) percentages of the financial target achievement are associated with HPs reporting high mission achievement percentages. The relationship between the financial target raised and jurisdiction, although significant, is very weak (.094).

Table 5.2: Financial Target Cross-tabulations

\begin{tabular}{llccc}
\hline Variable Association & \multicolumn{1}{c}{$\begin{array}{l}\text { Pearson Chi-squared Test } \\
\text { P value }\end{array}$} & Gamma & N \\
\hline $\begin{array}{l}\text { Financial Target Raised by Mission } \\
\text { Achievement }\end{array}$ & 0.003 & 0.545 & 57 \\
\hline
\end{tabular}

On average HP budgets increased from 2007 to two thousand nine. The impact of the economic downturn on HPs is significantly associated (0.009) with budget changes (Table 5.3). Measures of association indicate a moderate and positive relationship among these variables. The two-by-two table shows that HPs indicating financial impacts resulting from the economic downturn are likely to report budget increases. The relationship between budget changes and function is significant (0.024). According to measures of association, the relationship is positive but weak (0.199), meaning that budgetary increases exist in HPs with all types of functions. Budget changes and the percentages of the financial target raised are significantly associated (0.029). The association is positive of moderate strength (0.302), in that budget increases are 
associated with high (81 percent to 100 percent) percentages of the financial target raised in two thousand-nine.

Table 5.3: Budget Change Cross-tabulations

\begin{tabular}{lccc}
\hline Variable Association & $\begin{array}{l}\text { Pearson Chi-squared } \\
\text { Test (P Value) }\end{array}$ & Gamma & N \\
\hline $\begin{array}{l}\text { Budget Change by Impact of Economic } \\
\text { downturn }\end{array}$ & 0.009 & 0.347 & 55 \\
Budget Change by Function & & & \\
Budget Change by Financial Target Raised & 0.024 & 0.199 & 53 \\
\hline
\end{tabular}

Financial assistance provision and function are significantly associated $(0.015)$ (Table 5.4). Measures of association indicate a negative and moderate $(-0.327)$ relationship among these variables, which means that financial assistance is likely provided by HPs that have comprehensive functions/activities including services such as construction, rehabilitation, education, and advocacy. The relationship between jurisdiction and the provision of financial assistance is significant (0.035) and coefficient results indicate a positive direction and moderate strength for this association. The relationship among variables indicate that "other jurisdictions" representing mixes of counties and cities, states and cities, states and counties are associated with HPs that reported a high (81 percent to100 percent) percentage of customers receiving financial assistance after it was requested. 
Table 5.4: Financial Assistance Provision Cross-tabulations

\begin{tabular}{lccc}
\hline Variable Association & $\begin{array}{l}\text { Pearson Chi-squared Test } \\
\text { (P Value) }\end{array}$ & Gamma & N \\
\hline $\begin{array}{l}\text { Financial Assistance Provision by } \\
\text { Function }\end{array}$ & 0.015 & -0.327 & 57 \\
$\begin{array}{l}\text { Financial Assistance Provision by } \\
\text { Jurisdiction }\end{array}$ & 0.048 & 0.209 & 55 \\
\hline
\end{tabular}

\subsection{Conclusion}

This chapter provided an analysis of HPs' performance from the financial perspective. The perspective assists my study in identifying financial-related performance factors, such as funding sources. Revenue diversification is a factor for successful performance of HPs allowing them to have the resources necessary to meet their mission through the availability of financial support for affordable housing production and housing-related programs and services. Survey responses revealed that HP revenues consist of mostly public and private funds, accounting for approximately 75 percent of funding. However, follow-up responses indicate that service fees are becoming more frequently used, which means that percentages of funding from service fees are likely to be similar to those from the public or the private sectors. In addition, survey data analysis revealed that the source of funding (government, private, service fees) influences the funding allocation for different programs and activities.

The survey shows that on average HP budgets increased between the years 2007 to two thousand nine. Survey follow-up information indicates that revenue increases were caused by additional service fees and/or funding to expand or develop new programs. Data analysis revealed a relationship between the economic downturn affecting HPs 
financially and budget changes. Housing Partnerships were financially affected by the economic downturn. There was a greater demand for services resulted in program expenses. 


\section{CUSTOMER PERSPECTIVE}

\subsection{Introduction}

In the Balanced Scorecard, customer related objectives and measures help identify whether an organization's strategy, implementation, and execution are contributing to the needs of customers (Kaplan and Norton, 1996). According to Niven (2003), in order for a nonprofit organization to achieve its mission, it must primarily determine whom it aims to serve and how requirements can best be made. Unlike the private or business sector where fiscal responsibility and stewardship are the primary factors to meet financial growth, the nonprofit sector performance is dependent upon meeting the mission. In the case of HPs, the main focus is to serve the affordable housing needs of community members. Hence, the main research question for this perspective is: Who makes up the main clientele of Housing Partnerships? The hypothesis is that Housing Partnerships serve low and moderate-income households. Housing Partnerships should be considered successful in terms of meeting their mission if low and moderate-income households form a high percentage of their customers.

Kaplan and Norton (1996) explain that improvement in performance is achieved when the clientele of the organization is identified. Once the clientele is identified, it is essential that organizations understand their needs so that the programs and services offered are aligned with them. Wylde (1986) indicates that a successful HP identifies and addresses specific community needs and is responsive to their local environment so that they have ability to deal with external opportunities and limitations. 


\subsection{Customer Needs and Awareness}

Community members are the customers of Housing Partnerships. It is important to develop open and honest communication for needs to be recognized and addressed through programs and services. Affordable housing delivery is a local process in which community involvement is crucial during all stages. The delivery of affordable housing and related services in a community depends on many factors, mostly local, such as resident needs, their demographics, and the environment (such as geographical setting, and financial and political situation and support). Affordable housing provision does not follow a single approach or solution because each community and region is different.

Housing Partnerships are local efforts that take into consideration the areas they will serve. In order for successful performance along the customer perspective, HPs need to understand the issues underlying affordable housing in a community, and take action in partnership with other entities such as government officials, private investors, and donors. The partnership is among organizations and that share a commitment to preserving, delivering, and developing affordable housing through innovative and creative efforts (Gilliard, 2011).The collaborative efforts help narrow the particular facets of affordable housing and related services in the community. Housing Partnerships have well defined roles to achieve the shared mission of the community's goals for affordable housing.

Kaplan and Norton (1996) and Niven (2003) indicate that the identification of needs allows for the development of programs and services that achieve the mission. Community awareness allows HPs to identify the housing-related needs of the locations served. Through community awareness HPs establish the needs of a community. The identification of needs allows HPs to develop programs and services to assist community 
needs. Patrick McNamara, CEO, Housing Partnership, Inc., explained the relationship between community awareness and customer satisfaction thus, "In order for an HP to have the support and satisfaction of a community it needs to have an understanding of its housing market and dynamics, as well as service delivery that adapts to meet needs.”

The awareness of the communities assisted by HPs is important for its success. Once the needs are established, HPs must work towards addressing the identified needs. A successful HP is one that effectively responds to a community's changing housing issues as well as the changing needs of its population. An effective response is usually accomplished by providing services addressing these needs and by leveraging public and private resources to fund these new programs or services.

Reichl (1999) recommends that housing and/or community development agencies, such as HPs, need to be responsive to the community they are serving in order to gain support from community members and other stakeholders. Responsiveness is achieved through the involvement of community members in decisions regarding the development of programs and services in order for them to best serve their needs. Housing Partnerships should review needs by maintaining a way in which community members are able to communicate if as a result of new or changing issues requiring program or service adaptation, origination or discontinuation. By providing and adapting programs and services that address community needs, HPs gain support that could influence the resources and allocations received. Communication and community feedback is obtained through community forums or meetings. During such interactions, the HP should openly discuss and explain how some current events affect housing in order for community members to discuss how such changes are affecting them and their 
neighborhoods. Through these forums and meetings, HPs should be able to examine the community's needs in order to form a strategy and goals that address these issues.

Housing Partnerships have to be aware of the changes and respond to them

through delivering programs and services that address the new needs. The new programs and services should be comprehensive and flexible approaches that address multiple needs. According to Sanger (2008), flexibility is the ability of an organization to adapt plans to changing needs. The support of the members of the organization as well as that of external stakeholders is necessary for changes and flexibility to take place.

\subsection{Customer Advocacy}

Housing Partnerships that advocate as part of their goals or as their sole purpose, support the communities by listening to the residents' affordable housing concerns, and examining their needs and service gaps. Once needs are established, the role of advocacy is to encourage the participation of private and nonprofit organizations, government, and individuals to achieve solutions. Participation can take place as collaboration between several community members and organizations representing all sectors. A representative of the Columbus Housing Partnership explained how to attain community awareness thus:

We have a lot of events and programs to educate the private sector and government about what we are doing and we also educate community members on the importance of affordable housing. We bring in nationally recognized speakers to draw in the public and 
raise our profile. We also try to get media coverage at least monthly.

An example of the type of advocacy role or policy/education work of Housing Partnerships is described by Ms. Cathy Hinko, Executive Director of the Metropolitan Housing Coalition (MHC) located in Louisville, Kentucky. The mission of MHC is "to bring together this community's private and public resources to provide equitable, accessible housing opportunities for all people though advocacy, public education and support for affordable housing providers." Ms. Hinko illustrates the type of advocacy and research work conducted by HPs and how these efforts shape and influence the affordable housing policies and awareness of related issues in a jurisdiction.

The Metropolitan Housing Coalition prepared a report called "Where Do You Live? Louisville's Homeless Children and the Affordable Housing Crisis" in the 20082009 on homeless children in the public school system in Louisville. This report highlighted that 8,582 (or nearly 9 percent of all children) in the Jefferson County Public Schools (JCPS) system were homeless at some time in the year. The report indicates an increase in homelessness as a result of the high foreclosure rate in the Louisville area. The report provided a basis for MHC to formulate policy, recommendations, and actions to help resolve the area's shortage of affordable housing. According to Ms. Hinko:

Several considerations went into choosing that subject. One was that we believe that people respond more to issues that affect children. Another is that educational attainment is a popular topic right now. A critical consideration is that the U.S. Department of Housing and Urban Development (HUD) had defined 
homelessness so narrowly. According to the HUD definition of homelessness half the people who were homeless would have been left out of the count. So by using the federal definition affecting school children and using the public school system data, we could get longitudinal data and even see educational attainment as well as geographic distribution. It was a compelling tale.

One of the outcomes of these efforts was an application by the housing authority for a pilot program for homeless families with school age children. Ms. Hinko stated, "Metropolitan Housing Coalition will continue to educate the public so that affordable housing is a critical issue, because such advocacy efforts by partnership lead to public awareness and action.”

As highlighted by the survey, nearly all Housing Partnerships answered that the principal jurisdiction served were either counties and/or cities within the same region. States were mentioned as principal jurisdictions mostly when the HP's main role was that of advocacy and policy formation. There are groups and Housing Partnerships that specialize in the role of advocacy for the needs and requirements of community members in a location. The advocacy role could be one of the various roles of HPs besides housing construction, rehabilitation, and construction. The Housing Partnerships whose main or only role is that of advocacy are generally small nonprofits, with small budgets, and whose staff is primarily of volunteers. These entities do not provide direct services to the community such as credit counseling or foreclosure assistance. As a result, the number of staff is limited. 


\subsection{Customer Characteristics}

The identification of the population that is served is critical to the type of services and programs offered by Housing Partnerships. In this context, the customer perspective section in the survey included six questions. The first question in this section was: How many households did the Housing Partnership assist during 2009? On average, each Housing Partnership assisted 1,411 households. The number of households assisted ranged from 20 to 2,300. Although a few Housing Partnerships indicated that they assisted zero households because their housing projects had not been completed by two thousand-nine.

Figure 6.1: Change in Number of Households Assisted Between 2007 and 2009

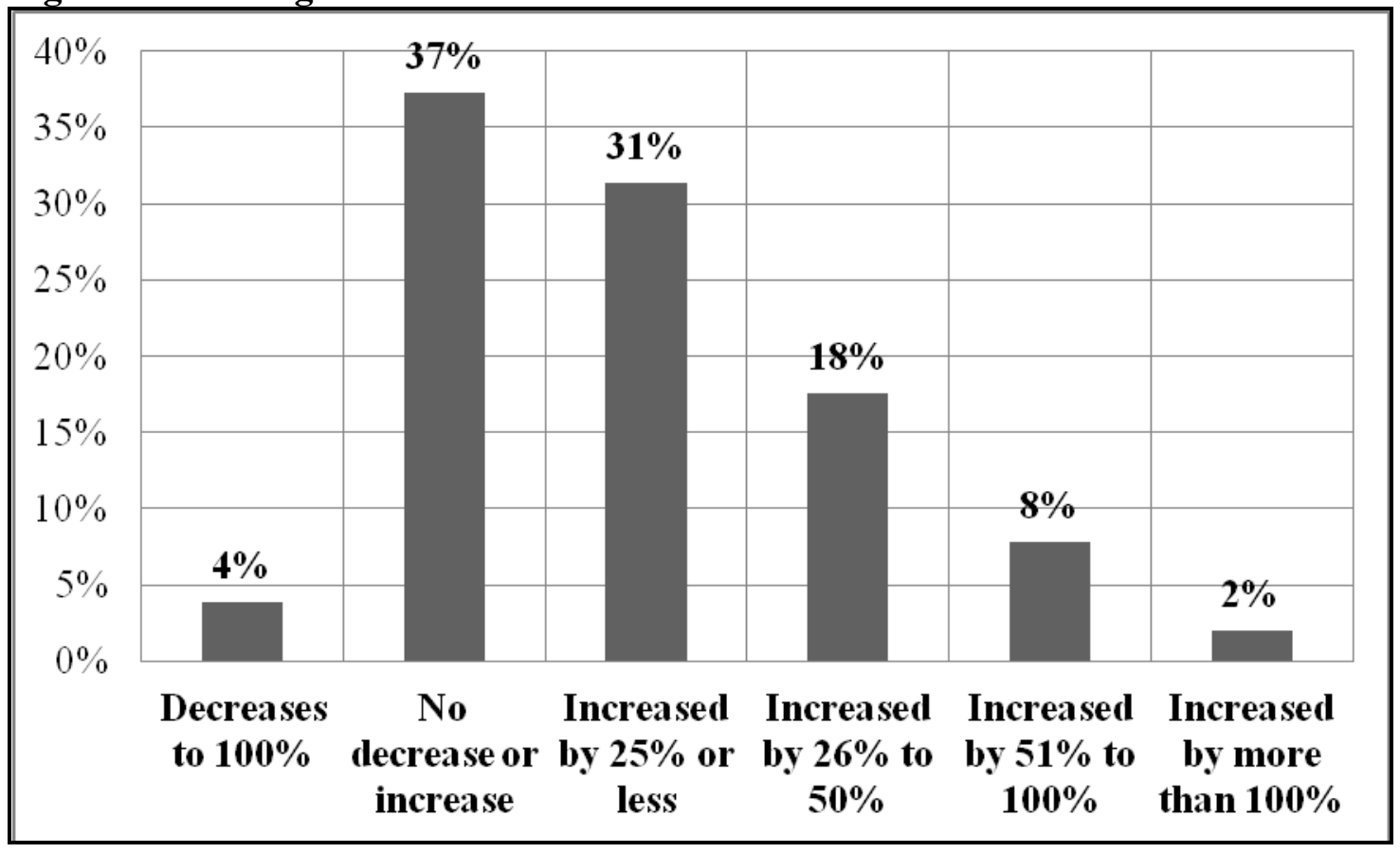

The next question in the customer perspective section of the survey was: If the Housing Partnership is three years or older, how did the number of households assisted change between 2007 and 2009? Only a small percentage (four percent) indicated a 
decrease in the number of households assisted (Figure 6.1). About 37 percent indicated no decrease or increase in the number of households assisted. The rest (59 percent) indicated an increase in the number of their clientele. Clearly, this indicates that the role of the Housing Partnerships increased in the period of the economic crisis, thus highlighting the use of Housing Partnerships as an innovative mechanism to be effective local solutions for housing purposes.

The third question in the customer perspective section of the survey is key to the clientele of the Housing Partnerships: Please give the percentage of households assisted in each income bracket in 2009. The response choices for the income bracket were based on the Area Median Income (AMI) criteria defined by the U.S. Department of Housing and Urban Development (HUD): Very-low-income (households with income less than 30 percent of AMI); Low-income (households with income between 30 percent and 50 percent of AMI); Moderate-income (households with income between 51 percent and 80 percent of AMI); Middle-income (households with income between 81 percent and 120 percent of AMI); and High-income (households with income above 120 percent of AMI). The survey responses are illustrated in Figure 6.2. As the figure indicates, Housing Partnerships cater principally to a mixture of very-low, low and moderate-income population. The very-low and low-income categories make up 70 percent of the clientele; another 25 percent are from the moderate-income category. This indicates that the HPs have played a crucial role in housing the very-low, low, and moderate-income segments of the population. 
Figure 6.2: Percentage of Households Assisted

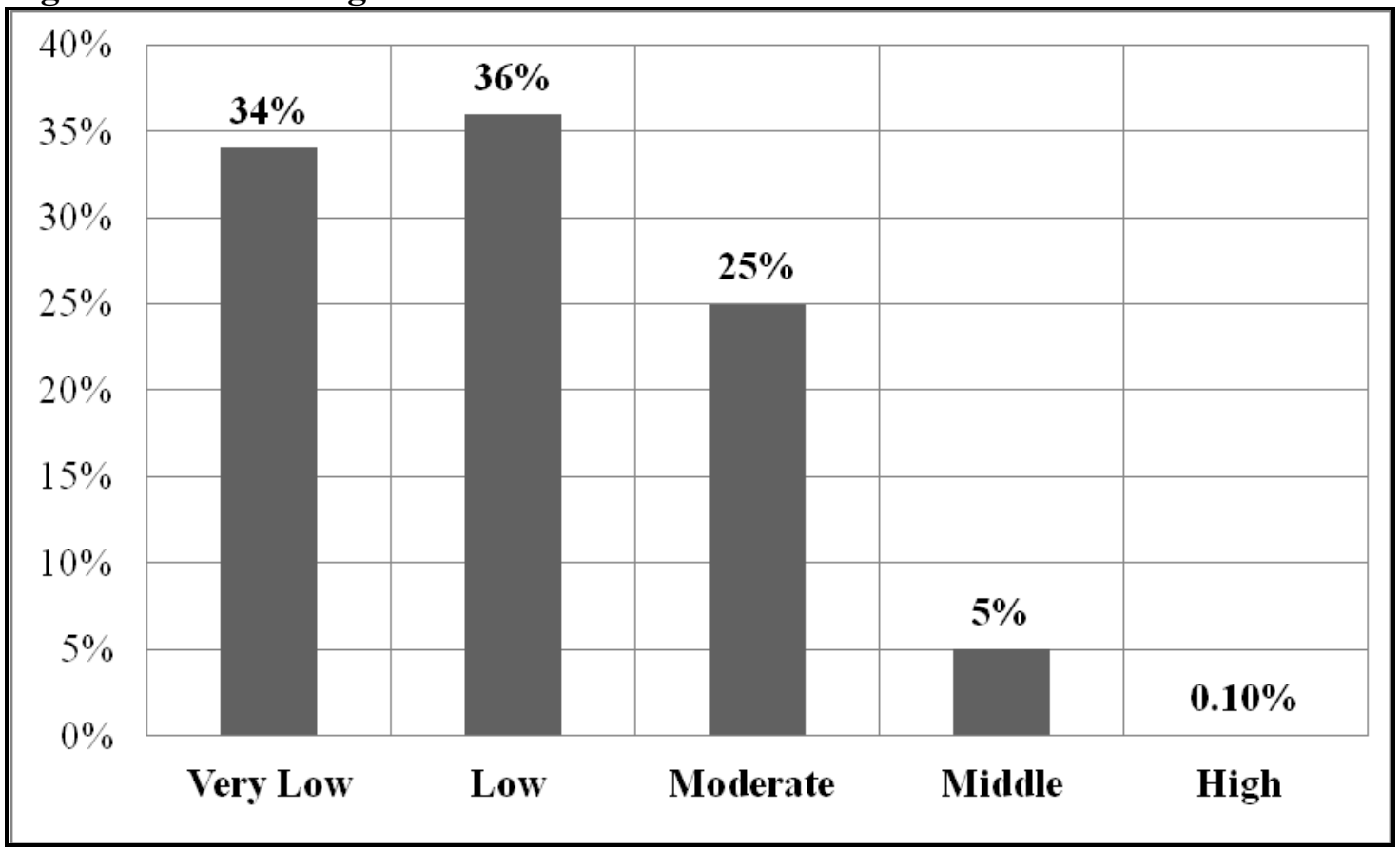

Related to the previous question, the next question asked: Which group(s) did your organization provide housing services to in 2009? The choices for responses were: the homeless, senior citizens, veterans, victims of domestic violence, and other. Respondents could choose more than one category; hence the choices are not mutually exclusive. An overwhelming majority (77 percent) of the HPs chose the "other" category (Figure 6.3). They indicated that they do not provide services on the basis of a specific group. Housing Partnerships provide services and programs to households based on income criteria and need. The following responses are illustrative of how HPs provide services:

All individuals and families who need help and financially qualify.

Everyone who cannot afford housing.

Housing services provided to all groups. 
Nearly 43 percent of the HPs indicated "senior citizens" as their main clientele. About 30 percent indicated they serve the homeless. A smaller percentage (21 percent and 14 percent) indicated that they serve the veterans and victims of domestic violence respectively. These responses suggest that income is the principal factor for these HPs to provide housing services.

\section{Figure 6.3: Services Provided to Specific Groups}

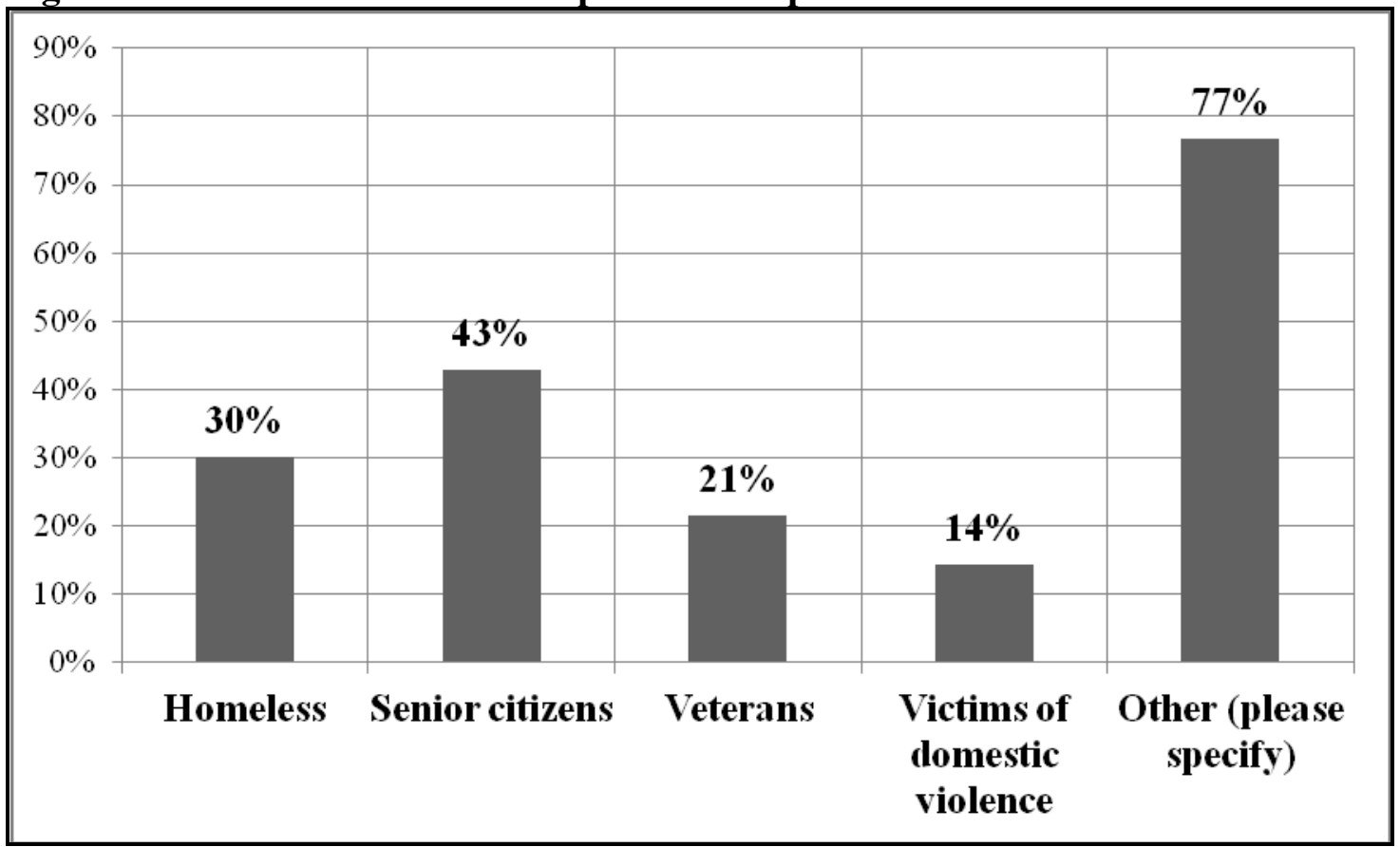

Note: The categories do not add up to 100 percent since they are not mutually exclusive.

\subsection{Customer Feedback}

The last two questions in the survey were related to obtaining customer feedback. Responses to these questions indicate the extent to which the Housing Partnerships serve their customers. The first feedback question was: Which of the following customer feedback mechanisms do you use in program planning and evaluation? The answer choices were: annual meetings with customers, periodic visioning meetings with 
customers, customer input in strategic planning, input through suggestions/ complaints box, and "other." Respondents could choose more than one category, so that the choices were not mutually exclusive.

The responses to this question suggest that usually Housing Partnerships have a mechanism that enables them to know if their customers are satisfied with services and if there are needs in the community that it can assist through the development and delivery of programs and services. About eighty percent of survey respondents indicated that a customer feedback mechanism was used by their Housing Partnership. The responses indicate that several Housing Partnerships consider direct customer input important. About thirty-seven percent of respondents indicated that their Housing Partnership met annually with customers; nineteen percent of respondents indicated that they hold periodic visioning meetings with customers (Figure 6.4). About thirty percent of the respondents indicated that they obtained customer input in strategic planning; the same share of respondents indicated that they used input through suggestions/ complaints box. About forty-four percent of respondents indicated that other forms of customer input were used. Closer examination of the "other" category reveals that Housing Partnerships obtained customer feedback through quarterly community meetings, by having customers on committees, or having community and low-income representation on the board. Some used satisfaction survey questionnaires and focus groups to gather client input. 


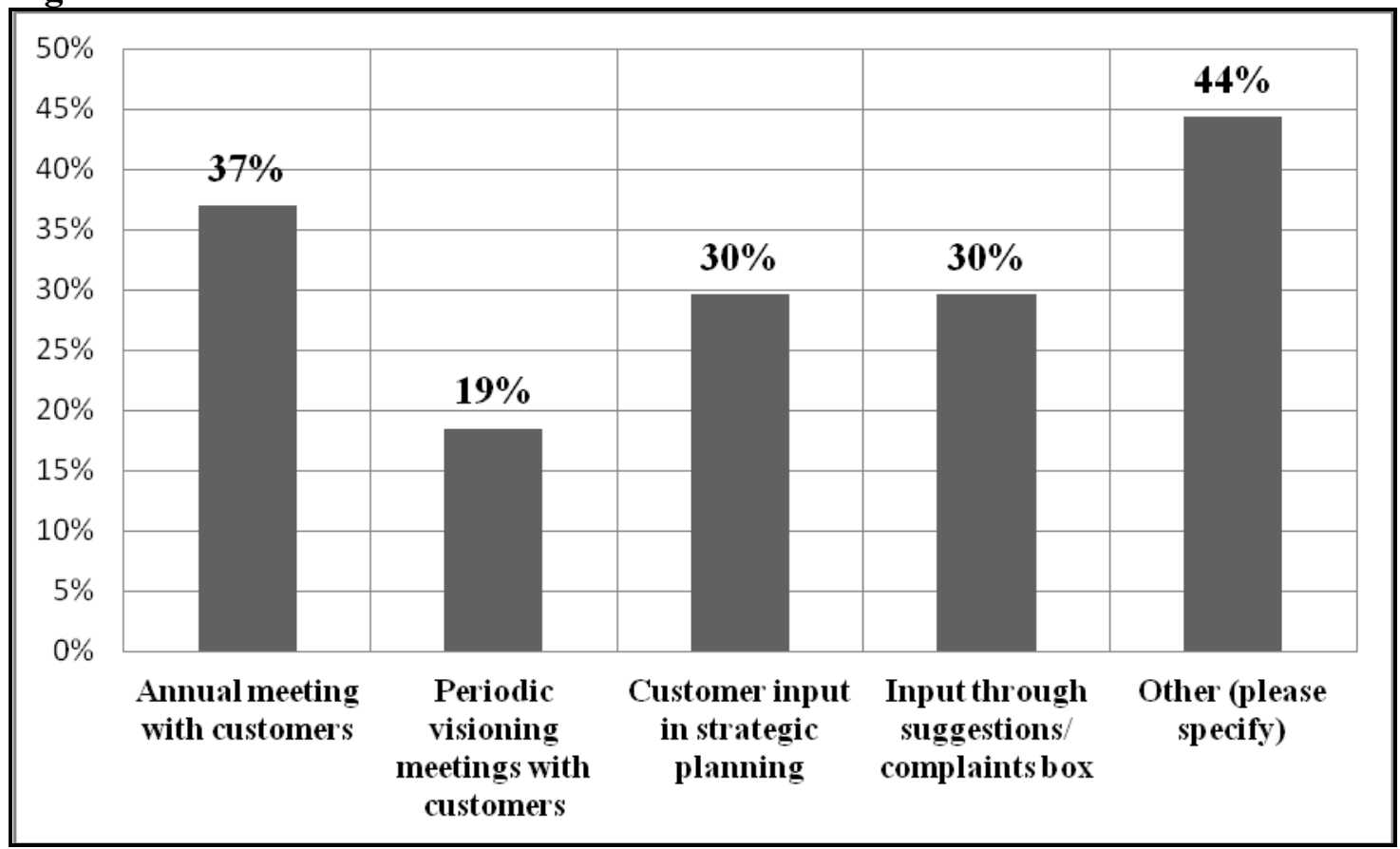

Note: The categories do not add up to 100 percent since they are not mutually exclusive.

The last question in the customer perspective question for the feedback

mechanism was open-ended: Please give three major feedback comments received from customers in 2009. Respondents could give upto three major answers. Although the responses provided were quite varied, they could be aligned into three groups. The three resulting feedback groups were: (1) Positive feedback on programs and services provided, (2) Negative feedback or feedback dealing with issues affecting positive HP performance, and (3) Suggestions on the types of services or assistance needed to deal with changing needs and challenging economic conditions. Table 6.1 summarizes the representative responses along these three categories. The positive feedback indicates the general appreciation of the clients about the HPs' staff and services. The negative feedback indicates the need for more communication between the HPs' staff and the 
clients. The suggestions for improvement mainly suggested the need for more staff and other resources to carry out the programs.

Table 6.1: Top Three Customer Feedback Comments

\begin{tabular}{|c|c|}
\hline Type & Comments \\
\hline $\begin{array}{l}\text { Positive } \\
\text { Feedback }\end{array}$ & $\begin{array}{l}\text { "Excellent Information made me more at ease with my problems because I } \\
\text { had nowhere else to turn and I was scared" } \\
\text { "Much needed services provided and knowledgeable" } \\
\text { "Staff is approachable and the supportive services offered helped because } \\
\text { they were responsive to my problems" }\end{array}$ \\
\hline $\begin{array}{l}\text { Negative } \\
\text { Feedback }\end{array}$ & $\begin{array}{l}\text { "I would like to be heard" } \\
\text { "Staff needs to work on listening skills. Communicate more effectively } \\
\text { with members" } \\
\text { "Communication needs to be improved } \\
\text { Communicate more effectively with legislators }\end{array}$ \\
\hline Suggestions & $\begin{array}{l}\text { "Not sufficient staffing and the funding of the foreclosure program should } \\
\text { increase" } \\
\text { "More staff and training needed to attend clients in need of services who } \\
\text { have never sought any service in the past" } \\
\text { "More funding for rehab/weatherization assistance because resources are } \\
\text { stretched thin which means less resources to go around" }\end{array}$ \\
\hline
\end{tabular}

\subsection{Cross-Tabulation Analysis}

The cross-tabulation analysis gives the measures of association such as Gamma and two-way table's row/column percentages. The cross-tabulation is provided between 
the responses in the "overview" section of the survey and the responses in the "customer perspective" section. Overall, the cross-tabulation analyses indicate that increases in the number of households assisted from 2007 to 2009 are associated with the type of mission, the type of functions/activities, and income of customers of Housing Partnerships.

The change in the number of households assisted from 2007 to 2009 is significantly (0.008) associated with the mission. According to measures of association, the relationship among these variables is positive in direction and moderate $(0.383)$ in strength, indicating that as mission statements are more detailed indicating the provision of affordable housing delivery for a particular income bracket and location, the number of households increase.

The change in the number of households assisted from 2007 to 2009 is significantly (.010) associated with HP programs and services (Table 6.2). Measures of association illustrate a relationship among these variables as positive in direction and moderate in strength $(0.350)$, suggesting that as the number of households receiving assistance increases, HPs offer more programs and services. The relationship between the change in the number of households assisted and moderate income customers is significant (0.037), and measures of associations show a weak but positive relationship among variables $(0.158)$. Results suggest that increases in the numbers of households receiving assistance are related to HPs assisting higher percentages of moderate income customers when compared to the other income brackets. However, the association is weak, meaning that other income brackets also increased in number and that changes in household assistance is not or little associated with income characteristics. 
Table 6.2: Cross-tabulations of Change in the Number of Households

Variable Association

Change in the number of households

assisted from 2007 to 2009 by HP

mission

Change in the number of households

assisted from 2007 to 2009 by HP

function

Change in the number of households

assisted from 2007 to 2009 by

household income bracket

(moderate)

\section{Pearson Chi-squared Test Gamma N}

(P Value)

$\begin{array}{lll}0.008 & 0.383 & 51\end{array}$

0.010

0.350

51

0.037

0.158

51

Nearly all HPs indicate the use of customer feedback mechanisms in program planning and evaluation. The relationship between very-low-income bracket and customer feedback mechanisms is significant (0.029) and measures of association highlight the association as positive in direction, meaning that organizations reporting high percentages in the use of customer feedback mechanism in program planning and evaluation are likely to provide most of their services and programs to very-low-income households (Table 6.3). The relationship is positive in direction and strong in strength (0.537), suggesting that clients' income brackets influence the use of customer feedback mechanisms in program planning and evaluation.

Table 6.3: Household Income Bracket Cross-tabulations

\begin{tabular}{lccc}
\hline Variable Association & $\begin{array}{l}\text { Pearson Chi-squared Test } \\
\text { (P Value) }\end{array}$ & Gamma & N \\
\hline $\begin{array}{l}\text { Household income bracket } \\
\text { very low) by customer }\end{array}$ & 0.029 & .537 & 53 \\
feedback mechanism & & & \\
\hline
\end{tabular}


According to survey follow-up information, changing affordable housing needs, results in increasing numbers of households requesting and receiving assistance. Housing Partnerships reported increased participation in counseling, education, and financial services. Awareness of community changes and challenges assisted HPs to revise how to best accomplish their mission and usefulness in communities. Programs and services were created, expanded or discontinued on the basis of community needs.

Housing Partnerships programs and services were developed to assist the affordable housing needs of very-low-income (households with income less than 30 percent of AMI), low-income (households with income between 30 percent and 50 percent of AMI) and moderate-income households (households with income between 51 percent and 80 percent of AMI) as per U.S. Department of Housing and Urban Development guidelines. Housing Partnerships provide services and programs to assist households and individuals from particular income brackets rather than specific groups. Originally, programs and services were aimed at assisting very-low to low-income households. However, in the last few years HPs have experienced an increase of moderate-income households and working families asking for services. Survey respondents consider the current economic downturn and the growth of housing affordability issues as the main factors contributing for the increases. Mr. Bill Lazar, CEO, Saint John's Housing Partnership stated regarding this increase "Most of our work is based in verifying income of applicants for services. We have begun working in neighborhoods and with families that in the past were over-income for 120 percent of the area median income." 
Ms. Cathy Brudnicki, Executive Director of Ventura County Homeless and Housing Coalition (VCHHC), explained that her organization also experienced an increase in moderate to medium-income households requesting services. She referred to them as "new" type of clients in need of housing-related assistance. She described her agency's experience and that of other HPs and other affordable housing services providers in the state of California regarding changing needs and the increase in the number of households that requested assistance. According to Ms. Brudnicki, "new" clients come to the service providers as a result of the continued economic downturn. She explained that the unemployment rate in the state of California is in the double digits. The U.S. Bureau of Labor Statistics listed the unemployment rate for the state of California in November 2010 at 12.4 percent. Her worry was that as of the end of November many people would have lost the extended 99 weeks of unemployment benefits. This would increase the "new" type of clients in her Housing Partnership:

The maximum rate for California unemployment benefits is $\$ 450$ per week or $\$ 1800$ per month. The average local rents are $\$ 1200$ 1400 for an affordable apartment. Unemployment benefits cover the rent and services such as electricity. So people who were able to retain their housing with unemployment benefits are now in danger of losing it.

Housing Partnerships across the country reported similar concerns to those voiced by the HP in California. The national unemployment rate as of November 2010 was 9.6 percent. Unemployment rates ranged from the low of 3.7 percent in North Dakota to the high of 13 percent in Michigan. Communication with customers ensures that there is 
interaction between the HP and the community it serves. The community needs to feel that the HP listens. One way in which some HPs accomplish this is by giving community member ways such as, membership in committees or the board, in which they are able to provide input. It is important for communities to feel that the HP is approachable and receptive to their needs because through community interaction their support is gained. If community members feel HP services and programs are effective and of quality then they will be more likely to use them. Although community members are not the primary funding agents of HPs, they influence funding allocations towards the organization they feel will provide program and services addressing their needs.

\subsection{Conclusion}

This chapter presented the customer perspective as it affects HP performance. The customer perspective in this study through survey responses explored the characteristics of HP clients. Furthermore, this chapter investigated client engagement and needs assessment. Survey results show that HP clientele consists of mostly very-low, low, and moderate-income households. Follow-up information indicates that HPs have experienced increases in request for housing related assistance from moderate to middle income households, suggesting that programs and services will adjust to fit the needs of moderate to middle income housing related needs. Survey data analysis revealed that besides the relationship between clients' income brackets and program development, clients' income brackets also influence the use of customer feedback mechanisms in program planning and evaluation. 
The responses varied, yet for most HPs, the number of households seeking and receiving assistance increased from the previous years. Data analysis indicates that as the number of households receiving assistance increases, HPs offer more programs and services. As highlighted by survey responses, HPs adopted, expanded, or discontinued some programs and services in order to fulfill new clients' needs. Survey follow-up responses suggest that HPs develop and implement programs and services that assist the housing needs of communities in order to be useful and successful to client. A successful HP is one that effectively responds to a community's changing housing issues and the changing needs of its population. The identification of client needs enables HPs to develop programs and services that further the mission of affordable housing delivery. Finally, communication with customers ensures that there is interaction between the HP and the community it serves. The survey responses highlighted the importance to Housing Partnership performance when customers feel that the HP is listening to their concerns. 


\section{INTERNAL-BUSINESS PERSPECTIVE}

\subsection{Introduction}

The internal business perspective is significant in terms of the programs and processes undertaken to achieve the HPs' missions. In the Balanced Scorecard, the measures from this perspective summarize the extent to which the organization's strategy, implementation, and execution contribute to improvements in programs and internal procedures. These measures examine if the internal processes in place assist the achievement of the organizational mission (Kaplan and Norton, 1996). Niven (2003) argues that in public and nonprofit sectors the internal/business perspective deals with the key internal processes that lead to improved outcomes for customers. These outcomes allow organizations to achieve their mission.

This chapter focuses on the internal-business perspective in terms of Housing Partnerships' (HPs) program and service development and provision. My examination highlights the need for HPs to have programs and services that address the changing needs of the populations served. The development and provision of programs and services affects HP successful performance because these impact the support and trust from clients, stakeholders, the public sector, and the private sector. The main question for HPs in this perspective is: What are the programmatic activities of Housing Partnerships? The hypothesis is that Housing Partnerships undertake programmatic activities that contribute toward increasing affordable housing options. 


\subsection{Housing Partnership Programs: Overall Success Factors}

Housing Partnerships in general provide a mix of affordable housing services. By having a mix of programs and services, HPs establish the use of a comprehensive approach to deal with affordable housing delivery. The following quote from Tom Merkel, the CEO of the Impact Group, explains the importance of the comprehensive approach:

We have changed as our needs change. We feel that it is very important to have a mix of programs to meet the needs, but we have no problem discontinuing a program when there is no longer a need or another organization takes it on, as long as that other organization is doing a good job.

Comprehensive approaches provide program flexibility to support changing needs and provide long-term assistance to affordable housing needs because one type of service alone in most cases is not sufficient for households to obtain permanent housing. A household or a community might be given monetary assistance to either pay for a down payment on a house or to build units. Financial assistance is sometimes necessary, for instance the money for a down payment on a house to enable a family to purchase a home. However, once financial assistance is received for the down-payment for a house, a household could need advice on how to keep that home and counseling and/or technical assistance to deal with challenges that are unforeseen. Comprehensive approaches are used by HPs to address affordable housing issues permanently. If a client or household is given funds to pay for a down-payment without education or follow-up assistance, that 
client could suffer financially in the long run if s/he did not know how to handle homeownership issues.

Housing Partnerships develop new partnerships and undertake new ventures as ways to adapt to changing environments. For example, additional partners could provide experience and funding, allowing the development of programs and activities aimed at new customer services. In order to obtain new partners or to retain current ones, community members and other agencies must consider the HP to be reliable with staff that is knowledgeable and receptive to clients' needs and concerns, and that offers programs and services that are useful. Follow-up interviews with some of the HP representatives show that new or higher resource allocation is obtained by building a reputation of an organization that is professional, competent, with the ability to execute its commitments. Housing Partnerships attempt to effectively implement their programs through comprehensive approaches to affordable housing, including activities such as education, counseling, advocacy, construction, and rehabilitation of units.

Programs need to be flexible and adapt to changing times. Local and community changes and resulting needs dictate program participation, involvement and funding. For example, HPs spent very little on construction programs in 2009 because of the economic crisis. As Carol Dougherty, CEO of Partnerships in Housing, Inc. indicated, “... because of the economic crisis, housing development was delayed." Some HPs changed their tactics since the local communities indicated the need for rental units. The majority of the HPs (63 percent) reported increase in the affordable housing rental program from 2007 to 2009 and 59 percent of HPs undertaking this activity in 2009 reported high (81 percent to 100 percent) program achievement percentages. Interviews with HP representatives also 
suggest that the rental program became the main activity from 2007 to 2009 for HPs to meet their mission and address community needs. Related activities such as credit counseling also increased during this period.

A final aspect of successful partnerships is the relationship between the partners. Wylde, (1986) and Suchman et al. (1990) show that the successful relationship between partners requires shared values, trust, clear communication, and mutually productive relationships. A successful partnership begins with shared values and a common goal. In the case of HPs, partners need to share the same vision for the community. In order for partners to be compatible it is important that all partners share the philosophy, values and overall goals. The success of Housing Partnerships occurs when collaborative efforts produce the maximization of knowledge and resources to solve affordable housing problems in a community (HUD, 1999). Trust is important to HPs because it allows partners to rely on each other. They have to trust each other to contribute, for example, through funds or expertise to the mission of the Housing Partnership. In addition, the building and maintenance of strong, long-term relationships requires trust (Nichols and Spencer, 2011). Lastly, communication regarding each partner's role, expectations, and the anticipated outcomes must be clear, concise, and accessible.

\subsection{Housing Partnerships' Internal Process and Program Characteristics}

The programs and services provided by HPs are associated with their main mission, of affordable housing delivery. Various programs and services assist with the delivery of affordable housing such as construction and social services. Increases in activities and program implementation are dictated by local factors, such as the economy, 
support, and community members' demographics. Moira Carlstedt, CEO of Indianapolis Neighborhood Housing Partnership Inc., summed up the relationship between the mission and the programmatic activities of HPs succinctly: "Programs that do not directly further the mission and strategic plan will likely reduce the ability to accomplish the goals and have the intended impact."

Four questions in the internal business perspective section of the survey are central to the internal business processes and programs of Housing Partnerships. The first question in this section of the survey asked: How do you obtain your customers? This question was developed to examine the different ways in which Housing Partnerships obtain customers. The choices included: through radio advertisements, through newspaper advertisements, by word of mouth, referral from another agency, and "other." Respondents could select more than one category, so that the choices are not mutually exclusive. Figure 7.1 summarizes the responses to this question. As the figure shows, about eighty percent of the respondents indicated "word of mouth" and "referral from other agencies" as the common ways of obtaining customers. A smaller percentage (eighteen percent) obtained customers through newspaper advertisements; an even smaller percentage relied on radio advertisements. About one-third depended on "other" means of recruiting clients; such means included newsletters, public forums, and internet advertising. 


\section{Figure 7.1: Customer Recruitment}

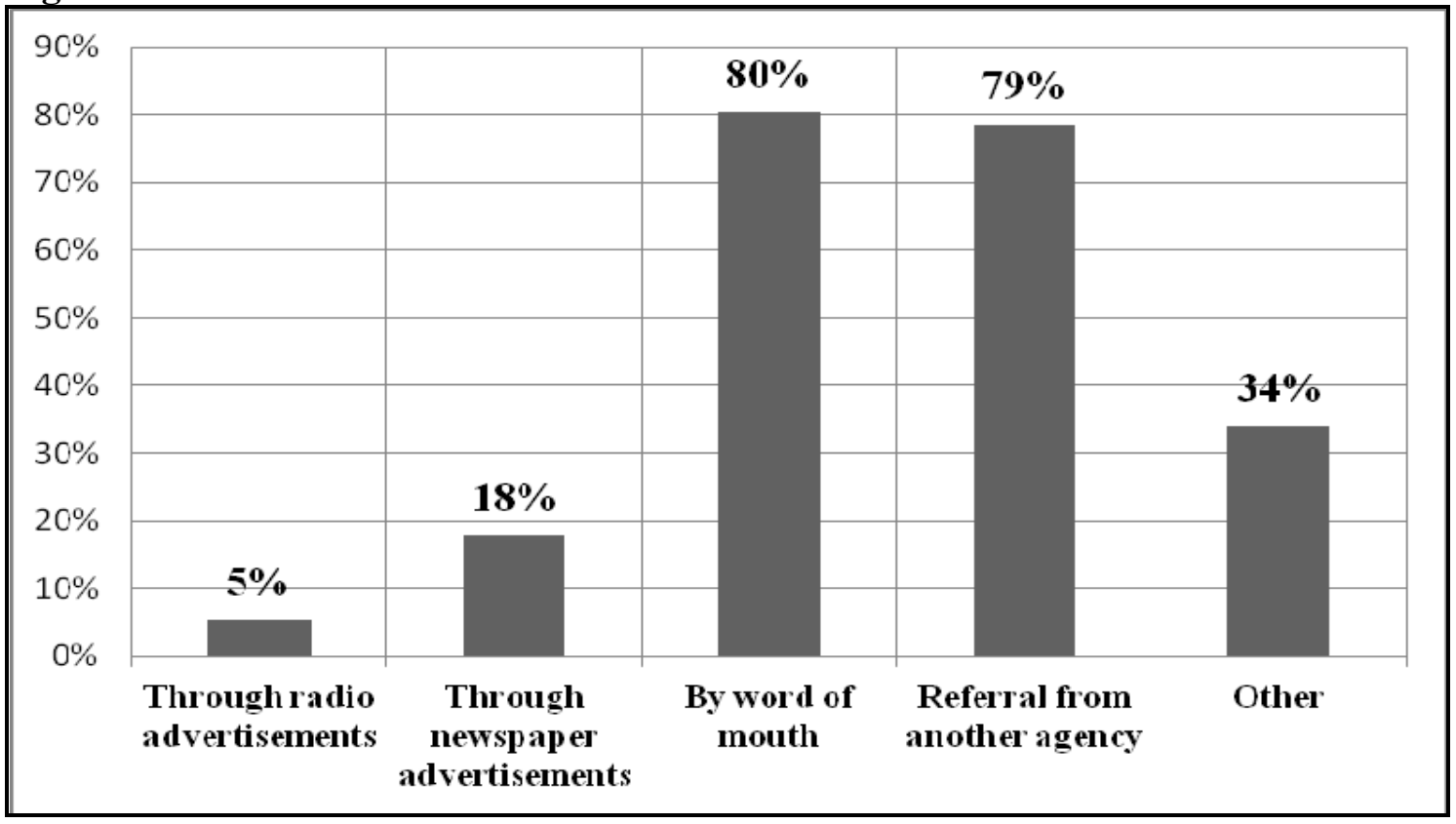

The next question in the survey is central to the programs carried out by the HPs:

If the Housing Partnership has carried out any of the following programs, please give the percentage of the program's target achieved in 2009. The answer choices included the following programs: affordable housing construction; rental housing construction/ management; housing rehabilitation; providing loans to customers; credit counseling to customers; technical assistance to customers; and "other." The target choices were 0-20 percent, 21 to 40 percent, 41 to 60 percent, 61 to 80 percent, and 81 to 100 percent. The programs undertaken and the targets achieved in 2009 are summarized in Table 7.1. As the table shows, a large percentage ranging from 34 percent to 72 percent indicated that they did not carry out the specific programs listed. A large majority (nearly 90 percent) indicated that they carried out "other" programs; such activities included advocacy and legislative work, credit counseling, technical assistance, supportive services (such as case management), education activities (such as first time homebuyer education), other types 
of counseling (such as foreclosure assistance), and community planning. Nearly 74 percent of such HPs had also achieved their target on the high end. The range of activities is interesting, and it indicates that the HPs had adjusted their programs to the specific needs of the housing crisis.

Table 7.1: Programs Implemented and their Achievement in 2009

\begin{tabular}{|l|c|c|c|c|c|c|}
\hline Answer Options & $0-20 \%$ & $\begin{array}{l}21 \%- \\
40 \%\end{array}$ & $\begin{array}{l}41 \%- \\
60 \%\end{array}$ & $\begin{array}{l}61 \%- \\
80 \%\end{array}$ & $\begin{array}{l}81 \%- \\
100 \%\end{array}$ & $\begin{array}{l}\text { Not } \\
\text { undertaken }\end{array}$ \\
\hline $\begin{array}{l}\text { Affordable housing } \\
\text { construction }\end{array}$ & $23.40 \%$ & $2.10 \%$ & $2.10 \%$ & $6.40 \%$ & $21.30 \%$ & $44.70 \%$ \\
\hline $\begin{array}{l}\text { Rental housing } \\
\text { construction/ } \\
\text { management }\end{array}$ & $4.50 \%$ & $2.30 \%$ & $2.30 \%$ & $11.40 \%$ & $34.10 \%$ & $45.50 \%$ \\
\hline $\begin{array}{l}\text { Housing } \\
\text { rehabilitation }\end{array}$ & $9.10 \%$ & $4.50 \%$ & $0.00 \%$ & $9.10 \%$ & $22.70 \%$ & $54.50 \%$ \\
\hline $\begin{array}{l}\text { Providing loans to } \\
\text { customers }\end{array}$ & $9.50 \%$ & $4.80 \%$ & $0.00 \%$ & $4.80 \%$ & $9.50 \%$ & $71.40 \%$ \\
\hline $\begin{array}{l}\text { Credit counseling to } \\
\text { customers }\end{array}$ & $4.30 \%$ & $6.50 \%$ & $0.00 \%$ & $2.20 \%$ & $30.40 \%$ & $56.50 \%$ \\
\hline $\begin{array}{l}\text { Technical assistance } \\
\text { to customers }\end{array}$ & $10.60 \%$ & $10.60 \%$ & $2.10 \%$ & $10.60 \%$ & $31.90 \%$ & $34.00 \%$ \\
\hline Other & $7.70 \%$ & $3.80 \%$ & $3.80 \%$ & $11.50 \%$ & $61.50 \%$ & $11.50 \%$ \\
\hline
\end{tabular}

Affordable housing construction was taken up by 55 percent of the respondents; the share of HPs achieving their targets is a reverse bellshape across the spectrum of low to the high end of target achievement. Rental housing construction/ management was also undertaken by 55 percent of the respondents, but more of such HPs ( 45 percent) were at the higher end of the spectrum of target achievement. Housing rehabilitation was undertaken by 45 percent of the respondents, and 31 percent of such HPs indicated high degree of target achievement. Providing loans was not a major activity for most HPs; only 30 percent indicated implementing such a program. The target achievement for the loan provision is low. Credit counseling was carried out by 44 percent of the respondents, 
and 32 percent of these respondents indicated a high degree of achievement of their target. Technical assistance to customers is given by nearly 66 percent of the respondents, and 43 percent indicated a high degree of achievement of their targets. Overall, the programs show that the HPs are quite diverse in terms of their activities.

The next major question with respect to the programs in the survey was: If the Housing Partnership is three years or older, how did the size of above programs change from 2007 to 2009? The answer choices were on a ten point scale, ranging from "Decreased by seventy-six percent to one hundred percent" to "Increased by more than one hundred percent", in twenty-five percent intervals. The results are summarized in Table 7.2. Almost fifty percent of respondents indicated that they did not undertake affordable housing construction from two thousand-seven to two thousand-nine. Housing Partnerships not undertaking affordable housing construction in 2009 usually reported decreasing program size between these three years. Almost half (forty-seven percent) of HPs that undertook affordable housing construction reported fifty-one percent to onehundred percent decrease in size of the program. The responses provided for other programs when taken as a whole indicate that the need for affordable housing delivery increased from two thousand-seven to two thousand-nine. Both the need for affordable housing units and related services increased. Unit development and provision programs such as rental housing construction/management and housing rehabilitation programs increased in size. Social service, education, and counseling programs increased in size. In general, Housing Partnerships do not undertake lending to clients. However, the size of the loan provision activity increased from two thousand- seven to two thousand-nine. Programs that provide supportive services such as credit counseling and technical 
assistance also increased. The responses provided for "other" programs also establish an increase in these activities. Housing Partnerships that indicated "other" program increases were contacted to elaborate on this response. Although responses varied, this increase is mostly associated with an increase of programs offered. Increases in foreclosures and the impact of other financial issues resulted in an expansion of programs in financial-related counseling and education. Also, new programs and services were established such as foreclosure education courses and counseling assistance.

The last question in the internal business perspective section was: Did the Housing Partnership implement any of the following internal management systems between 2007 and 2009? The answer choices were: online application, enterprise resource planning (ERP) systems, outcomes/results measurement, changed internal application tracking systems, organizational assessment, reduced customer paperwork requirements, changed accounting systems, customer satisfaction survey, and "other." About eighty-seven percent of respondents indicated implementing at least one internal management system from two thousand-seven to two thousand-nine. 
Table 7.2: Change in Program Size, 2007 to 2009

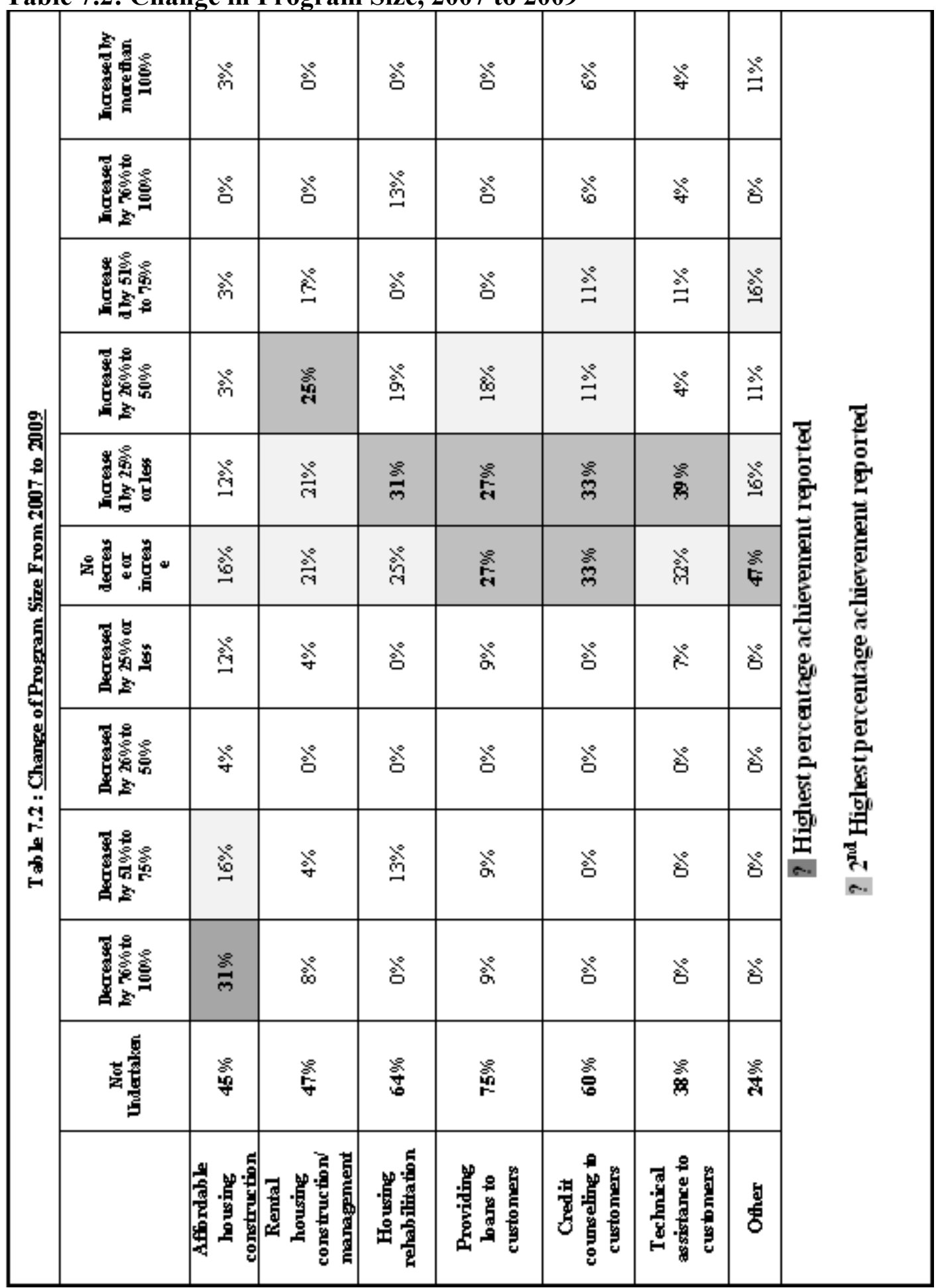

Among the options for internal management, organizational assessments emerged as the primary form of internal management systems, used by nearly 40 percent of the 
responding HPs (Figure 7.2). Outcomes/ results measurements comes a close second at 37 percent. Customer satisfaction surveys, changed accounting systems, and online applications were in the 25 percent to 29 percent range. Interestingly, none of the respondents indicated implementation of Enterprise Resource Planning (ERP) systems, which is widely used by other organizations to increase performance and to maximize resources.

\section{Figure 7.2: Types of Internal Management Systems}

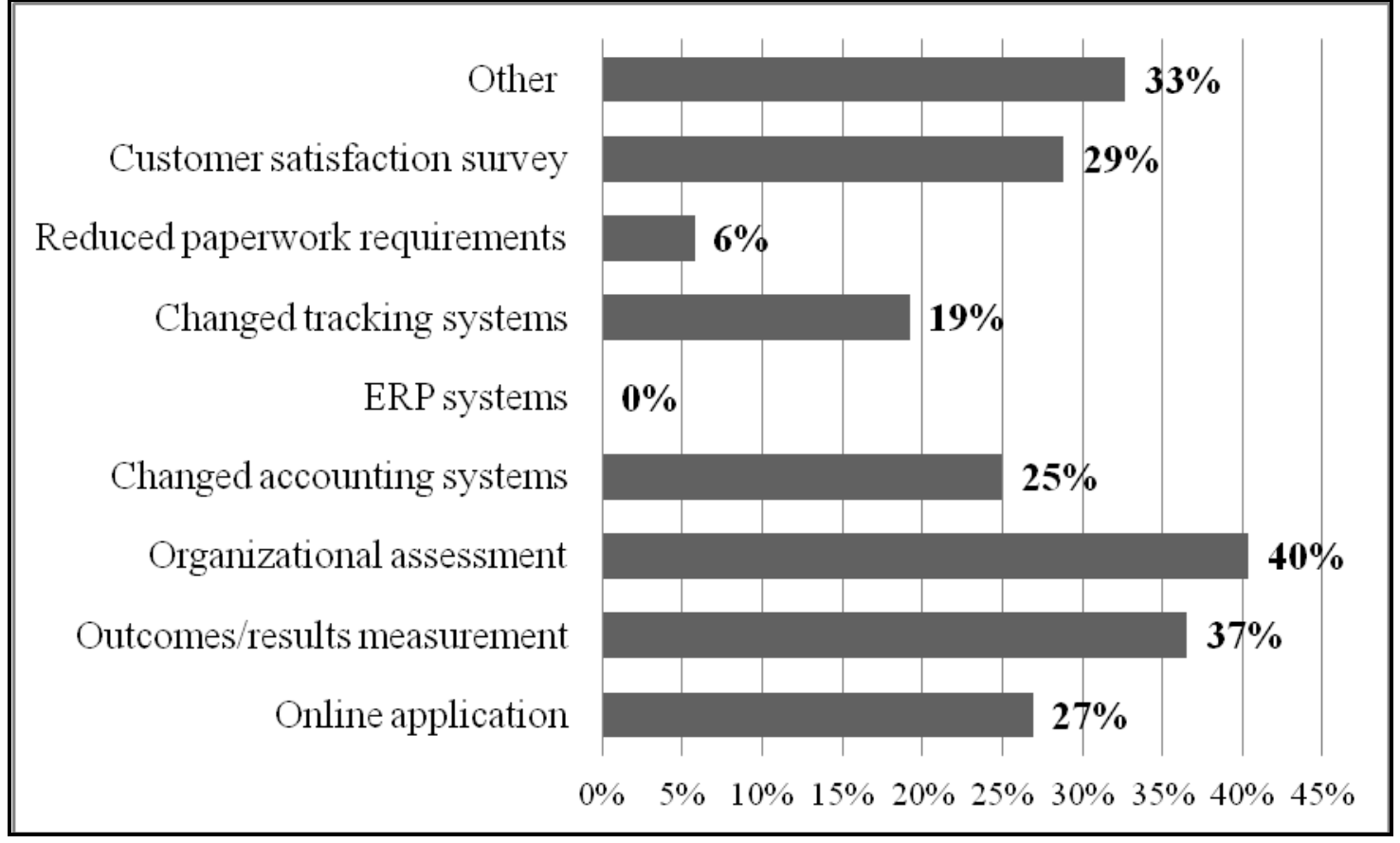

Follow-up inquiries highlighted the link between successful performance and the implementation of management systems and technology. Tom Merkel, CEO, of The Impact! Group stated, "I think that financial systems and management systems are crucial in maintaining accountability and successful performance. Since they help so much, funding to purchase and maintain appropriate systems is needed.” Similarly, another CEO of long standing with another HP stated, "Something to guarantee "success" is the 
capacity/ability of HPs to track performance.” Management systems and technology allow HPs to track changes inside the organization as well as in the community. The implementation of new systems involves the development of skills and knowledge.

Tracking performance allows organizations to establish whether the strategies in place are aligned with short and long-term objectives (Kaplan and Norton, 1996). Research indicates that many nonprofit organizations are aware of the concepts of strategy and performance tracking (Rivenbark and Venter, 2006). Research has further concluded that several nonprofits have been committed to the performance accountability of service delivery, so it is not their willingness, but their lack of organizational capacity, that impedes these organizations to track service performance (Fredericksen and London, 2000).

Survey responses as well as literature suggest that HPs should track their performance so that their short and long-term goals are achieved. The answers and follow-up explanations provided for this section of the survey indicate that, as a part of the operations or internal function of HPs, an investment in time and technology must be seriously considered and implemented to track performance. If such tracking takes place, then a process or activity can be examined so that it can be improved or changed. The literature highlights a capacity issue in nonprofits. The inability to track performance could be changed by training staff to track various aspects of performance, such as financial, program, and services related performance. 


\subsection{Cross-Tabulation Analysis}

Similar to the previous perspectives, I undertook cross-tabulation analyses between the organizational mission and funding with the internal/business perspective responses. First, I analyzed the relationship between affiliate organizations with the programs carried out by the Housing Partnerships. The measures of association show a moderate to strong and inverse relationship (-0.481) between public affiliates and credit counseling, which indicates that the percentage achievement of the credit counseling decreases as the number of public affiliates increases (Table 7.3). "Other" programs, such as education and advocacy are strongly associated (-0.541) with public affiliates, the relationship is negative, suggesting that program achievement percentages decrease as the numbers of public affiliates increase. The number of nonprofit affiliates and the percentages of target achievement for the construction (.044) and the technical (.034) programs are significantly associated. The gamma values show that the relationship between the achievement of the construction program and nonprofit affiliates is strong and positive (0.600), implying that target percentages for construction increase as the number of nonprofit affiliates increase. The association between technical achievement and nonprofit affiliates is moderate/strong-negative (-0.460), implying that technical programs' target achievement decrease as HPs increase the numbers of nonprofit affiliate organizations. The relationships suggest that the representation of HPs' affiliates influence program target achievement percentages. 
Table 7.3: Program Target Achievement Cross-tabulations

\begin{tabular}{lccc}
\hline Variable Association & $\begin{array}{l}\text { Pearson Chi-squared Test } \\
\text { (P Value) }\end{array}$ & Gamma & N \\
\hline $\begin{array}{l}\text { Percentage of target (credit) } \\
\text { achievement for programs by affiliates } \\
\text { (public) }\end{array}$ & 0.024 & -0.481 & 60 \\
$\begin{array}{l}\text { Percentage of target (other) } \\
\text { achievement for programs by affiliates } \\
\text { (public) }\end{array}$ & 0.037 & -0.541 & 60 \\
$\begin{array}{l}\text { Percentage of target (construct) } \\
\text { achievement for programs by affiliates } \\
\text { (nonprofit) }\end{array}$ & 0.044 & & \\
$\begin{array}{l}\text { Percentage of target (technical) } \\
\text { achievement for programs by affiliates } \\
\text { (nonprofit) }\end{array}$ & & 0.600 & 60 \\
\hline
\end{tabular}

The mission of HPs is significantly associated with the percentages of target achievement for the rental provision (0.008) and credit counseling (0.049) programs (Table 7.4). Although, significantly associated, the relationship for the mission and credit counseling program target achievement is weak $(-0.028)$, which indicates that little to no association exists between the organization's mission and the target achievements of programs such as construction and credit counseling. The mission and rental target achievements show a weak to moderate positive (0.278) relationship, in that high percentages (81 percent to 100 percent) of target achievement for the rental program are found in HPs with clear and specific mission statements that include affordable housing assistance for specific locations and income groups. 
Table 7.4: Mission and the Percentage of Program Target Achievement

\begin{tabular}{lccc}
\hline Variable Association & $\begin{array}{l}\text { Pearson Chi-squared } \\
\text { Test (P Value) }\end{array}$ & Gamma & $\mathbf{N}$ \\
\hline $\begin{array}{l}\text { Percentage of target (rental) achievement } \\
\text { for programs by Mission }\end{array}$ & 0.008 & 0.278 & 60 \\
$\begin{array}{l}\text { Percentage of target (credit) achievement } \\
\text { for programs by Mission }\end{array}$ & 0.049 & -0.028 & 60 \\
\hline
\end{tabular}

The cross-tabulation analysis shows significant association between the change in size of programs from 2007 to 2009 with the HPs' mission (0.045) and functions (0.003) (Table 7.5). The relationship between mission and changes in the rental program is strong (0.706) and positive in direction, implying that HPs with high percentages of mission achievements were likely to experience increases in size of the rental program. The association between functions and changes in "other" programs is moderate $(0.319)$ in strength and positive in direction, suggesting that HPs with comprehensive approaches experienced from 2007 to 2009 increases in size for "other" programs such as, education and advocacy.

Table 7.5: Cross-tabulations of Change in Size of Programs

\begin{tabular}{lccc}
\hline Variable Association & $\begin{array}{l}\text { Pearson Chi-squared } \\
\text { Test (P Value) }\end{array}$ & Gamma & N \\
\hline $\begin{array}{l}\text { Change in size of programs (rental) by } \\
\text { Mission }\end{array}$ & 0.045 & 0.706 & 51 \\
$\begin{array}{l}\text { Change in size of programs (other) by } \\
\text { Function }\end{array}$ & 0.003 & 0.319 & 51 \\
\hline
\end{tabular}

Correlation analysis between changes in the size of programs from 2007 to 2009 and program target achievement in 2009 shows that construction program size change is significantly associated with target achievement for the construction (0.035), rental (0.042), rehabilitation (0.008), and “other" (0.024) assistance programs. In addition, 
changes in the loan program are significantly associated with its target achievement in two thousand-nine (0.013). Changes in construction from 2007 to 2009 and its target achievement for 2009 (0.452) have a moderate positive association, which means that HPs experiencing increases in the size of construction activities are likely to report high percentage target achievements for the program (Table 7.6). The relation between changes in the size of the construction program and the target achievement for the rental program is significant $(0.042)$, but moderate $(-0.483)$ and negative in direction. That is, HPs reporting increases in the size of construction are likely to report low percentages of achievement for the rental program. The target achievements for rehabilitation $(-0.675)$ and that of "other" $(-0.820)$ programs show strong negative associations with the change in construction activities. Decrease in construction activities occurred most likely in HPs with high target achievements for housing rehabilitation and "other" programs. Increases in the loan program are strongly associated with increases in the target achievement for the loan program. 


\begin{tabular}{|c|c|c|c|c|c|c|c|c|c|}
\hline & & & 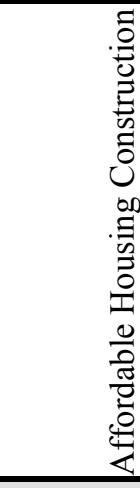 & 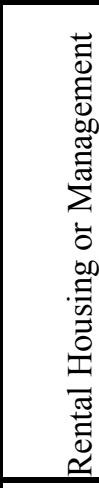 & 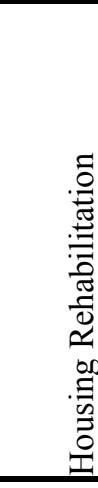 & 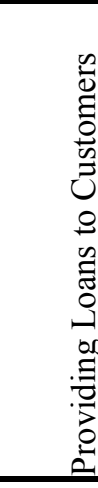 & $\begin{array}{c}0 \\
0 \\
0 \\
0 \\
0 \\
0 \\
0 \\
0 \\
0 \\
00 \\
: \Xi \\
0 \\
0 \\
\vdots \\
0 \\
: \\
: 0 \\
0 \\
0 \\
0\end{array}$ & 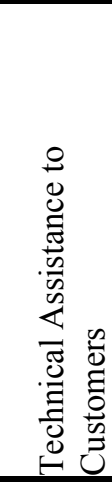 & $\begin{array}{l}\bar{\Xi} \\
\overline{0} \\
\end{array}$ \\
\hline \multirow{7}{*}{ 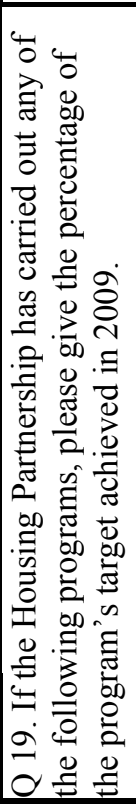 } & $\begin{array}{l}\text { Affordable Housing } \\
\text { Construction '09 target }\end{array}$ & $\begin{array}{l}\text { Sig. (2- } \\
\text { tailed) }\end{array}$ & $\begin{array}{l}0.035 \\
0.452 \\
\end{array}$ & 0.442 & 0.463 & 0.878 & 0.261 & 0.454 & 0.640 \\
\hline & $\begin{array}{l}\text { Rental Housing } \\
\text { Construction or Mgmt } \\
09 \text { target }\end{array}$ & $\begin{array}{l}\text { Sig. (2- } \\
\text { tailed) }\end{array}$ & $\begin{array}{r}0.042 \\
-0.483 \\
\end{array}$ & 0.943 & 0.133 & 0.721 & 0.326 & 0.187 & 0.312 \\
\hline & $\begin{array}{l}\text { Housing Rehabilitation } \\
\text { '09 target }\end{array}$ & $\begin{array}{l}\text { Sig. (2- } \\
\text { tailed) }\end{array}$ & $\begin{array}{r}0.008 \\
-0.675 \\
\end{array}$ & 0.564 & 0.100 & 0.334 & 0.758 & 0.132 & 0.184 \\
\hline & $\begin{array}{l}\text { Providing Loans to } \\
\text { Customers '09 target }\end{array}$ & $\begin{array}{l}\text { Sig. (2- } \\
\text { tailed) }\end{array}$ & 0.407 & 0.258 & 0.219 & $\begin{array}{l}0.013 \\
0.781 \\
\end{array}$ & 0.730 & 0.964 & 0. \\
\hline & $\begin{array}{l}\text { Credit Counseling to } \\
\text { Customers ' } 09 \text { target }\end{array}$ & $\begin{array}{l}\text { Sig. (2- } \\
\text { tailed) }\end{array}$ & 0.790 & 0.783 & 0.388 & 0.734 & 0.122 & 0.672 & 0. \\
\hline & $\begin{array}{l}\text { Technical Assistance to } \\
\text { Customers '09 target }\end{array}$ & $\begin{array}{l}\text { Sig. (2- } \\
\text { tailed) }\end{array}$ & 0.101 & 0.549 & 0.964 & 0.599 & 0.109 & 0.975 & 0.644 \\
\hline & $\begin{array}{l}\text { Other program's '09 } \\
\text { target }\end{array}$ & $\begin{array}{l}\text { Sig. (2- } \\
\text { tailed) }\end{array}$ & $\begin{array}{l}0.024 \\
-0.820\end{array}$ & 0.410 & 0.659 & 0.333 & 0.333 & 0.946 & 0.904 \\
\hline
\end{tabular}

\subsection{Conclusion}

The survey responses indicate that HPs undertake programmatic activities that contribute toward increasing affordable housing options. Most HPs have a comprehensive approach. Comprehensive approaches include programs and activities to assist affordable housing needs in a community. Besides comprehensiveness, the results of the survey, indicate that program and service flexibility are crucial to the successful performance of Housing Partnerships. As highlighted by the changes in needs of HP customers as a result of the current economic downturn, besides a mix of programs, HPs need to have the ability to change programs and services in order to survive. Customer 
needs changed in general and for many HPs there was an increase in the demand of assistance and the introduction of new customers. As a result, HPs adapted their programs and services to meet the changing environment. 


\section{LEARNING AND GROWTH PERSPECTIVE}

\subsection{Introduction}

Factors that affect the development of the staff and the capability of organizations to learn and grow are examined as part of the Learning and Growth perspective of the Balanced Scorecard Framework. This chapter examines those factors that affect development and capacities of Housing Partnerships. The examination highlights the need for Housing Partnerships (HPs) to have a system in place where staff and board members can learn and grow. Additionally, staff and the board members must be chosen for their capability, flexibility, and their dedication and enthusiasm towards the achievement of the mission. The capacities and the opportunities given to staff at all levels, as well as to the members of the board of directors will allow HPs to achieve their mission, even if challenges such as the current economic downturn arise.

Niven (2003) argues that the skills and capacities of the workforce and organizational performance are related, particularly, in the successful achievement of the mission in public and nonprofit sectors:

Operating as mission-based organizations, nonprofit and publicsector agencies rely heavily on the skills, dedication, and alignment of their staff to achieve their socially important goals...Motivated employees with the right mix of skills and tools operating in an organizational climate designated for sustaining improvements are the key ingredients in driving process 
improvements, working within financial limitations, and ultimately

driving customer and mission success.

The learning and growth perspective highlights the importance of non-financial factors in the successful performance and survival of an organization. While financial resources are necessary for an HP to be able to operate, so are the skills, motivation, and dedication of the staff. Niven's explanation suggests that since HPs are mission-driven entities, staff at all levels and the board must have or be able to develop the particular skills that allow mission achievement. In addition, staff at all levels and the board must share similar views and believe in the vision and goals of the HP in order to achieve its mission. The programs and services must be staffed with individuals who will transfer and develop knowledge and skills to clients.

The research question for this perspective explores the organizational capacities

of Housing Partnerships. The main question is: What are the organizational capacities of Housing Partnerships? The hypothesis is that successful partnerships have a committed leader, high degree of involvement of a board of directors, and a requisite skilled staff.

\subsection{Housing Partnerships' Employee Capacity Needs}

There are two key aspects of employees' capacities in Housing Partnerships. First, the employees must be well versed in housing and real estate issues. While financial expertise is a key requirement, there are several other dimensions, including the legal system, the local policies, fair housing issues, and so on. Second, as nonprofits with several organizations as members, employees must be able to navigate through the public, private and nonprofit sectors. At the same time, the sectors can bring their own 
specific strengths. For instance, private sector organizations such as banks and businesses could provide skills and knowledge in financing needed by Housing Partnerships.

The overall board composition is significant for the knowledge exchange among the sectors. Siciliano (1996) states, "Research studies have revealed associations between board member characteristics and financial measures of organizational performance.” In addition, board member representation is also related to the type of services and programs implemented, staff size, and mission target achievements. In sum, board representation is a key factor in the success of Housing Partnerships. According to Amy Klaben, CEO of Columbus Housing Partnership, "Successful Housing Partnerships have high quality staff that is educated, passionate, hard working, adequately paid and committed to the mission... In our case, our board has been helpful in recent years in addressing major issues and lending their expertise and opening doors for us."

One CEO of an HP highlighted the significance of the board thus: "Our board of directors has been helpful in recent years in addressing major issues and lending their expertise and opening doors for us.” This statement suggests that board members should be selected with the understanding that it is an entity that plays a major role for decision making. A diverse board with complementary strengths would be important for the HPs' success, with members having strengths in finance, organizational management, technology, human resources, and representative of customer base and local community. The board members should be able to interact often with each other, HP staff, and the community members. For this, board members should be able to attend regular meetings to ensure successful organizational planning and see that all resources are managed effectively. 
Learning and skill building of staff is necessary in the successful performance of any organization allowing employees at all levels to develop the knowledge necessary to assist needs. Goh (1998) argues that learning is a critical component for organizations to succeed. Learning in an organization could mean that employees are encouraged to transfer skills and knowledge throughout the organization and to learn from previous failures. As one of the BSC perspectives, learning and growth suggests that staff development mirrors organizational growth. Education should be an ongoing part of employment at the Housing Partnership. Housing Partnership employees need to be equipped with the appropriate skills to perform tasks and roles. These skills can be developed by providing them with training and support opportunities.

Staff activities that increase knowledge and education might be overlooked for other priority issues. For instance, funding issues, such as the allocation of less money from a grant, might take precedence over the introduction of a new training module. The board, leadership, and staff may devote more time, efforts and finances to issues that are considered a priority. Unlike fiscal elements, such as rent or mortgage, or where outcomes and results are seen immediately, education and skill building takes time and financial commitment. Time is required for the development of skills and knowledge and training requires costs. Therefore, some organizations do not provide learning and growth-related programs because the results and outcomes of staff development activities are not seen immediately and require funding.

The work provided by volunteers also provides valuable knowledge and skills. The Saint John's Housing Partnership (SJHP) seeks volunteers since they "are a large factor in the success of the [organization]. Volunteering brings the community closer 
together in reaching mutual goals of safe and secure housing" (http://www.sjhp.org/get involved.php). The Community Housing Partnership of Williamson County (CHP) involves volunteers for doing physical work (www.communityhousing.info/index.htm):

On an annual basis the Community Housing Partnership of Williamson County does moderate rehabilitation to over 100 homeowners in Williamson County each year. These rehabilitations include handicap ramps, plumbing and heating and air conditioning repairs, painting, light carpentry and other miscellaneous emergency repairs. These repairs are performed by over two dozen volunteer groups that perform the labor with the Community Housing Partnership of Williamson County providing the supplies necessary for the work. Current and previous volunteer groups include Dell Computer, ATMOS, the Boy Scouts of America, Tractor Supply, Journal Communications and a number of area churches.

Housing Partnerships offer volunteers a wide range of other options in which all community members can participate. The Minnesota Housing Partnership, for example, relies on volunteers and interns for research and policy support, campaign support, support for housing technical assistance, and event planning and coordination (http://www.mhponline.org/jobs/intern-volunteer). As a result of the various services offered by HPs, there are many areas (from physical labor to sedentary work) which could benefit from volunteer efforts. Depending on the function, volunteers might need 
specific capabilities such as the ability to conduct physical labor in construction and rehabilitation activities, or skills and education, such as research and policy writing.

The top leadership staff requires interpersonal skills to assist their employees, to build new or maintain existing partnerships, to build a good working relationship with the board, and to build relationships with other HP stakeholders such as governmental officials and private investors. The leadership staff must to be able to gain support for activities that assist the HP to achieve its mission by communicating to others how the HP helps to meet and assist the community's affordable housing needs and by listening to concerns. The leader must also be responsive to the needs of the HP's board, staff, and clients. In addition, the educational achievement and time in that capacity of HPs Chief Executives are associated with staff characteristics such as size and educational background.

Deaborn (2002) argues that the roles of leaders in organizations are changing. Housing Partnership CEOs also state that their organizations are becoming more service oriented and their level of assistance and communication with staff and the communities served is increasing by requiring their leadership role to change. Besides the organization, planning, and control that occurs in agencies, leadership roles must also motivate and inspire others. The increase of listening, communication, counseling, and problem solving skills allow CEOs to foster positive attitudes at work and increase productivity in stressful environments. Furthermore, increasing contact with staff and communities creates a sense of contribution and importance of themselves and the Housing Partnership. 
Housing Partnerships associate employee skill development with their successful performance. Two of the most common ways listed by HPs and organizational performance literature as ways in which staff capabilities affect performance, deal with strategic planning and adjustment to change. Kaleba (2006), Towers and Spanyi (2004), and Studer (2007) explain that strategic plans are integral to the successful management of any organization because they define the decisions and actions that will allow them to meet their mission. The programs and services of HPs are the strategies to assist the affordable housing needs of the communities served resulting in meeting the mission.

Once the needs are identified, programs and services are created as strategies to address these needs. Programs and services must then be equipped with staff. Staff at all levels (from leadership, management, to volunteers) affects the effectiveness of programs and services, thus influencing mission achievement and organizational performance. The ability of staff to adjust to change is necessary for HPs successful performance. The capacity of staff to adjust to changes increases through training and education. By building on the capabilities of staff, HPs have a workforce that is aware and able to assist clients. Building skills and training as important to performance was seen by several HPs as a result of the current economic environment. The following comments by HPs CEOs illustrate how staff development is important because of the changing needs of the population:

More people are aware of what can happen if they are not prepared to become homeowners; therefore, every component of the home ownership program is experiencing record numbers of participants. 
The corporate community is more aware of our programs and they are inviting us to communicate with their employees.

As the staff of organizations grows, which they need to do to handle the complexities of real estate development and providing services to appropriately house low-income individuals, the infrastructure of the organization must grow as well and becomes more complex. The ability of an organization to adapt as needs, organizational structure, funding, programs, services, experience change is a critical factor in its survival. The economic downturn, which presented changes in the environment, highlights flexibility and adaptability as these relate to organizational survival. Communities' needs were altered, and financial resources changed as a result, many HPs had to accommodate for these challenges. Housing Partnerships reacted to new or changing needs by adopting new strategies, forming new partnerships, creating new programs services, and discontinuing or decreasing some functions. In addition, the roles, responsibilities, and services provided by staff at all levels also changed.

\subsection{Housing Partnerships' Employee Characteristics}

Ten questions in the Employee Learning and Growth perspective section of the survey are useful to profile the employee capacities of the Housing Partnerships, These questions provide deeper insights into the characteristics of the board, leadership, and staff that assist in the successful performance of Housing Partnerships. The first question in this section dealt with the HPs' board: How many members of the Board of Directors were from the following organizations in 2009? The options for choices included: members representing government agencies, members representing nonprofit 
organizations, members representing business organizations, members representing universities, and "other." The responses to the question are summarized in Figure 8.1. According to the survey results, the average size of the Housing Partnership boards was ten. Nearly half of the board members (approximately five) were from the private sector; three were from the nonprofit sector; one from the government; and the rest from the universities and other organizations. Other organizations are churches and schools. Representation from community members was indicated by some Housing Partnerships. By having member diversity, HPs have boards composed of individuals that bring knowledge and experience from various sectors and viewpoints. The responses suggest that member diversity is found and encouraged on HP boards. However, board structure and representation changes as skills and knowledge are required from a particular sector. For instance, board membership representing the private sector increased in some HPs as financial knowledge was needed.

Follow-up responses to the survey suggest that HPs view the role of the board of directors as an entity that assists them to manage, discuss, implement and maintain their mission and goals. As indicated by some HPs, the current economic downturn increased their awareness of the importance of the board and how the knowledge and expertise of its members are valuable assets that are of significant assistance in making challenging decisions. In addition, some HPs explained that the numbers of board members from the private sector increased because of increasing demand for financial knowledge and expertise resulting from the downturn economy. 
Figure 8.1: Housing Partnership Board Composition

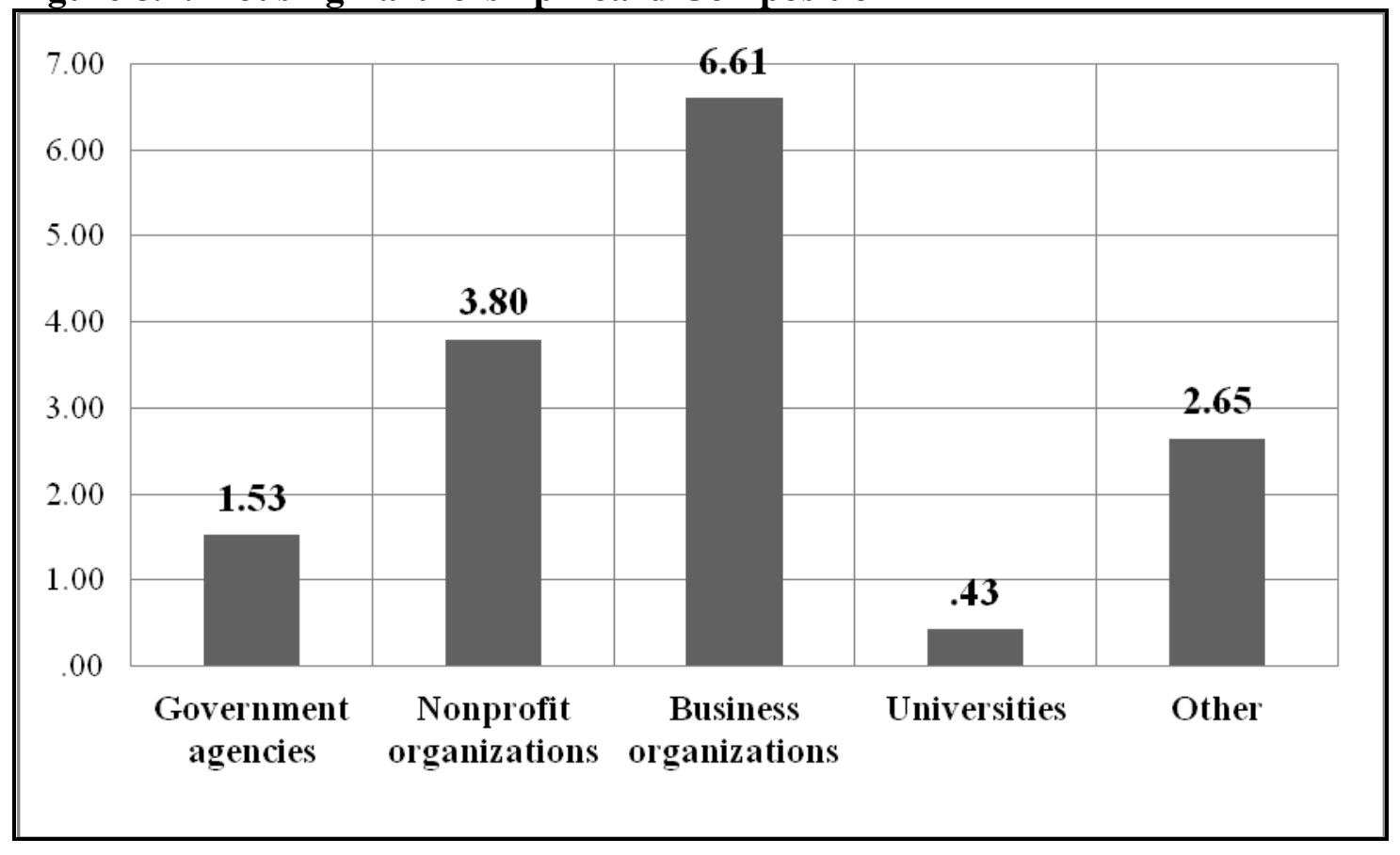

The next question in this section of the survey was: How many times did the Board of Directors meet in 2009? The response to this question is significant to elicit information regarding board communication. The frequency distribution of the meetings is given in Figure 8.2. On average, the board met 11 times in 2009, or approximately once per month reflecting only official or in-person meetings. As indicated by some HPs, besides official meetings, board members interacted with each other, partners, and staff through other means. For instance, Patricia Garret, CEO, Charlotte-Mecklenburg Housing Partnership, Inc. explained that board communication is very important, especially when the HP has to make challenging decisions. She indicated that meetings represent only one form of interaction and feedback from the board. Depending on the issue that the HP needs assistance with, e-mails and conference calls might be necessary. Communication methods to address an issue rather than set meetings, allow HPs to have constant feedback and assistance from board members who may have knowledge and 
expertise on a particular factor affecting the organization. Taking into account this explanation as well as other survey responses, even without the current economic climate, the board is an entity that could provide possible solutions to various challenges. For instance, the board might offer solutions to increase community awareness.

Figure 8.2: Frequency distribution of Board Meetings

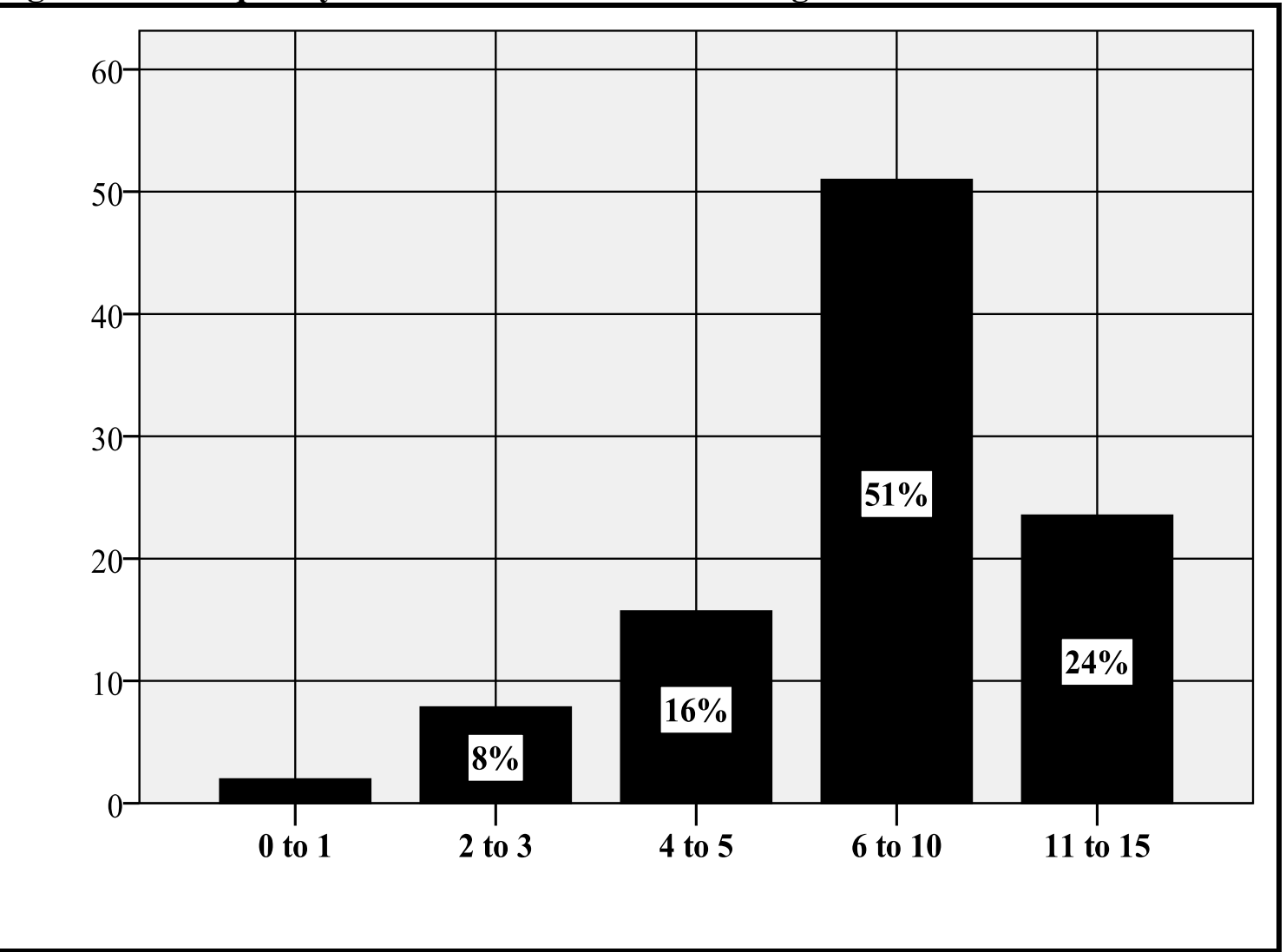

The third question in this section dealt with the employee strength: How many Full Time Equivalent (FTE) employees were working in 2009? According to survey responses, HPs had an average of 59 full-time employees (accounting for outliers of zero and two thousand). However, the analysis of the responses as a whole seemed significantly low for the variety of programs and services provided by Housing Partnerships. Individual analyses of surveys revealed that some HPs had zero full-time 
employees although they offered various programs and services. For instance, some respondents answered that no full-time employees work for the Housing Partnership, yet, some of these HPs indicated involvement in areas such as construction and counseling. Follow up interviews with the HPs indicated that nearly all of their staff was either volunteer or part-time. Various reasons exist for minimal full-time employment, such as duration of projects and cost of fringe benefits. Consequently, several projects are undertaken by volunteer staff in order for most of their funding to go towards assistance activities.

The fourth question in this section asked: If the Housing Partnership is three years or older, how did the number of FTE employees change between 2007 and 2009? Survey responses show that variations in employment were not significant for full-time employees. For the most part, responses indicate that between 2007 and 2009, the number of employees either did not change or increased (Figure 8.3). Follow up interviews revealed that the increase in full-time equivalent employees is accounted for by HPs' adding services and/or programs resulting from government allocations that became available to assist communities to address negative effects from the downturn in the housing market. For instance, some HPs expanded or developed programs for foreclosure counseling and assistance. 
Figure 8.3: FTE employee change between 2007 and 2009

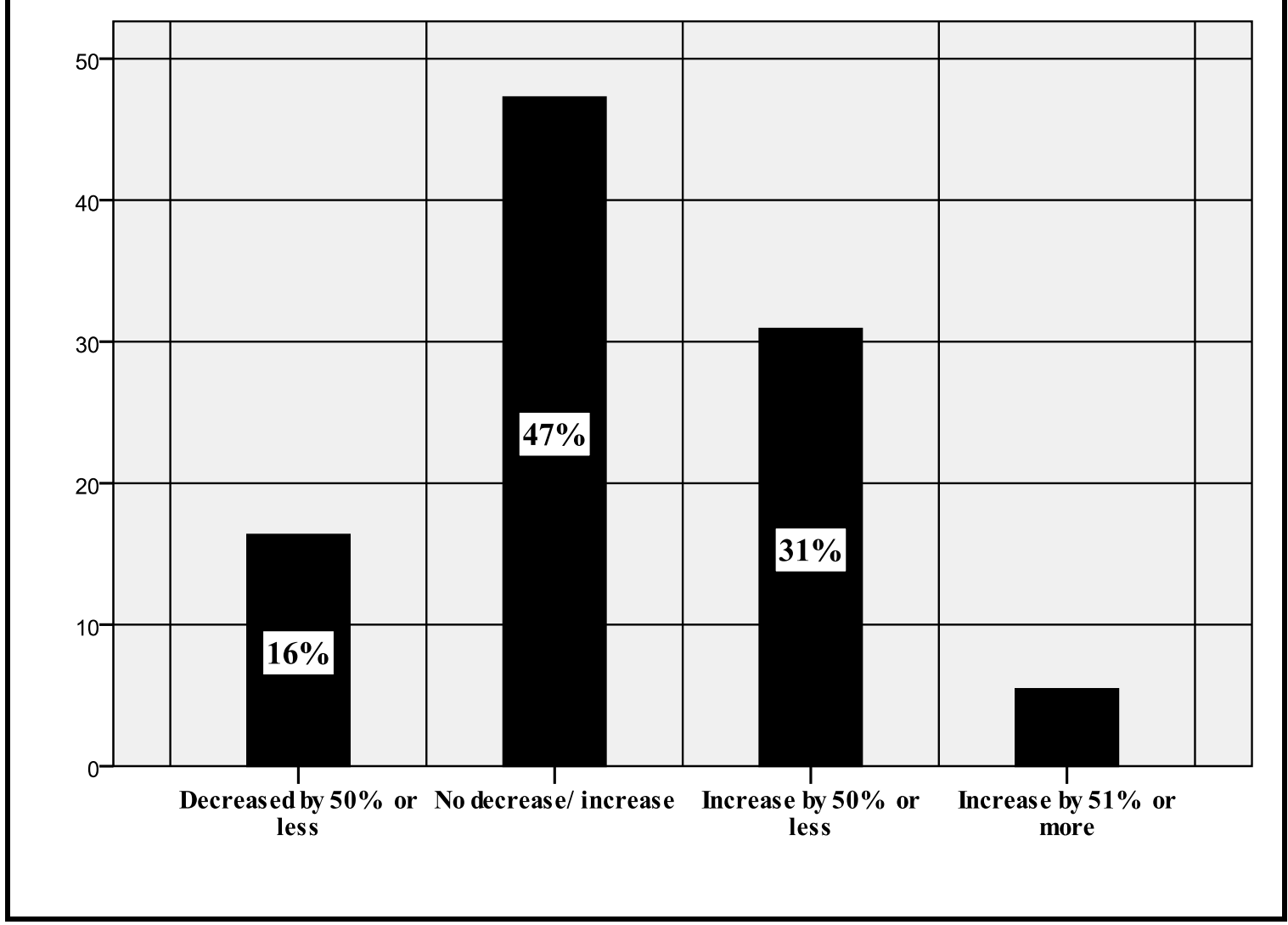

The fourth question in this section of the survey was: What was the employee turnover ratio of the Housing Partnership in 2009? Besides little variation in employment positions, turnover rates were low. About 81 percent of the respondents indicated that the turnover rates were between 0 and 20 percent (Figure 8.4). Housing Partnerships indicated that their workforce had not increased or decreased as a result of the economic downturn. A few responses indicated that staff was laid off as a result of the economic downturn. Some responses suggest an increase in workforce resulting from the current economic climate. As mentioned in follow-up conversations, staff layoffs occur when other options like changes in hourly structure and wage decreases do not assist HPs to 
decrease a financial gap. Furthermore, staff increases result from receiving financial allocations to provide new programs/services or to expand existing ones.

\section{Figure 8.4: Employee Turnover Ratio}

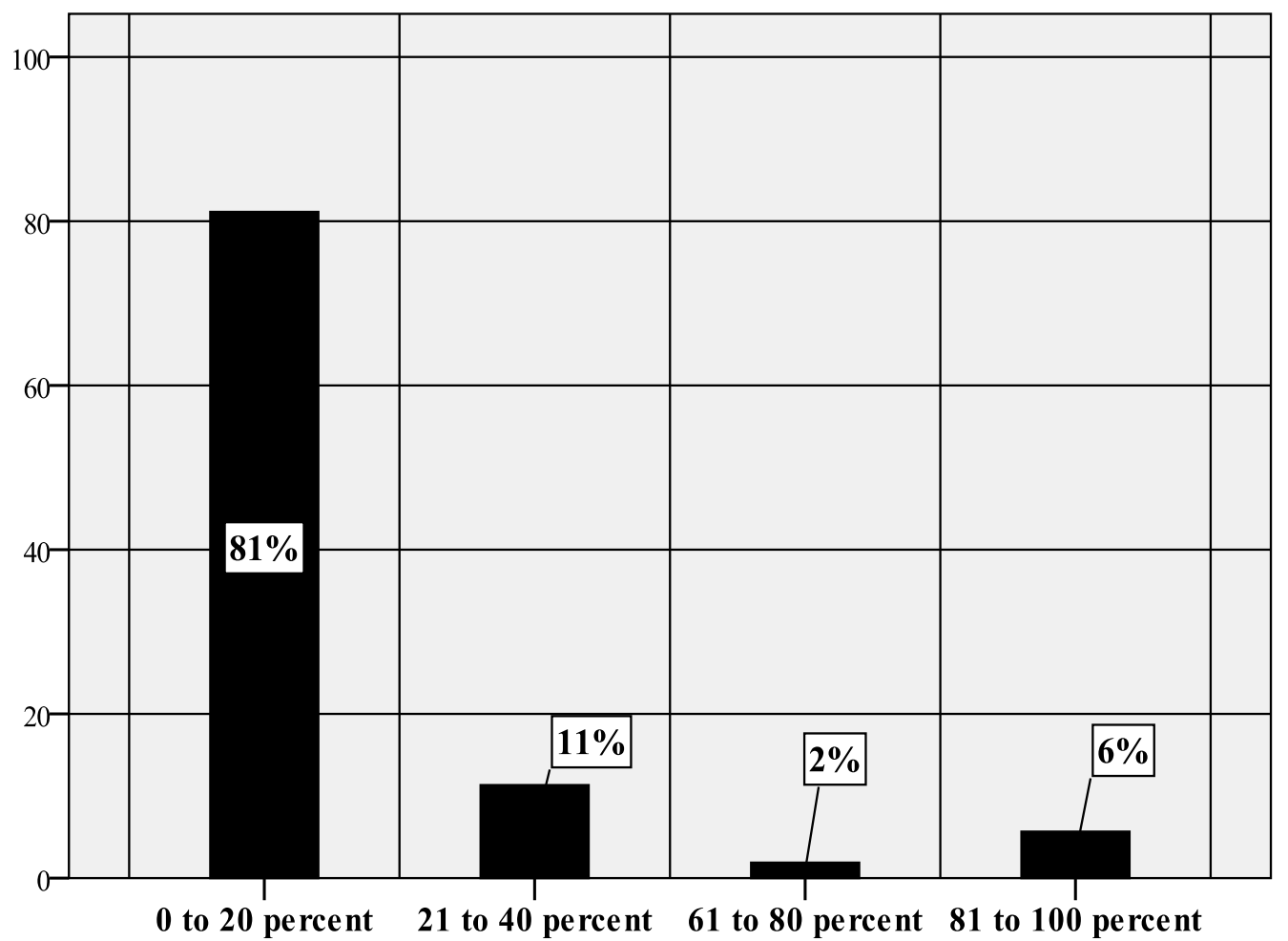

The fifth question in the survey dealt with the staff capacity: What was the educational background of the FTE employees in 2009? The answer choices were: High school or equivalent, some college, bachelor's degree, master's degree, doctoral degree (For instance, Ph.D, J.D). Survey responses indicate that the majority of full-time employees or 70 percent have a Bachelors degree (Figure 8.5). The leadership staff such as CEOs, CFOs, Program Directors, usually had a master's degree. The most common degrees for CEOs were either a Masters in Business Administration, a Master's in Architecture, or a Juris Doctor degree. In some instances, some HP CEOs possess more 
than one advanced degree. Survey responses and HP websites suggest that all have several years of housing-related experience and/or certifications, such as Community Planning.

\section{Figure 8.5: Educational Background}

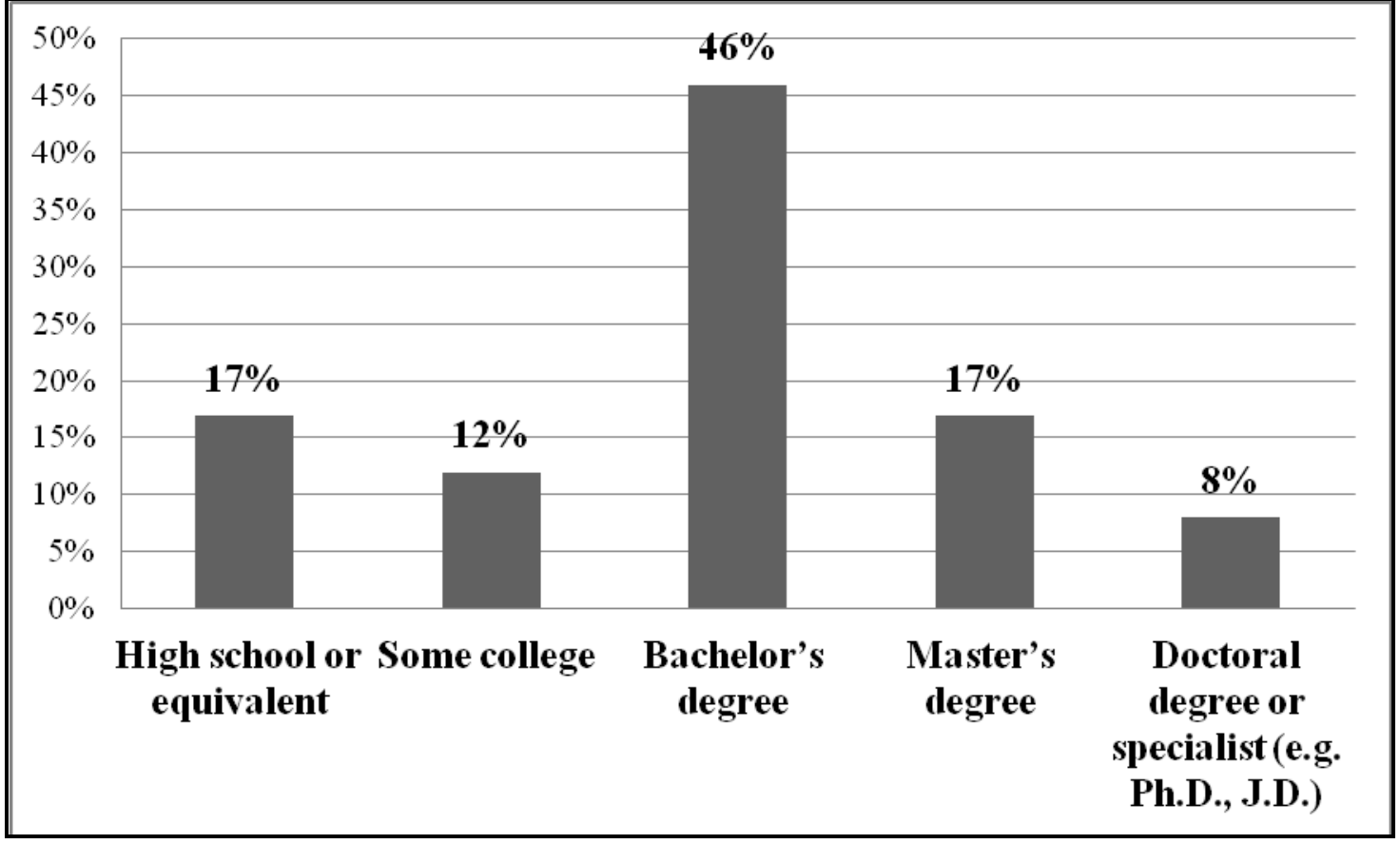

The sixth question in the Employee Learning and Growth section of the survey was: Did the Housing Partnership provide any of the following employee programs in 2009? The answer choices were: financial management training, payment for attending conferences, human resource management training, tuition credits for attending college, IT/computer training, "other." About 87 percent of the HPs indicated that they have at least one employee program. The types of employee programs provided are summarized in Figure 8.6. Nearly 70 percent provided funding to employees for funding conferences. Other types of programs were provided by 20 to 33 percent of the Housing Partnerships. Some of the responses under the section "other" included NeighborWorks, HUD, or 
specialized training, scholarship opportunities, and on-line courses. According to some HPs, staff members have particular qualities assisting their performance. Since not all employees have the knowledge required in an activity, and given the economic downturn, new skills are required to provide programs or activities. It is important that HPs have a mechanism in which the development of skills takes place. Such skill development allows staff to successfully perform their jobs, which translate into the successful performance of the programs or services they operate.

\section{Figure 8.6: Learning and Growth Programs Offered by Housing Partnerships}

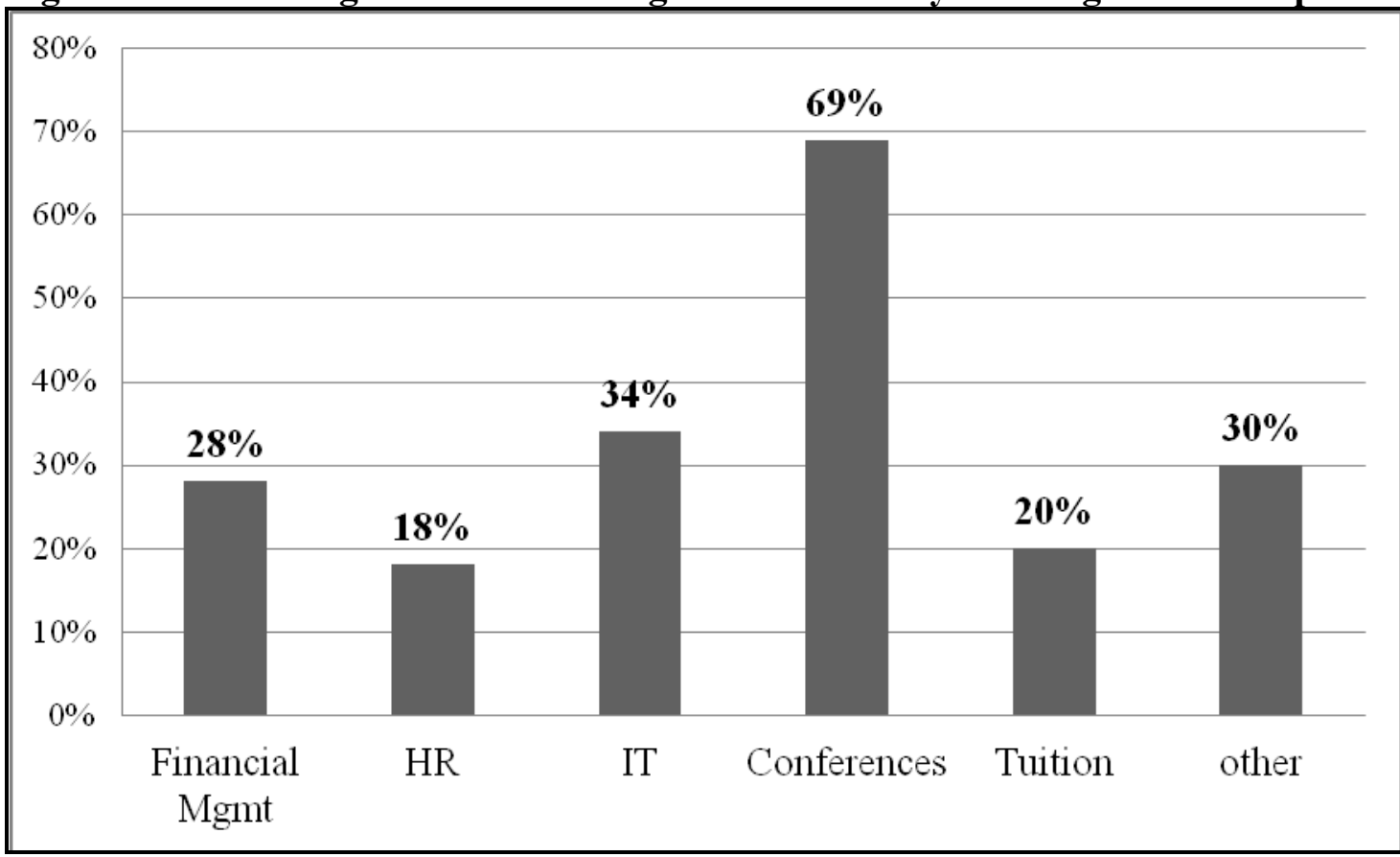

The seventh question in this section of the survey was: What is the highest educational degree of the current chief of the organization (e.g. CEO or Director)? According to survey responses, nearly all (96 percent) executive directors have at least a Bachelors degree. The Masters degree (42 percent) is the most frequent educational level 
among executive directors (Figure 8.7). The Masters of business administration and architecture are the primary fields of education.

\section{Figure 8.7: Educational Degrees of HP CEOs}

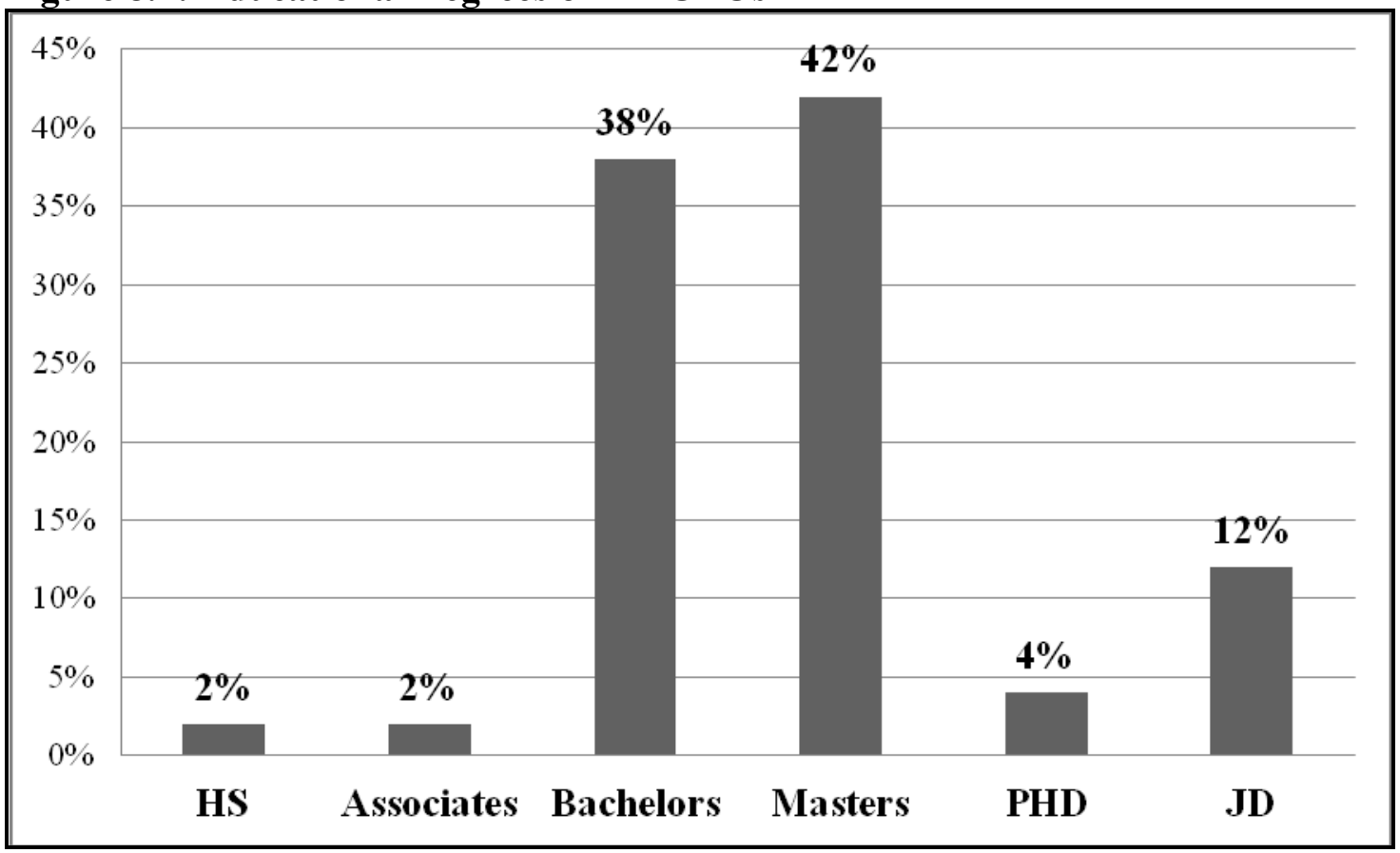

The seventh question in this section of the survey was: How many years has the present chief served the organization in that capacity? Current CEOs have served the HPs in that capacity for an average of nine years and four months. The least amount of years in that capacity is two months and the most are twenty-five years. Twelve HPs indicated that the current CEO is the founder or co-founder of the Housing Partnership. These CEOs have served the HPs in that capacity for an average of twenty years.

The eight question in the survey asked: What is the age of the present chief of the organization? The average age of HPs Executive Directors was 54 and 83 percent were in the age range of 50 to 64 (Figure 8.8). The two outliers representing the youngest and oldest reported ages are 21 and 71 years old. 
Figure 8.8: Age of HP CEOs

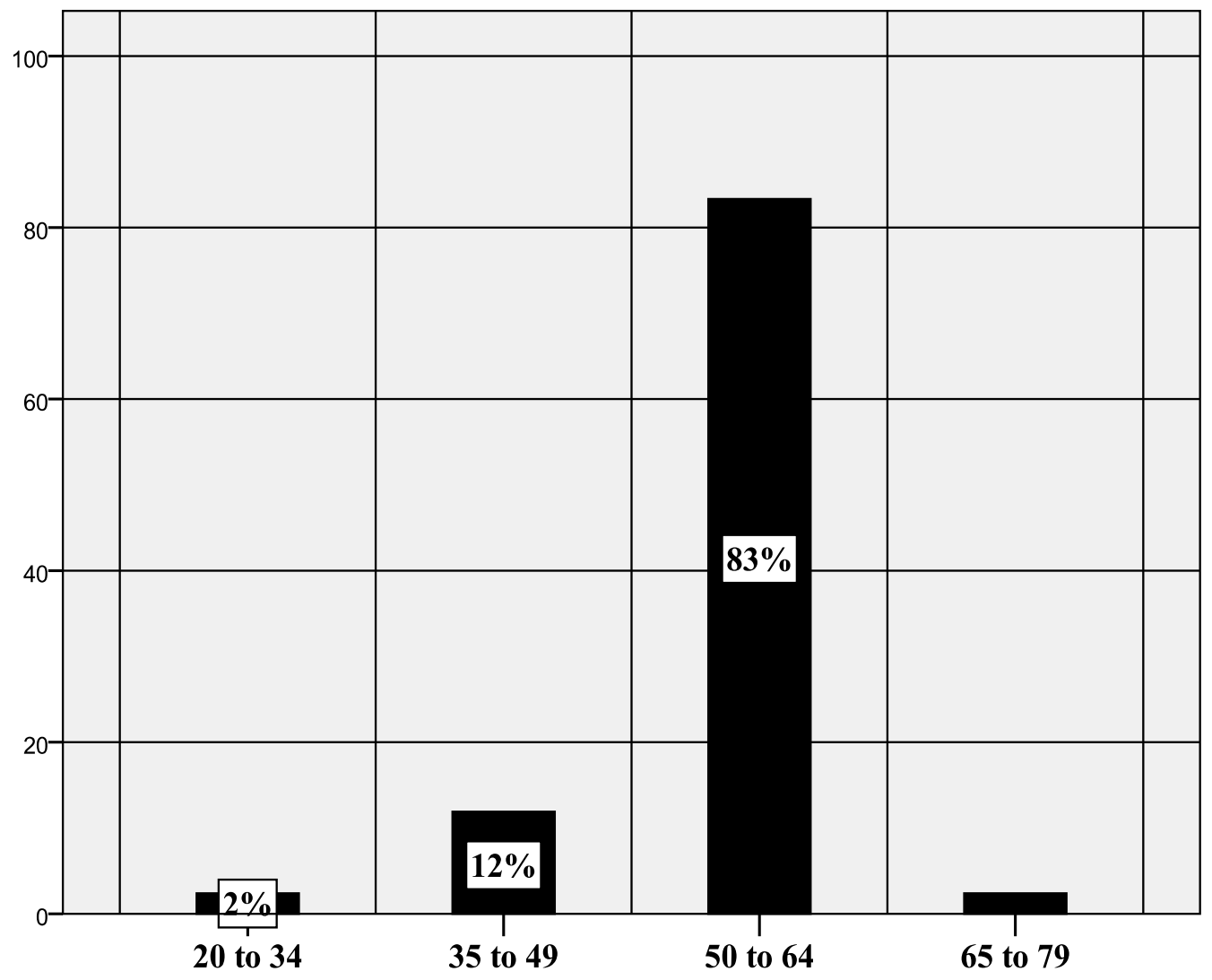

The majority of surveys ( 82 percent) were completed by Chief Executives of Housing Partnerships. The rest or 18 percent of surveys were prepared by Assistant Executive directors, board members, and program directors. As a result, the majority of follow-up quotes and responses used in my study are from Chief Executives of Housing Partnerships. Feedback representing only one level of HPs provides bias to the study. However, this study requires the assistance of HP members such as Chief Executives who have knowledge of all aspects of HPs and their performance. 


\subsection{Cross-Tabulation Analyses}

Cross-tabulation analysis for the learning ang growth perspective indicate statistically signficant relationships between board membership and Housing Partnership functions (0.005), mission target achievements (0.034), and the number of full-time equivalent employees (0.004) (Table 8.1). The relationship between the number of board members from the private sector and functions is moderate to strong and positive (0.414); that is, Housing Partnerships with higher percentages of private sector representatives when compared to other sectors are associated with comprehensive functions. The association between mission target achievements and the number of private sector board membership is moderate to strong and positive, suggesting that as the number of private board members increase Housing Partnerships achieve higher mission target achievement percentages. The relation between the number of private sector board members and the number of full-time equivalent employees is moderate-strong positive $(0.417)$ which means that the more private sector members on the board are likely to be in Housing Partnerships with large numbers of full-time equivalent employees when compared to other organizations. The number of board members representing nonprofits and mission target achievements are significantly associated (.002). The magnitude of this relationship is moderate (-.318) in a negative direction, which means that as the representation of nonprofit board members increase, mission target achievement percentages decrease. 
Table 8.1: Cross-tabulations of the Board of Directors' Representatives

\begin{tabular}{|c|c|c|c|}
\hline Variable Association & $\begin{array}{l}\text { Pearson Chi-squared Test } \\
\text { (P Value) }\end{array}$ & Gamma & $\mathbf{N}$ \\
\hline $\begin{array}{l}\text { Board of Director } \\
\text { Member Rep (business) } \\
\text { by Function }\end{array}$ & 0.005 & 0.414 & 47 \\
\hline $\begin{array}{l}\text { Board of Director } \\
\text { Member Rep (nonpro) } \\
\text { by Mission Target } \\
\text { Achievement }\end{array}$ & 0.002 & -0.318 & 48 \\
\hline $\begin{array}{l}\text { Board of Director } \\
\text { Member Rep (business) } \\
\text { by Mission Target } \\
\text { Achievement }\end{array}$ & 0.034 & 0.545 & 48 \\
\hline $\begin{array}{l}\text { Board of Director } \\
\text { Member Rep (business) } \\
\text { by \# of FTE Employees }\end{array}$ & 0.004 & 0.417 & 48 \\
\hline
\end{tabular}

The cross-tabulation analysis between the number of meetings in 2009 of the board of directors with the provision of employee programs in 2009 is significantly associated (0.005) (Table 8.2). The relationship is moderate $(0.005)$ and positive, which means that as the number of meetings increase, more employee programs are provided.

Table 8.2: Cross-tabulation of Number of Board Meetings

\begin{tabular}{lccc}
\hline Variable Association & $\begin{array}{l}\text { Pearson Chi-squared Test } \\
\text { (P Value) }\end{array}$ & Gamma & N \\
\hline $\begin{array}{l}\text { Number of Board of Directors } \\
\text { Meetings by Employee Program }\end{array}$ & 0.005 & 0.430 & 51 \\
Provision & & & \\
\hline
\end{tabular}

The number of full-time equivalent employees is significantly associated with the functions (0.002) and missions (0.035) of Housing Partnerships. The relation between the number of full-time equivalent employees and functions is strong $(0.625)$ positive, suggesting that HPs with high numbers of full-time equivalent employees when 
compared to other responses have comprehensive type functions (Table 8.3).

Comprehensive approaches focus on the growth of the client and the community, resulting in HPs with various programs such as counseling and education. Thus, full-time equivalent staff is necessary for programs that require specialized training and skills and long-term follow-up of the client. Missions and numbers of full-time equivalent employees have a moderate negative relationship, which means that as higher numbers of full-time equivalent employees belong to HPs with mission statements stating a combination of low-income, affordable housing assistance in a given location.

Table 8.3: Cross-tabulations of Number of Employees

\begin{tabular}{llcc}
\hline $\begin{array}{l}\text { Variable } \\
\text { Association }\end{array}$ & $\begin{array}{l}\text { Pearson Chi-squared Test } \\
\text { (P Value) }\end{array}$ & Gamma & N \\
\hline $\begin{array}{l}\text { Number of FTE } \\
\text { Employees by }\end{array}$ & 0.002 & 0.625 & 51 \\
$\begin{array}{l}\text { Functions } \\
\text { Number of FTE }\end{array}$ & & & \\
$\begin{array}{l}\text { Employees by } \\
\text { Mission }\end{array}$ & 0.035 & -0.418 & 53 \\
\hline
\end{tabular}

The educational background of chief executives and employee educational achievements (0.002-some college, 0.033 -BA/BS, 0.002-PHD) are significantly associated. Other learning and growth perspective factors indicate that the more years that a chief has served in that capacity are associated with high numbers of full-time equivalent employees and chief executive officers with high educational degrees (MA/MS and above) are associated with HPs whose employees have high educational achievements. 
Table 8.4: Cross-tabulations of Chief Executive Officer's Characteristics

\begin{tabular}{lccc}
\hline Variable Association & $\begin{array}{l}\text { Pearson Chi-squared } \\
\text { Test (P Value) }\end{array}$ & Gamma & N \\
\hline $\begin{array}{l}\text { Years CEO in that Capacity by } \\
\text { Number of FTE Employees }\end{array}$ & 0.004 & 0.668 & 47 \\
$\begin{array}{l}\text { Education Degree of CEO by FTE } \\
\text { Employee Ed Background (some } \\
\text { college) }\end{array}$ & 0.002 & -0.054 & 46 \\
$\begin{array}{l}\text { Education Degree of CEO by FTE } \\
\text { Employee Ed Background (BA/BS) }\end{array}$ & 0.033 & & \\
$\begin{array}{l}\text { Education Degree of CEO by FTE } \\
\text { Employee Ed Background (PHD) }\end{array}$ & & -0.237 & 46 \\
\hline
\end{tabular}

\subsection{Conclusion}

The survey responses and related comments indicate that to ensure successful performance, HPs have a committed leader, high degree of involvement of a board of directors, and a requisite skilled staff. The board serves an essential role to Housing Partnerships. As such, their composition and interaction with each other and the HP are very important. The board assists HPs through the provision of knowledge and expertise. Board membership should be representative of the composition of the HP (sectors, clients, incomes) in order for knowledge and expertise to exist in all aspects.

The characteristics that CEOs associate with effective staff (full-time, part-time, volunteer) are knowledge of the housing needs of the community, hard working, and committed to the mission of the Housing Partnership. In order for programs and services to perform successfully, it is important for HPs to commit time and funds to staff development. Staff can develop and gain skills and knowledge through education and training. 
The leadership or supervisory staff, such as the CEO, must know and understand the housing market and needs of the community served and must possess interpersonal skills. The relationship between the CEO and community members and stakeholders assists HPs to gain support for the development of programs and activities that furthers the HP mission. Survey responses suggest that technology and systems purchase and maintenance are important to performance, requiring staff training on how to use new systems and education efforts across the HP on their benefits. In addition, as experienced by some HPs, many outcomes of external changes cannot be fully forecasted or thought of; as a result, flexibility has to be built in all aspects of the organization. In regards to the learning and growth perspective, staff at all levels, should be given the capacity to have various roles. In order for staff to have various roles, training should include skills necessary to carry out the current position as well as other skills.

Housing Partnership board, staff, and leadership require education and knowledge to grow and develop the skills that will allow the HP to achieve its mission. Additionally, the clients of the HP and the community they reside in benefits from development and information activities, such as outreach and education. Through community outreach efforts, the HP gains the awareness of the community. By building community awareness, an HP, could build a reputation and role in the community to obtain support. 


\section{POLICY CONCLUSIONS}

\subsection{Introduction}

The main objective of this study is to identify the principal factors that contribute to the successful performance of Housing Partnerships in achieving their affordable housing mission. In this context, the main question is: What are the factors affecting the successful performance of Housing Partnerships? Towards this end, the previous chapters focused on the factors for successful performance with respect to the four perspectives of Balanced Scorecard (BSC). In this chapter, I synthesize the four perspectives to obtain holistic policy insights into the factors for the successful performance of Housing Partnerships.

The summary findings from each perspective are outlined at first. Next, the interperspective linkages that are relevant to successful performance of HPs are identified. Then, the chapter concludes with the principal policy implications of the study.

\subsection{Findings from each BSC Perspective}

Housing Partnerships (HPs) emerged in the eighties as local solutions to affordable housing delivery in major urban areas. They grew rapidly in the nineties. Housing Partnerships increased their investments in affordable housing, despite the decrease in revenues in the recent downturn in the housing market. Analysis of the missions of Housing Partnerships shows that they perform a range of affordable housing activities. Such services include construction, education, rehabilitation, and advocacy efforts. Some Housing Partnerships take a comprehensive approach that includes activities such as rental assistance and management, counseling, and other services, so 
that they are one stop centers for housing services. Most Housing Partnerships, however, have been involved in a combination of low-income assistance, affordable housing, and location receiving assistance. Housing Partnerships also serve a large jurisdiction, which is characteristically different from the Community Development Corporations, which serve mainly at the neighborhood or the city level. Housing Partnerships provide a complementary service at the macro level of county, state, and even across states. Housing Partnerships are also genuine partnerships with private and nonprofit participation; public sector participation is comparatively less.

From the Balanced Scorecard framework's financial perspective, the research question was: What are the financial activities of successful Housing Partnerships? The hypothesis that Housing Partnership activities are mainly oriented toward funding affordable housing related activities is borne out. Housing Partnerships invested more in affordable housing despite reduction in their revenues. Program and service development and expansion addresses the changing affordable housing needs of communities. Housing Partnerships have filled a gap in the affordable housing market by increasing their activities to meet their targets.

Revenue diversification has been a major factor for successful performance of Housing Partnerships allowing them to have the resources necessary to meet their mission. Financially, HPs achieve their mission, through the availability of financial support for affordable housing production and housing-related programs and services. Survey responses revealed that Housing Partnership revenues consist of mostly public and private funds, accounting for approximately 75 percent of funding. Service fees are 
also increasingly used more frequently. Despite the housing market downturn, the survey shows that HP budgets increased from two thousand-seven to two thousand-nine.

From the Balanced Scorecard's customer perspective, the question was: Who are the main clientele of Housing Partnerships? The hypothesis that Housing Partnerships cater mainly to very-low, low and moderate-income households is borne out by the study. In addition, Housing Partnerships have experienced increases in requests for housingrelated assistance from moderate-income households. According to the survey responses, the very-low and low-income categories make up 70 percent of the clientele; another 25 percent are from the moderate-income category. Overall, for most Housing Partnerships, the number of households seeking and receiving assistance increased in 2009 compared to previous years. Housing Partnerships adopted, expanded, or discontinued some programs and services in order to fulfill new clients' needs. In this, a successful Housing Partnership is one that effectively responds to a community's changing housing issues and the changing needs of its population. The identification of client needs enables Housing Partnerships to develop programs and services that further the mission of affordable housing delivery. Communication with customers ensures that there is interaction between the Housing Partnership and the community it serves.

From the Balanced Scorecard's internal business perspective, the question was: What are the programmatic activities of Housing Partnerships? The study confirms the hypothesis that Housing Partnerships undertake programmatic activities that contribute toward increasing affordable housing options. However, Housing Partnership programmatic activities are not limited to affordable housing construction, rental housing, and loans. Most Housing Partnerships have a comprehensive approach. Housing 
Partnerships have expanded their activities from this traditional set of programs that they used to undertake in the eighties. A large majority (nearly 90 percent) indicated that they carried out "other" non-traditional programs, such as advocacy and legislative work, credit counseling, technical assistance, supportive services (such as case management), education activities (such as first time homebuyer education), other types of counseling (such as foreclosure assistance), and community planning. Comprehensive approaches assist the sustainability over the long-term of affordable housing in communities (Katkov, 2009). Nearly 74 percent of the Housing Partnerships had nearly achieved their target. The range of activities is interesting, and it indicates that the Housing Partnerships had adjusted their programs to the evolving needs of affordable housing.

From the Balanced Scorecard's employee learning and growth perspective, the question was: What are the organizational capacities of Housing Partnerships? The survey responses and related comments indicate that to ensure successful performance, Housing Partnerships indeed have a committed leader and a high degree of involvement of a board of directors; however, the survey yielded mixed results on the adequacy of skilled staff. The current CEOs have served the Housing Partnerships in that capacity for an average of nine years and four months. Their average age was 54 years. They possessed at least a bachelor's degree, but most had master's degree (in business administration, community planning, architecture, law, and related areas). The Housing Partnership boards are also highly committed, with more than half coming from private sector and others from nonprofit or government sectors. They met almost on a monthly basis. The Housing Partnerships have about 60 people on average on their staff. However, the analysis of the responses as a whole seemed significantly low for the 
variety of programs and services provided by Housing Partnerships. Individual analyses of surveys revealed that some Housing Partnerships had zero full-time employees although they offered various programs and services. The voluntary staff members were used to carry out these programs. Nearly 70 percent of the full-time staff have at least an undergraduate degree; the Housing Partnerships did not have a reduction in staff strength or a high turnover rate during the recent housing market downturn.

\subsection{Inter-Perspective Analysis}

To assess the inter-perspective associations in the successful performance of Housing Partnerships, I performed a cross-tabulation analysis of the survey results across the perspectives. The analysis provides additional interesting insights in the factors associated with the successful performance of Housing Partnerships. The interperspective associations that are statistically significant are highlighted below.

Association between funding sources and income groups served: Funding from service fees is significantly associated with low (0.004) and moderate (0.043) customer income (Table 9.1). Service fees and the low-income customer bracket have a moderate negative (-0.372) association, which means that as HPs have higher percentages of funding from service fees, the numbers of low-income clients receiving assistance decreases. The relation between service and the moderate-income customer bracket is moderately positive (0.471), suggesting that as HPs increase the use of service fees as a funding source, the number of moderate-income clients also increases. Funding sources from private sector sources and changes in the size of the rental program are significantly associated (.004) with a moderate-positive relationship, that is, HPs with high 
percentages of private funding, when compared to other streams, are likely to report increases in the size of the rental program. Overall, this finding is significant and interesting. With HPs increasingly dependent on service fees as a major revenue source, the breakdown of clientele according to income groups has changed. Moderate-income households have increased in size of clients requesting and receiving HP assistance.

\begin{tabular}{lccc} 
Table 9.1: Association between Funding Sources and Income Groups served & \\
\hline Variable Association & $\begin{array}{l}\text { Pearson Chi-squared Test } \\
\text { (P Value) }\end{array}$ & Gamma & N \\
\hline $\begin{array}{l}\text { Percentages of HP funding (service } \\
\text { fees) by Income Brackets (low) }\end{array}$ & 0.004 & -0.374 & 53 \\
$\begin{array}{l}\text { Percentages of HP funding (service } \\
\text { fees) by Income Brackets (moderate) }\end{array}$ & 0.043 & 0.472 & 53 \\
$\begin{array}{l}\text { Percentages of HP funding (private) } \\
\text { by Change in size of programs (rent) }\end{array}$ & 0.004 & & \\
\hline
\end{tabular}

Association between funding and programs: The relationship between HP budget changes from 2007 to 2009 and size changes (increase/decrease) of the housing rehabilitation program is significant (0.011) and strongly positive (0.771). Hence, HPs with budgetary increases from 2007 to 2009 are likely to experience growth in the size of the housing rehabilitation program. Budget changes and the size of the technical assistance program are significant but and weakly negative (-0.215), meaning that HPs with budgetary increases from 2007 to 2009 are likely to report reductions in the size of the technical assistance program. The relationship between the budget and changes in the number of households assisted from 2007 to 2009 is significant (0.000) and moderately positive. Therefore, as budgets increase from 2007 to 2009, HPs assist more households. In addition, budget changes are strongly associated (0.039) with the number of full-time 
equivalent employees. The relationship is weakly positive (0.247), suggesting that budgetary increases translate into more full-time equivalent employees. Budgetary changes and the educational background of employees were cross-tabulated in order to examine which group of employees increased. Budgetary changes are strongly associated with full-time equivalent employees with a $\mathrm{PhD}$ as educational background. However, the relationship is very weak (0.035), suggesting that educational background is not associated with full-time equivalent employee increase.

Table 9.2: Association between Budget Changes from 2007 to 2009 and Programs

\begin{tabular}{lccc}
\hline Variable Association & $\begin{array}{l}\text { Pearson Chi-squared } \\
\text { Test (P Value) }\end{array}$ & Gamma & N \\
\hline $\begin{array}{l}\text { HP budget change from 2007 to 2009 by } \\
\text { Program Size Changes (rehab) }\end{array}$ & 0.011 & 0.771 & 51 \\
$\begin{array}{l}\text { HP budget change from 2007 to 2009 by } \\
\begin{array}{l}\text { Program Size Changes (tech) } \\
\text { HP budget change from 2007 to 2009 by }\end{array}\end{array}$ & 0.020 & -0.215 & 51 \\
$\begin{array}{l}\text { Change of Households Assisted } \\
\text { HP budget change from 2007 to 2009 by }\end{array}$ & 0.000 & 0.432 & 51 \\
Number of FTE employees change & 0.039 & 0.247 & 51 \\
\hline
\end{tabular}

Association between Income Groups served and Programs: The percentage of households assisted with moderate-income by HPs is significantly associated with the HPs' funding allocation to construction (0.011) and loan provision (0.017) programs (Table 9.3). The association is moderately positive ( 0.366$)$ for construction, suggesting that as the percentage of moderate-income households assisted by HPs increases, funding allocated to construction also increases. The association is strongly positive $(0.820)$ with the funds spent on loan provision, meaning that HPs reporting increases in the percentage 
of moderate-income household assisted are likely to fund more loan provision activities.

The assistance to very-low-income households is significantly associated with the percentage of financial target achieved by the HPs (0.008) and is moderately strong and negative (-0.449), suggesting that financial targets percentages decrease as the percentage of households assisted from very-low-incomes increases. Very-low-income household assistance and the credit counseling programs have a strong-negative association (-0.697), which indicates that HPs reporting increases in the percentage of very-lowincome household assistance are likely to fund less loan provision activities.

Table 9.3: Association between Income Groups Served and Programs

\begin{tabular}{lccc}
\hline Variable Association & $\begin{array}{l}\text { Pearson Chi-squared } \\
\text { Test (P Value) }\end{array}$ & Gamma & N \\
\hline $\begin{array}{l}\text { Percentage of households assisted } \\
\text { (mod income) by the percentage of } \\
\text { funds the HP spent in Construction }\end{array}$ & 0.011 & 0.366 & 53 \\
$\begin{array}{l}\text { Percentage of households assisted } \\
\text { (mod income) by the percentage of } \\
\text { funds the HP spent in providing loans }\end{array}$ & 0.017 & 0.820 & 53 \\
$\begin{array}{l}\text { Percentage of households assisted } \\
\text { (very-low-income) by the percentage } \\
\text { of the financial target raised by HPs in } \\
2009\end{array}$ & 0.008 & & \\
\hline
\end{tabular}

Role of Chief Executive Officer (CEO) in Programs: The Chief Executive Officer has had a crucial role to play in providing a leadership role to enhance HPs housing programs. The tenure (i.e. the number of years served by a person as the CEO) is significantly associated with the change in the program sizes of affordable housing construction (0.032) and the housing rehabilitation programs (0.040) (Table 9.4). The relationship with the construction program is moderately strong and negative (-0.478), 
suggesting that HPs with CEOs serving in that capacity for several years are likely to have decreased the construction program activities. The relationship with the rehabilitation program is very weak (0.001). The Chief Executive Officers with long experience on the jobs are thus likely to have moved away from traditional activities like construction and rehabilitation.

Table 9.4: CEOs' Role in Program Size Changes from 2007 to 2009

\begin{tabular}{lccc}
\hline Variable Association & $\begin{array}{l}\text { Pearson Chi-squared Test } \\
\text { (P Value) }\end{array}$ & Gamma & N \\
\hline $\begin{array}{l}\text { Program size change } \\
\text { (construction) } \\
\text { by Years of chief in that title }\end{array}$ & 0.032 & -.478 & 51 \\
\hline
\end{tabular}

Role of Board of Directors: The make-up of the members of the Board of Directors influence Housing Partnerships' programmatic activities and their clientele characteristics. The Housing Partnerships with board members from the private sector are significantly associated with the number of households assisted (0.049), the percentage of clients of very-low-income groups (0.004) and the rental programs (0.030) (Table 9.5). The relationship with the number of households assisted is moderately positive $(0.258)$, which indicates that more private sector representation on the board is likely to result in more number of households assisted when compared to other Housing Partnerships. However, the relationship with very-low-income clients is strongly negative (-0.544), which means that as HPs gain more private sector representation in the board, they are likely to reduce assistance to very-low-income households. The relationship with the rental program is strongly positive $(0.675)$, which means that private sector board members influence implementation of rental programs. 
Table 9.5: Role of Board of Directors

Variable Association

Pearson Chi-squared Gamma N

Test (P Value)

Board of Directors (pvt sector) by

0.049

0.258

60

Number of households assisted.

Board of Directors (pvt sector) by

0.004

$-0.544$

60

Income groups (very-low)

Board of Directors (pvt sector) by Rental

0.030

0.675

60

programs

Number of Board meetings by Rental

0.040

0.164

60

program achievement

Number of Board meetings by

0.025

0.767

60

Implementation of management systems

Close monitoring by the Board of Directors helps in meeting the program targets.

In this, the number of times the members of HP Board of Directors met in 2009 is

significantly associated with the rental program achievement $(0.040)$ and the

implementation of management systems $(0.025)$. The relationship with the rental program

achievement is weakly positive $(0.164)$, which means that frequent board meetings helps

in achieving rental program targets. The relationship with the implementation of

management systems is strong-positive $(0.767)$, indicating that frequent board meetings

are likely to increase the implementation of management systems.

\subsection{Policy Implications}

The dissertation contributes to public administration in terms of identifying the policy responses to increase the effective use of HPs as affordable housing delivery solutions. In this context, the study is significant to public administrators because it identifies the factors for successful performance of HPs using as guide the four BSC 
perspectives. The inter-perspective cross tabulations also assist in highlighting the specific factors the governments should take into account. The study's national scope allows the use of its findings by local, state and federal governments. Insights into the factors for successful performance allow public administrators to devise appropriate policies to strengthen the role of HPs in the delivery of affordable housing. The insights are also useful to the HP managers themselves for more effective use of their resources to deliver affordable housing.

Overall, the main aspect highlighted by the dissertation is that HPs are appropriate agents for delivering affordable housing. Housing Partnerships collaborative efforts produce the maximization of knowledge and resources to solve affordable housingrelated issues in a community (HUD, 1999). They emerged in the eighties in the face of reduction in state and local funding. Their roles increased by implementing various approaches to meet the specific needs of the local communities served. Yet, policymakers have not paid sufficient attention to the HPs, as compared to other organizational mechanisms such as the Community Development Corporations (CDCs). As Leroux (2011) argues, the CDCs now represent only a small portion of all the nonprofit development organizations in the United States. Other nonprofits such as the HPs have emerged to address the crucial affordable housing gap. Housing Partnerships are true partnerships, which capitalize on the strengths of the private, nonprofit, as well as the public sectors. They are important in the present context when government funds for affordable housing have depleted at the federal, state, as well as local government levels.

Financially, from a policy perspective, revenue diversification is a major factor for successful performance of Housing Partnerships. With the decrease in government 
funding, HPs have had to rely increasingly on private sources. In this, HPs have been quite entrepreneurial in tapping into the local businesses for their funding. However, HPs have also increasingly depended on service fees to finance their operations. While these funding sources are entrepreneurial, the inter-perspective analysis shows that a heavy dependence on these sources also affects the ability of the HPs to reach down the income groups or provide programs that very-low income households can participate in. Yet, HPs could be emblematic of public private partnerships where limited amounts of public funding could be leveraged with the private sources and service fees for reaching down the income group levels. Local governments have a particularly important role in providing the local regulatory support for the Housing Partnerships (for example, permits, zoning, and other ordinances).

From a customer perspective, the overwhelming majority of the HPs serve the very-low and low-income categories. According to the survey and follow-up responses, as of 2009 the number of households seeking and receiving assistance increased from previous years. Successful HPs have had to adapt and be flexible in addressing the community's changing housing needs. The chief executives and the board of directors of HPs thus need to be cognizant of the changing realities of their communities, and adjust their programmatic activities accordingly. The inter-perspective analysis also shows how the tenure of the CEOs and the active involvement of the board of directors (through frequent meetings) increase the responsiveness of the HPs to local affordable housing needs. A successful relationship with clients or customers affects the performance of an organization. In order to develop such relationships, an organization must create and maintain a service culture that is oriented toward client service needs (Pollen, 1991). 
In terms of the internal business perspective, HPs are not limited to the traditional affordable housing activities such as construction, rental housing, and loans. Housing Partnerships have expanded their activities from this traditional set of programs that they used to undertake in the nineteen-eighties. Housing Partnerships routinely undertake nontraditional programs, such as advocacy and legislative work, credit counseling, technical assistance, supportive services (such as case management), education activities (such as first time homebuyer education), other types of counseling (such as foreclosure assistance), and community planning. From a policy perspective, the range of activities indicates that the HPs are not only for construction purposes, but they are useful as supportive organizations for technical assistance and education. Such activities could supplement local government outreach efforts for technical assistance and educational activities.

From an employee learning and growth perspective, the CEOs, the board of directors, and the staff play an important role in steering the HPs' activities. On average, the HPs have committed leaders (with long tenure) and a committed board of directors (that meets regularly). The Chief Executive Officers' tenure and the board of directors are also associated with program quality and addressing customer and community affordable housing needs. The staff capacities are mixed: the full-time staff persons possess adequate skills to meet their customers' needs, but they seem to be stretched thin. Many HPs reported running their programs with the assistance of voluntary staff. Although voluntary staff are indeed useful, they are also prone to high turnover rates. It would be important for HPs to strike the right balance between full-time staff and the voluntary staff to carry out the programmatic activities effectively. 


\subsection{Conclusion}

The main purpose of the dissertation was to identify the major factors for the successful performance of Housing Partnerships to achieve their affordable housing goals. The dissertation identifies these factors along the four perspectives of Balanced Scorecard framework. The dissertation explains how revenue diversification, cognizance

of changing customer needs, programmatic activities, and staff capabilities are significant for the achievement of the affordable housing goals. Zahra et al. (2008) argue that the survival and successful performance of organizations rests on their ability to achieve and sustain strategic flexibility, and the capability to respond quickly and creatively to changing competitive and environmental conditions.

Housing Partnerships could play a useful role in addressing the affordable housing problems in the current context of the downturn in the housing industry and economy. They do not only undertake the traditional activities of affordable housing construction, rental, and loan provision, but also other programs such as advocacy, education, technical assistance, and other services. Housing Partnerships have adjusted their programs according to the changing demands. My dissertation thus fills an important gap in housing research since the literature on HPs is quite thin. The insights would be useful to HP managers and policymakers in making the HPs more effective. 


\section{LIST OF REFERENCES}

Agranoff, R. (2007). Managing within networks : Adding value to public organizations. Washington, DC: Georgetown University Press.

Aguilar, O. (2003). How strategic performance management is helping companies create business value. Strategic Finance, 84(7), 44-49.

Andrisani, P., Hakim, S., and Savas, E. (2002). The new public management : Lessons from innovating governors and mayors. Boston, MA: Kluwer Academic Publishers.

Bartholomew, D. (2008). Analysis of multivariate social science data. Boca Raton, FL: CRC Press.

Brassil, M. (2010). The creation of a federal partnership : The role of the states in affordable housing. Albany, NY: State University of New York Press.

Bryson, J. (2004). Strategic planning for public and nonprofit organizations : A guide to strengthening and sustaining organizational achievement (3rd ed.). San Francisco, CA: Jossey-Bass.

Burlin, T., and Kamensky, J. (2004). Collaboration: Using networks and partnerships. Lanham, MD: Rowman and Littlefield Publishers.

Chan, Y., and DeGroote, M. (2004). Performance measurement and adoption of balanced scorecards: A survey of municipal governments in the USA and Canada. The International Journal of Public Sector Management, 73(3), pp. 204-221.

Chapman, C. (2005). Controlling strategy : Management, accounting, and performance measurement. New York, NY: Oxford University Press.

Cizek, G. (2001). Setting performance standards: Concepts, methods, and perspectives. Mahwah, NJ: Lawrence Erlbaum Associates.

Cooper, C., Knotts, H., and Brennan, K. (2008). The importance of trust in government for public administration: The case of zoning. Public Administration Review, $68(3), 459-68$.

Cooper, P. (2003). Governing by contract: Challenges and opportunities for public managers. Washington, DC: CQ Press.

Cooper, T., Bryer, T., and Meek, J. (2006). Citizen-centered collaborative public management. Public Administration Review, 66(6), 76-88.

Creswell, J. (2003). Research design : Qualitative, quantitative, and mixed methods approaches (2nd ed.). Thousand Oaks, CA: Sage Publications. 
Creswell, J., and Plano, C. (2007). Designing and conducting mixed methods research. Thousand Oaks, CA: Sage Publications.

Davis, P., and New York City Partnership (1986). Public-private partnerships: Improving urban life. Broadway, N.Y: U.S. Academy of Political Science.

Denhardt, J., and Denhardt, R. (2003). The new public service: Serving, not steering. Armonk, N.Y: M. E. Sharpe.

Dohoney, M. (2006). Collaboration is key to advancing housing opportunities. Public Management, 88(7), 21-3.

Donahue, J. (1989). The privatization decision : Public ends, private means. New York, NY: Basic Books.

Euske, K., and Malina, M. (2005). The pyramid of organizational development as a performance measurement model. Advances in Management Accounting, 14, 167175

Farazmand, A. (2001). Privatization or public enterprise reform?: International case studies with implications for public management. Westport, CT: Greenwood Press.

Forrer, J., Kee, J., Newcomer, K., and Boyer, E. (2010). Public-private partnerships and the public accountability question. Public Administration Review, 70(3), 475-84.

Fredericksen, P., and London, R. (2000). Disconnect in the hollow state: The pivotal role of organizational capacity in Community-Based Development Organizations. Public Administration Review, 60 (3), 230-239.

Frederickson, H., and Ghere, R. (2005). Ethics in public management. Armonk, NY: M.E. Sharpe.

Froelich, K. (1997). The 990 return: beyond the Internal Revenue Service. Nonprofit Management and Leadership, 8, 141-55.

Froelich, K., and Knoepfle, T. (1996). Internal Revenue Service 990 data: Fact or fiction? Nonprofit and Voluntary Sector Quarterly, 25, 40-52.

Froelich, K., Knoepfle, T., and Pollak, T.H. (2000). Financial measures in nonprofit organization research: Comparing IRS 990 return and audited financial statement data. Nonprofit and Voluntary Sector Quarterly, 29, 232-254.

Frumkin, P., and Kim, M. (2001). Strategic Positioning and the Financing of Nonprofit Organizations: Is Efficiency Rewarded in the Contributions Marketplace?. Public Administration Review, 61, 3. p.266. 
Gilliard, H. (2011). The case of Gibson Plaza. Journal of Housing and Community Development, 68(3), 18-23.

Ghere, R. (2001). Probing the strategic intricacies of public_-private partnership: the patent as a comparative reference. Public Administration Review 61(4): 441-51.

Goldsmith, S., and Kettl, D. (2009). Unlocking the power of networks : Keys to highperformance government. Cambridge, MA; Washington, DC: Ash Institute for Democratic Governance and Innovation; Brookings Institution Press.

Guo, C. (2007). When government becomes the principal philanthropist: the effects of public funding on patterns of nonprofit governance. Public Administration Review, 458-473.

Guo, C., and Acar, M. (2005). Understanding collaboration among nonprofit organizations: combining resource dependency, institutional, and network perspectives. Nonprofit and Voluntary Sector Quarterly, 34(3), 340-61.

Guo, C., and Brown, W. (2006). Community foundation performance: bridging community resources and needs. Nonprofit and Voluntary Sector Quarterly, $35(2), 267-87$.

Guo, C., and Musso, J. (2007). Representation in nonprofit and voluntary organizations: a conceptual framework. Nonprofit and Voluntary Sector Quarterly, 36(2), 308-26.

Hancock, T. (2001). People, partnerships and human progress: Building community capital. Health Promotion International, 16(3), 275.

Hellevik, O. (1988). Introduction to causal analysis: Exploring survey data by crosstabulation. Oslo: Norwegian University Press.

Hemakom, R. (2002). New directions: Seattle and its surrounding areas have an entrepreneurial spirit that carries over to their innovative $\mathrm{H} / \mathrm{CD}$ partnerships, projects, and initiatives. Journal of Housing and Community Development, 59, 5. p.32(8).

Herman, R. (2009). Are public service nonprofit boards meeting their responsibilities?. Public Administration Review, 69(3), 387-90.

Herman, R., and Renz, D. (1998). Nonprofit organizational effectiveness: contrasts between especially effective and less effective organizations. Nonprofit Management and Leadership, 9(1), 23-38.

Herman, R., and Renz, D. (2004). Doing things right: Effectiveness in local nonprofit organizations, a panel study. Public Administration Review, 64(6), 694-704. 
Herman, R., and Renz, D. (2008). Advancing nonprofit organizational effectiveness research and theory: nine theses. Nonprofit Management and Leadership, 18(4), 399-415.

Herman, R., Renz, D., and Heimovics, R. (1997). Board practices and board effectiveness in local nonprofit organizations. Nonprofit Management and Leadership, 7, 37385.

Hodge. M., and Piccolo. R (2005), Funding source, board involvement techniques, and financial vulnerability in nonprofit organizations: a test of resource dependence. Nonprofit Management and Leadership, 16(2), 171-187.

Honaman, J. (2005). How can we boost our board from good to great?. Association Management, 57(1), 83-4.

Housing Partnership Development Corporation. (2010). Mission and accomplishments. Retrieved December 30, 2010, from http://www.housingpartnership.com

Housing Partnership Network. (2011). About us. Retrieved January 3, 2011, from http://www.housingpartnership.net

Johnson, C., Mawhinney, T., and Redmon, W. (2001). Handbook of organizational performance: Behavior analysis and management. New York, NY: Haworth Press.

Kaleba, R. (2006). Strategic planning: getting from here to there. Healthcare Financial Management, 60(11), 74-8.

Kamensky, J., and Burlin, T. (2004). Collaboration: Using networks and partnerships. The IBM Center for the Business of Government book series. Lanham, MD: Rowman and Littlefield.

Kaplan, R. S., and Norton, D. P. (1996). The balanced scorecard: Translating strategy into action. Boston, MA: Harvard Business School Press.

Katkov, D. (2009). Rebuilding Communities, One Home at a Time. Mortgage Banking, $70(2), 20,37$.

Kearns, K (1996). Managing for accountability: Preserving the public trust in public and nonprofit organizations. San Francisco CA: Jossey-Bass.

Knauft, E., Berger, R., Gray, S., and Independent Sector. (1991). Profiles of excellence : Achieving success in the nonprofit sector (1st ed.). San Francisco, CA: JosseyBass.

Korngold, A. (2005). Leveraging good will : Strengthening nonprofits by engaging businesses (1st ed.). San Francisco, CA: Jossey-Bass. 
Lederman, J. (1993). Housing america : Mobilizing bankers, builders and communities to solve the nation's affordable housing crisis. Chicago, IL: Probus.

Leroux, K. (2011). Who benefits from nonprofit economic development? Examining the revenue distribution of tax-exempt development organizations among U.S. cities. Journal of Urban Affairs (forthcoming).

Los Angeles Housing Partnership, Inc. (2011) About us. Retrieved January 3, 2011, from http://www.lahousingpartnership.com

Marwell, N. (2004). Privatizing the welfare state: Nonprofit community-based organizations as political actors. American Sociological Review, 69(2), 265-291.

Massachusetts Institute of Technology Center for Real Estate. (2011). Research. Retrieved May 18, 2011, from http://web.mit.edu/cre/research/

Mayer, N., and Temkin, K. (2007). Housing partnerships: the work of large-scale regional nonprofits in affordable housing. Washington, DC: Urban Land institute.

McGahey, R., and Vey, J. (2008). Retooling for growth : Building a 21st century economy in america's older industrial areas. Washington, DC: Brookings Institution.

Melendez, E., and Servon, L. J. (2007). Reassessing the role of housing in communitybased urban development. Housing Policy Debate, 18(4), 751-783.

Minnesota Housing Partnership. (2010). Programs and services. Retrieved December 30, 2010, from http://www.mhponline.org

Modell, S. (2009). Institutional research on performance measurement and management in the public sector accounting literature: a review and assessment. Financial Accountability and Management, 25(3), 277-303.

NeighborWorks America. (2009). Interview. Retrieved January 09, 2011, from http://www.nw.org

Nichols, B., and Spencer, W. (2011). Building Sustainable Organizations for Affordable Housing and Community Development: Impact Lessons and Recommendations from the Field [Monograph]. Retrieved October 16, 2011, from http://www.enterprisecommunity.org

Niven, P. (2003). Balanced scorecard step-by-step for government and nonprofit agencies. Hoboken, NJ: Wiley.

Nye, N., and Glickman, N. J. (2000). Working together: Building capacity for community development. Housing Policy Debate, 11(1), 163-198. 
Osborne, D., and Gaebler, T. (1992). Reinventing government : How the entrepreneurial spirit is transforming the public sector. Reading, MA.: Addison-Wesley Pub. Co.

O'Sullivan, E., Berner, M., and Rassel, G. (2003). Research methods for public administrators (4th ed.). New York, NY: Longman.

Pollen, E. (1991). The common thread: connecting functions to create a service culture. Employment Relations Today, 18, 229-34.

Porter, M. (1996). What Is Strategy? Harvard Business Review, 74(6), 61.

Posner, P. (2003). The tools of government: a guide to the new governance. New York, NY: Oxford University Press.

Posner, P., and United States General Accounting Office. (2003). Performance budgeting [electronic resource] : Current developments and future prospects. Washington, DC: U.S. General Accounting Office.

Quigley, J., and Raphael, S. (2004). Is housing unaffordable? why isn't it more affordable? The Journal of Economic Perspectives, 18(1), 191-214.

Reynolds, H. (1977). The analysis of cross-classifications. New York, NY: Free Press.

Reynolds, H. (1984). Analysis of nominal data. Beverly Hills, CA: Sage.

Riggin, L., Grasso, P., and Westcott, M. (1992). A framework for evaluating housing and community development partnership projects. Public Administration Review, 52, n1. p.40-46.

Rivenbark, W., and Menter, P. (2006). Building results-based management capacity in nonprofit organizations: the role of local government. Public Performance and Management Review, 29(3), 255-66.

Robinson, T. (1996). Inner-city innovator: The nonprofit Community Development Corporation. Urban Studies, 33(9), 1647-1670.

Rohe, W. M. and Bratt, R. G. (2003). Failures, downsizings, and mergers among community development corporations. Housing Policy Debate, 14(1-2), 1-46.

Russ-Eft. D., Preskill, H., and Preskill, H. (2001). Evaluation in organizations : A systematic approach to enhancing learning, performance, and change. Reading, MA: Oxford; Perseus.

Saint John's Housing Partnership. (2011). About us. Retrieved January 10, 2011, from http://www.sjhp.org/about.php 
Sako, M. (1992). Prices, quality, and trust : Inter-firm relations in britain and japan. Cambridge, MA: Cambridge University Press.

Savas, E. (2000). Privatization and public-private partnerships. New York, NY: Chatham House.

Sawhill, I. (1988). Challenge to leadership : Economic and social issues for the next decade. Washington, DC: Urban Institute Press.

Schill, M., and Wachter, S. (2001). Principles to guide housing policy at the beginning of the millennium. Cityscape, 5(2), 5-19.

Sengupta, U., and Tipple, A. (2007). The Performance of Public-sector Housing in Kolkata, India, in the Post-reform Milieu. Urban Studies, 44(10), 2009-27.

Siciliano, J. (1996). The relationship between formal planning and performance in nonprofit organizations. Nonprofit Management and Leadership 7(4): 387-403

Singh, K. (2007). Quantitative social research methods. Los Angeles, CA: Sage.

Stegman, M (1999). State and Local Affordable-Housing Programs: A Rich Tapestry. Washington, DC: Urban Land Institute.

Studer, Q. (2007). How to achieve and sustain excellence. Healthcare Financial Management, 61(6), 106-7.

Suchman, D., Middleton, D., and Giles, S. (1990). Public/private housing partnerships. Washington, DC: Urban Land Institute.

Swanson, R. (2007). Analysis for improving performance : Tools for diagnosing organizations and documenting workplace expertise. San Francisco. CA: BerrettKoehler Publishers.

The Housing Partnership (of NH and ME). (2011). Mission. Retrieved January 3, 2011, from http://www.housingpartnership.org

Towers, M., and Spanyi, A. (2004). Herding Cats: Engaging the Organization In Executing Strategy. Financial Executive, 20(9), 48-50, 52.

U.S. Department of Housing and Urban Development (HUD). (2007). The Department of Housing and Urban Development's National Call to Action for Affordable Housing through Regulatory Reform. Washington, DC: U.S. Dept. of Housing and Urban Development, Office of Community Planning and Development.

U.S. Department of Housing and Urban Development (HUD). (1996). Building Publicprivate Partnerships to Develop Affordable Housing. Retrieved May 21, 2009, from http://hud.gov/hud-1583-cpd, May 1996 
U.S. Department of Housing and Urban Development (HUD). (1999). Archives: Initiatives. Retrieved October, 2011, from http://hud.gov

U.S. Department of Housing and Urban Development (HUD). (2009). News. Retrieved April 12, 2009, from http://hud.gov

U.S. Department of Housing and Urban Development (HUD). (2010). Policy papers. Retrieved July 01, 2010, from http://hud.gov

U.S. Department of Housing and Urban Development (HUD). (2010). Time-line. Retrieved July 16, 2011, from http://www.huduser.org /hud-timeline-19302010.pdf

U.S. Department of Housing and Urban Development (HUD) (2011) Programs. Retrieved January 3, 2011, from http://hud.gov

U.S. Procurement Executives' Association, and U.S. Department of Commerce. (1998). Guide to a balanced scorecard : Performance management methodology: Moving from performance measurement to performance management. Washington, DC: U.S. Department of Commerce.

Vilagra, J. (2006). The housing partnership network. Fast Company, 72-3.

Wall Street Journal. (2009). U.S. News. Retrieved October 22, 2010, from http://online.wsj.com

Webster, L., and Mertova, P. (2007). Using narrative inquiry as a research method: An introduction to using critical event narrative analysis in research on learning and teaching. London: Routledge.

Wettenhall, R. (2003). The rhetoric and reality of public-private partnerships. Public Organization Review 3(1): 77-107.

Wylde, K. (1986). Partnerships for housing. Proceedings of the Academy of Political Science, 36(2), pp. 111-21.

Wylde, K. (1996). The contribution of Public-Private Partnerships to New York's Assisted Housing Industry. In Michael H. Schill (ed.), Housing and Community Development in New York City: Facing the Future. Albany, NY: State University of New York.

Yescombe, E. (2007). Public-private partnerships: principles of policy and finance. Burlington, MA: Butterworth-Heinemann/Elsevier.

Zahra, S., Hayton, A., Neubaum, D., Dibrell, C., and Craig, J. (2008). Culture of family commitment and strategic flexibility: the moderating effect of stewardship. Entrepreneurship Theory and Practice, 32(6), 1035-54. 
Zajac, G., and Kazemi A. (1997). Reinventing government and redefining leadership: implications for personnel management in government. Public Administration Review, 52, n1. p.40-46. 
APPENDICES 
Appendix 1: Preliminary Questionnaire 


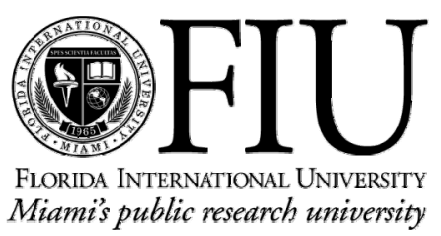

\section{Request of participation in a short questionnaire for the construction of a survey dealing with the factors present for a successful Housing Partnership}

You are being asked to participate in a short survey that asks for your input regarding the success of housing partnerships. The principal investigator is Zhayda Garzon - one of the Doctoral Candidates in the Public Management Program at Florida International University who is conducting a study concerning Housing Partnerships in the United States. More specifically, the investigator is interested in analyzing the determinants of success in housing partnerships.

You are invited to participate in the form of an open ended questionnaire of about 15 minutes. Responses to these open ended questions are asked to be answered within ten (10) business days of receiving the questions The investigator will contact you in the form of either: telephone, mail, e-mail, or fax. The participants for the study asked to answer the survey were among the following categories: High-level partnership program officials such as the Partnership's Executive Director, Assistant Director, or Director of housing related services who is well aware of the administrative and financial aspects of the agency.

Your participation would be extremely valuable to the development of a survey that aims to examine the factors that are essential in a successful housing partnership. Your answers will be kept completely confidential. Your opinion will be compared to the opinions of other subjects and the results will be reported as a group aggregate. If you choose not to participate, no other action is required.

Should you need more information about this research before or after completing the survey, you may contact Dr. Meredith Newman or Zhayda Garzon at 305-348-0410 or 305-348-5890.

Thank you very much for your time and cooperation! 


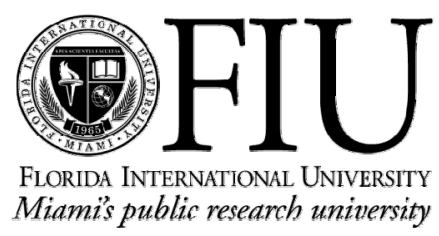

The answers to these questions will assist in the development of a survey aimed at studying the factors necessary in order for a housing partnership to be successful.

1. How would you describe a successful partnership?

2. What would you consider to be the critical success factors that contribute to your partnership's long term development?

3. How does the mix of programs (too many or too few) impact your success? 
4. How have you encouraged the cooperation of the government and the private sector to leverage your operations?

5. What impact has the housing crisis had on your current operations and how will it change your plans and programs in the future?

6. Is there anything else you believe researchers should consider when studying the success or failure of housing partnerships? 
Appendix 2: Survey Consent Letter and Survey 


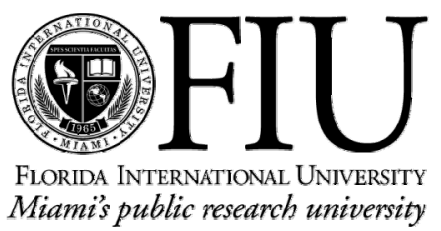

\section{CONSENT TO PARTICIPATE IN THE RESEARCH STUDY PERFORMANCE EVALUATION OF HOUSING PARTNERSHIPS USING THE BALANCED SCORECARD FRAMEWORK}

You are invited to participate in a research study. The principal investigator is Zhayda Garzon - a Doctoral Candidate in the Public Management Program at Florida International University conducting a study concerning Housing Partnerships within all regions of the United States. The research will identify the factors affecting the performance of HPs. Performance evaluation allow HPs to improve their processes.

You are invited to participate in the form of a mailed survey of about 30 minutes. This survey will have five parts. The participants for the study asked to answer the survey are among the following categories: High-level partnership program officials such as the Partnership's Executive Director, Assistant Director, or Director of housing related services.

It is not expected that you will be harmed by participating in the study. If you feel uncomfortable during the survey and/or follow-up questions you may take a break or discontinue it. Your participation is considered voluntary and you will not get any direct benefits from being in the study. Your consent is given once you decide to participate in the survey.

Your participation would be extremely valuable to the present research, as well as to the knowledge of factors that affect the performance of HPs. Your answers will be kept completely confidential by reporting responses as a group aggregate. If you choose not to participate, no other action is required.

Should you need more information about this research before or after completing the survey, you may contact Dr. Sukumar Ganapati or Zhayda Garzon at 305-348-0410 or 305-348-5890. In case you have any questions regarding your rights as a participant in this research study you may contact Dr. Patricia Price, the Chairperson of the FIU Institutional Review Board at 305-348-2618 or 305-348-2494.

Thank you very much for your time and cooperation! 


\section{Housing Partnerships Survey}

I am conducting the following survey to examine the factors that contribute to the successful performance of housing partnerships. Your responses will be very helpful in advancing academic and practical knowledge on how to enhance partnerships' performance. I hope you can provide your organization's insights through this survey. This should take no more than 30 minutes of your time. Your responses will be kept confidential and your participation is voluntary. For every completed survey returned, I will donate $\$ 1$ to the Habitat for Humanity for its work in Chile's housing recovery. For the purposes of this study, "Housing Partnerships" are broad coalitions of private, public, and nonprofit organizations to provide housing related services.

\section{Section A: Overview}

1. Please give the name of housing partnership.

2. What is the main mission of the housing partnership?

3. What percentage of the above mission's targets was achieved overall in 2009 ?
$\square 0-20 \%$
$\square 21-40 \%$
$41-60 \%$
$61-80 \%$
$81-100 \%$

4. What is the principal jurisdiction served by the partnership? Please check one.

$\square$ Neighborhood $\square$ County $\square$ Other

$\square$ City $\square$ State Please specify

5. How many organizations are affiliated with the housing partnership? (Affiliates are those organizations which support the housing partnership with funding or other tasks.)

Number of public agencies

Number of private firms

Number of nonprofits

Other organizations 


\section{Section B: Financial perspective}

6. What percentage of the housing partnership's funding came from the following sources in 2009? (Sum of all choices should be 100\%)

$\begin{array}{ll}\text { Private funding } & \% \\ \text { Government } \\ \text { funding }\end{array}$

7. What percentage of the housing partnership's funds was spent on the following activities in 2009? (Sum of all choices should be 100\%)

Affordable ownership housing construction

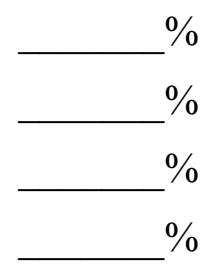

Homeless assistance $\%$

Providing affordable rental housing $\%$

Providing loans to households $\%$

Other Please specify

Total

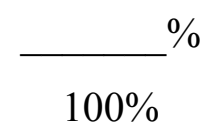

8. What percentage of the financial target did the housing partnership raise in 2009 ?
$\square 0-20 \%$
$\square 21-40 \%$
$\square 41-60 \%$
$\square 61-80 \%$
$81-100 \%$

9. If the housing partnership is three years or older, how did the budget change from 2007 to 2009 ? Please check one.

$\square$ Decreased by $76 \%$ to $100 \%$

$\square$ Decreased by $51 \%$ to $75 \%$

$\square$ Decreased by $26 \%$ to $50 \%$

$\square$ Decreased by $25 \%$ or less

$\square$ No decrease or increase $\square$ Increased by $25 \%$ or less

$\square$ Increased by $26 \%$ to $50 \%$

$\square$ Increased by $51 \%$ to $75 \%$

$\square$ Increased by $76 \%$ to $100 \%$

$\square$ Increased by $100 \%$ or more 
10. Out of the customers who sought financial assistance from the housing partnership in 2009 , what percentage actually received the assistance?

$\square 0-20 \% \quad \square 21-40 \% \quad \square 41-60 \% \quad \square 61-80 \% \quad \square 81-100 \%$

$\square$ Not applicable because

(e.g. partnership does not provide financial assistance)

11. What was the financial impact of the economic crisis on the housing partnership in 2009? Check all that apply? Check all that apply.

Housing partnership reduced programs

Housing partnership laid off staff

Housing partnership purchased foreclosure properties

Economic crisis did not impact the housing partnership

Other

(please specify)

\section{Section C. Customer perspective}

12. How many households did the housing partnership assist during 2009 ?

13. If the housing partnership is three years or older, how did the number of households assisted change between 2007 and 2009?

$\square$ Decreased by $76 \%$ to $100 \%$

Decreased by $51 \%$ to $75 \%$

Decreased by $26 \%$ to $50 \%$

Decreased by $25 \%$ or less

$\square$ No decrease or increase $\square$ Increased by $25 \%$ or less

$\square$ Increased by $26 \%$ to $50 \%$

$\square$ Increased by $51 \%$ to $75 \%$

$\square$ Increased by $76 \%$ to $100 \%$

$\square$ Increased by $100 \%$ or more 
14. Please give the percentage of households assisted in each income bracket in 2009. (Sum of all choices should be $100 \%$. AMI stands for Area Median Income, as defined by the U.S. Housing and Urban Development department).

Very low income (households with income less than $30 \%$ of AMI)

Low income (households with income between $30 \%$ and $50 \%$ of $\mathrm{AMI})$

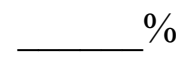

Moderate income (households with income between 51\% and $80 \%$ of AMI)

Middle income (households with income between $81 \%$ and $120 \%$ of $\mathrm{AMI})$

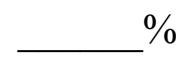

High income (households with income above $120 \%$ of AMI)

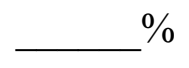

$$
\text { Total } 100 \%
$$

15. Which group(s) did your organization provide housing services to in 2009 ? Check all that apply.

$\square$ Homeless

$$
\begin{aligned}
& \square \text { Senior } \\
& \text { citizens }
\end{aligned}
$$

Other (please specify)

16. Which of the following customer feedback mechanisms do you use in program planning and evaluation? Check all that apply.

Annual meetings with customers

Periodic visioning meetings with customers

Customer input in strategic planning

Input through suggestions/ complaints box

Other (please specify)

$\square$ Victims of domestic violence

17. Please give three major feedback comments received from customers in 2009. 


\section{Section D: Internal/Business Perspective}

18. How do you obtain your customers? Check all that apply.

$\square$ Through radio advertisements $\square$ Through newspaper advertisements

$\square$ By word of mouth $\quad \square$ Referral from another agency

$\square$ Other (please specify)

19. If the housing partnership has carried out any of the following programs, please give the percentage of the program's target achieved in 2009.

\begin{tabular}{lcccccc}
\hline & $\begin{array}{l}0 \%- \\
\end{array}$ & $21 \%$ & $41 \%$ & $61 \%$ & $81 \%-$ & Not \\
& & $40 \%$ & $60 \%$ & $80 \%$ & & undertaken \\
\hline $\begin{array}{l}\text { Affordable housing } \\
\text { construction }\end{array}$ & $\square$ & $\square$ & $\square$ & $\square$ & $\square$ & $\square$ \\
\hline $\begin{array}{l}\text { Rental housing } \\
\text { construction/management }\end{array}$ & $\square$ & $\square$ & $\square$ & $\square$ & $\square$ & $\square$ \\
\hline $\begin{array}{l}\text { Housing rehabilitation } \\
\text { Providing loans to customers }\end{array}$ & $\square$ & $\square$ & $\square$ & $\square$ & $\square$ & $\square$ \\
\hline $\begin{array}{l}\text { Credit counseling to } \\
\text { customers }\end{array}$ & $\square$ & $\square$ & $\square$ & $\square$ & $\square$ & $\square$ \\
\hline $\begin{array}{l}\text { Technical assistance to } \\
\text { customers }\end{array}$ & $\square$ & $\square$ & $\square$ & $\square$ & $\square$ & $\square$ \\
\hline Other (please specify) & $\square$ & $\square$ & $\square$ & $\square$ & $\square$ & $\square$ \\
\hline
\end{tabular}

20. If the housing partnership is three years or older, how did the size of above programs change from 2007 to 2009? (Circle I for increase, D for decrease in appropriate box)

\begin{tabular}{|c|c|c|c|c|c|c|}
\hline & $\begin{array}{l}0 \%- \\
25 \%\end{array}$ & $\begin{array}{l}26 \% \\
- \\
50 \%\end{array}$ & $\begin{array}{l}51 \% \\
-75 \%\end{array}$ & $\begin{array}{l}75 \%- \\
100 \%\end{array}$ & $\begin{array}{l}\text { Over } \\
100 \%\end{array}$ & $\begin{array}{l}\text { No } \\
\text { change }\end{array}$ \\
\hline $\begin{array}{l}\text { Affordable housing } \\
\text { construction }\end{array}$ & $\mathrm{I} / \mathrm{D}$ & $\mathrm{I} / \mathrm{D}$ & $\mathrm{I} / \mathrm{D}$ & $\mathrm{I} / \mathrm{D}$ & I & \\
\hline $\begin{array}{l}\text { Rental housing } \\
\text { construction/management }\end{array}$ & $\mathrm{I} / \mathrm{D}$ & $\mathrm{I} / \mathrm{D}$ & $\mathrm{I} / \mathrm{D}$ & $\mathrm{I} / \mathrm{D}$ & I & \\
\hline Housing rehabilitation & $\mathrm{I} / \mathrm{D}$ & $\mathrm{I} / \mathrm{D}$ & $\mathrm{I} / \mathrm{D}$ & $\mathrm{I} / \mathrm{D}$ & I & \\
\hline Providing loans to customers & $\mathrm{I} / \mathrm{D}$ & $\mathrm{I} / \mathrm{D}$ & $\mathrm{I} / \mathrm{D}$ & $\mathrm{I} / \mathrm{D}$ & I & \\
\hline Credit counseling to & $\mathrm{I} / \mathrm{D}$ & $\mathrm{I} / \mathrm{D}$ & $\mathrm{I} / \mathrm{D}$ & $\mathrm{I} / \mathrm{D}$ & I & \\
\hline
\end{tabular}




\begin{tabular}{lccccc}
\hline customers & & & & & \\
\hline $\begin{array}{l}\text { Technical assistance to } \\
\text { customers }\end{array}$ & I / D & I / D & I / D & I / D & I \\
\hline Other (please specify) & I / D & I / D & I / D & I/ D & I \\
\hline
\end{tabular}

21. Did the housing partnership implement any of the following internal management systems between 2007 and 2009? Check all that apply.

$\begin{array}{ll}\square \text { Online application } & \square \text { Enterprise Resource Planning (ERP) systems } \\ \square \text { Outcomes/results measurement } & \square \text { Changed internal application tracking systems } \\ \square \text { Organizational assessment } & \square \text { Reduced customer paperwork requirements } \\ \square \text { Changed accounting systems } & \square \text { Customer satisfaction survey } \\ \square \text { Other (please specify) } & \end{array}$

\section{Section E: Employee learning and growth perspective}

22. How many members of the Board of Directors were from the following organizations in 2009 ?

Members representing government agencies

Members representing nonprofit organizations

Members representing business organizations

Members representing universities

Other (please specify)

Total

23. How many times did the Board of Directors meet in 2009 ? times

24. How many Full Time Equivalent (FTE) employees were working in 2009? 
25. If the housing partnership is three years or older, how did the number of FTE employees change between 2007 and 2009?

$\square$ Decreased by $76 \%$ to $100 \%$

$\square$ Increased by $25 \%$ or less

$\square$ Decreased by $51 \%$ to $75 \%$

$\square$ Increased by $26 \%$ to $50 \%$

$\square$ Decreased by $26 \%$ to $50 \%$

$\square$ Increased by $51 \%$ to $75 \%$

Decreased by $25 \%$ or less

$\square$ Increased by $76 \%$ to $100 \%$

$\square$ No decrease or increase

$\square$ Increased by $100 \%$ or more

26. What was the employee turnover ratio of the housing partnership in 2009? [Turnover ratio $=$ Number of FTE employees terminated from job in 2009 / Total number of FTE employees in 2009]
$\square 0-20 \%$
$21-40 \%$
$41-60 \%$
$\square 61-80 \%$
$81-100 \%$

27. What was the educational background of the FTE employees in 2009? (Sum of all choices should be 100\%)

High school or

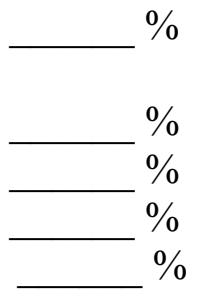

equivalent

Some college

Bachelor's degree

Master's degree

Doctoral degree

(e.g. Ph.D, J.D)

$$
100 \%
$$

28. Did the housing partnership provide any of the following employee programs in 2009? Check all that apply.

$\square$ Financial management training $\quad \square$ Payment for attending conferences

$\square$ Human resource management training $\quad \square$ Tuition credits for attending college

$\square$ IT/computer training $\quad \square$ Other (please specify)

29. What is the highest educational degree of the current chief of the organization (e.g. CEO or Director)?

30. How many years has the present chief served the organization in that capacity? years

31. What is the age of the present chief of the organization? years 
Section F: Background information about the person providing survey responses

32. What is your present position with the organization?

33. How many years have you served in this organization? years

34. Would you like a copy of the results of this survey? $\square$ Yes $\square$ No

35. May we contact you for any follow-up questions? $\square$ Yes $\square$ No

If you answered "yes" to either of the above two questions, please give the contact information

Name:

Address:

Email:

Telephone/ Fax:

(Your name will be kept confidential. It will be used only for follow-up or mailing the survey results. It will not be used in reporting the results.)

THANK YOU VERY MUCH FOR COMPLETING THE SURVEY. PLEASE MAIL THE SURVEY BACK TO ME IN THE POSTAGE PAID ENVELOPE. IF YOU HAVE ANY QUESTIONS REGARDING THIS SURVEY, YOU MAY CONTACT:

Zhayda Garzon

C/o Dr. Sukumar Ganapati

PCA 363-B, Public Administration Department

11200 S.W. 8th Street

Florida International University

Miami, Florida 33199

Tel: (305) 348-6275

Email: zgarz001@fiu.edu 
VITA

ZHAYDA GARZON

October 26, 1977

2000

May 2000 - October 2001

2002

November 2001 - January 2003

January 2003 - July 2005

July 2008 - March 2009

2006 - present
Born, Bogota, Colombia

B.A., Sociology

Florida International University

Miami, Florida

Homeless Outreach Case Manager

Douglas Gardens Community Mental Health Center

Miami Beach, Florida

M.S., Criminal Justice

Florida International University

Miami, Florida

Assistant Homeless Assistance Programs

Coordinator

City of Miami Beach

Miami Beach, Florida

Victim Services Coordinator/Crime Analyst

Village of Pinecrest Police Department

Pinecrest, Florida

County Manager's Urban Fellow

Miami-Dade County Office of Community and

Economic Development

Miami-Dade County, Florida

Candidate in Public Affairs

Department of Public Administration

Florida International University

Miami, Florida

\section{PUBLICATIONS AND PRESENTATIONS}

10/2010 Financial Performance of nonprofit Housing Partnerships - Southeastern Conference for Public Administration, October 13-16, 2010. Wilmington, $\mathrm{NC}$. 
4/2010 Mitigating the Effects of the Economic Downturn: How Organizations Cope With a Changing Environment - American Society for Public Administration, Best Practices Conference, April 23, 2010. Miami, FL

9/2008 Examination of Housing Partnerships in the delivery of affordable housing - Southeastern Conference for Public Administration, September 25, 2008. Orlando, FL. 